\title{
UC-NRLF
}

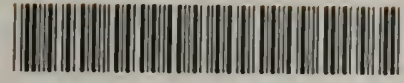

B 4 619 908

\section{THE ARMY HORSE}

\section{in \\ ACCIDENT AND DISEASE}

A MaNuAL

PREPARED FON THE USE OF 3TUDENTS OE THE

TRAINING SOHOOL FOA FARRIERS ANO HOFSESHOERS

BY THE

TRAINING SCHOOL INSTRUCTORS

1900 


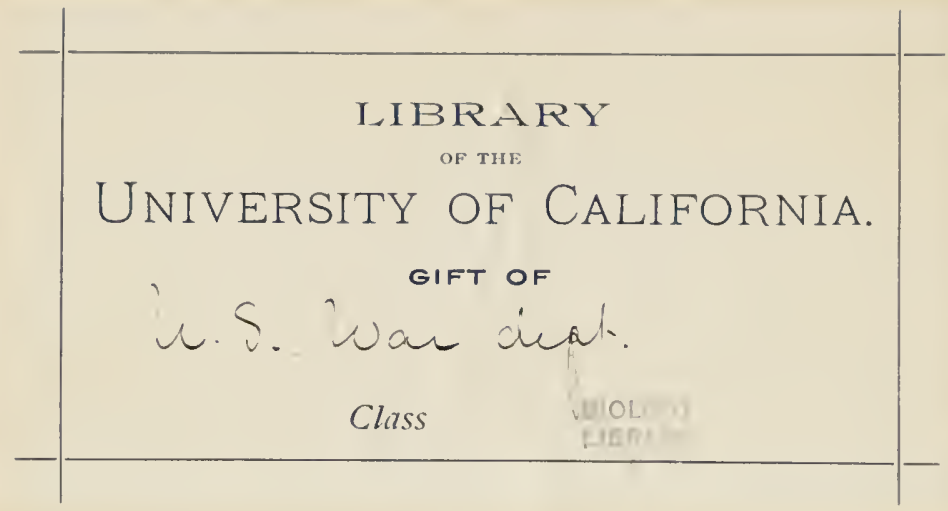







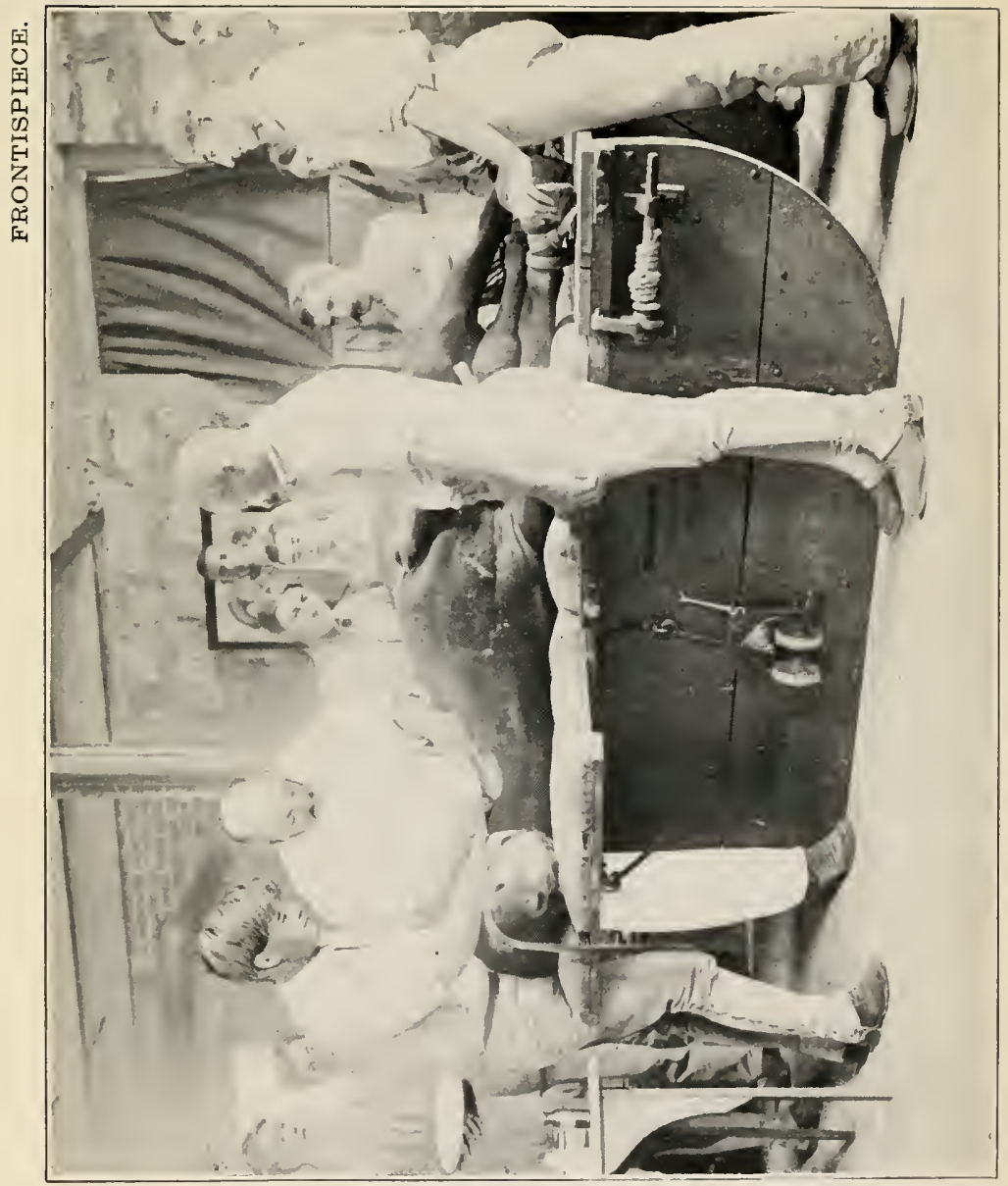

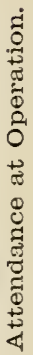




\section{THE ARMY HORSE \\ IN \\ ACCIDENT AND DISEASE}

EDITION: 1909

A MANUAL PREPARED FOR THE USE OF STUDENTS OF THE TRAINING SCHOOL FOR FARRIERS AND HORSESHOERS BY THE TRAINING SCHOOL INSTRUCTORS
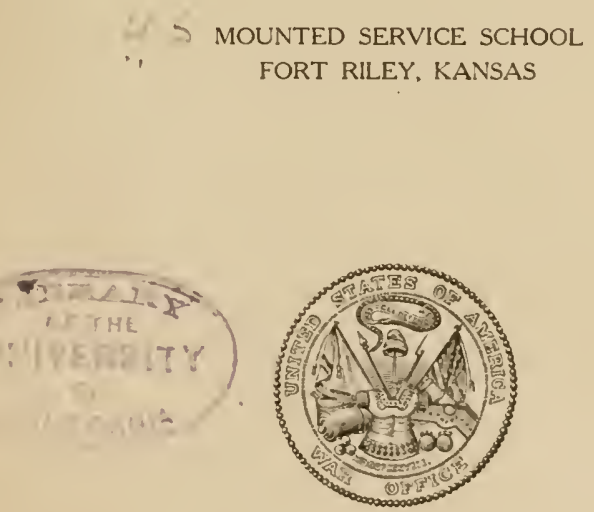

WASHINGTON GOVERNMENT PRINTING OFFICE 
SEqúl

10

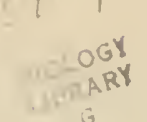




\section{WAL DePAl:TMENT, OFFIC E OF THE (HIEF OF STAFF, \\ Thashington, October S, 1.31\%.}

The Army Horse in Aecident and Discase, Rerised 1909, prepared at the Mounted Service School, Fort Riley, Kans., for the use of students of the training school for farriers and horseshoers, as well as for the army at large and the organized militia, is issued for the information and guidance of all concernerl.

By order of the Secretary of IV:rr:

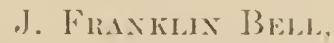

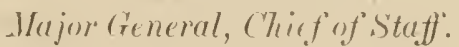




\section{AUTHORITIES COISULTEI.}

Bureau of Avimal Industry: Special Report on Diseases of the Itorse. CADIOT: A Treatise on Veterinary Therapeutics of the Domestir Animals. Cinaveau: Comparative Inatomy of Domesticated Animals.

Dux: Veterina:y Medicines, Their Aetions and Lses.

Fleming: Operative Veterinary Surgery.

Frienburger and Frönner: Patholugy and Therapeuties of the Ihome:tir Animala. Govbaux and Barrier: The Exterior of the Horse. (Translation.)

I.Aw: Veterinary Medicine.

Liavtard: Manual of Veterinary surgery.

Möller: Operative Veterinary Surgery. (Translation.)

Neumaxi: Parasites and Parasitic Diseases of the Domesticated Animals.

Qutuan: Notes on Veterinary Medicine.

Sитт: Veterinary Hygiene.

Sinth: A Manual of Veterinary Physiology.

Straxgeway: Veterimary Anatomy.

Willads: Principles and Practice of Veterinary Medicine and surgery.

Mriscow: Materia Meliea.

Wruax: Tiagnosis of Lameness in the IIorse. 


\section{CONTENTS.}

Chapter I.-Conformation anil Points. Defects and Blemishes.

II.-Stable Manarifment of the Sick and Injured.

III.-ANATOMY.

IV.-Administration of Medicines. Weights ani Measures.

V.- Wounds, Sprains, Bruises, Abrasions, ani Abscesses.

VI.-Diseases of the Respiratory System and Influenza.

VII.-Diseases of tile Ingestive, Crinari, Nervots, ani I,yiphatic SYSTEMS.

VIII.-MISCELLANEOUS IMSTEASES.

IX.-Diseases of tIIE SKIN AND EYe.

X.-Diseaşes of the Feet.

XI.-Diseases of Bone añ hetection of LaMeness.

XIl.-Age by the Teetr.

XiII.-Tropical Diseases.

XIV.-MEdicines, Them ArTIONS ani, I'ses. 


\section{LIST OF ILLUSTRATIONS.}

Frontrapteck.--Ittendance at operation.

I'IATE I. - Points of the horse.

II.-The horse in slings.

III.-Skeleton of the horse.

IV.-Museles and tendons of the horse.

V.-Respiratory apparatus.

II.-Digestive apparatus.

VII.-Circulatory apparatus.

VIII.-Section of the eye.

IX. Section of the hoof and pastern.

X.-Fig. 1, curb. Fig. 2, Bursal enlargement. Fig. 3, Spraiu of the llexor tendons (bowed tendons). Fig. 4, Line firing. Fig. 5, Capped hock.

XI. Fig. 1, Fistulous withers. Fig. 2, Poll evil.

XII.- 'hararteristic symptoms of spasmodic colic.

XIII.-lymphangitis.

NIV.-Purpura hemorrhagica.

XY. liarey.

IVI. Tetants.

Alil. Cirease.

IVIII.-Fig. 1, sidebone. Fig. 2, Ringbone. Fig. 3, Bonespaivin. Fig. 4, Splint.

XIX.-Longitudinal section and cross sections of lower incisor.

XIXa.-Surra: characteristic swellings.

XX.-Surra parasite.

XXI.-Chronic epizootic lymphangitis (tropical). 



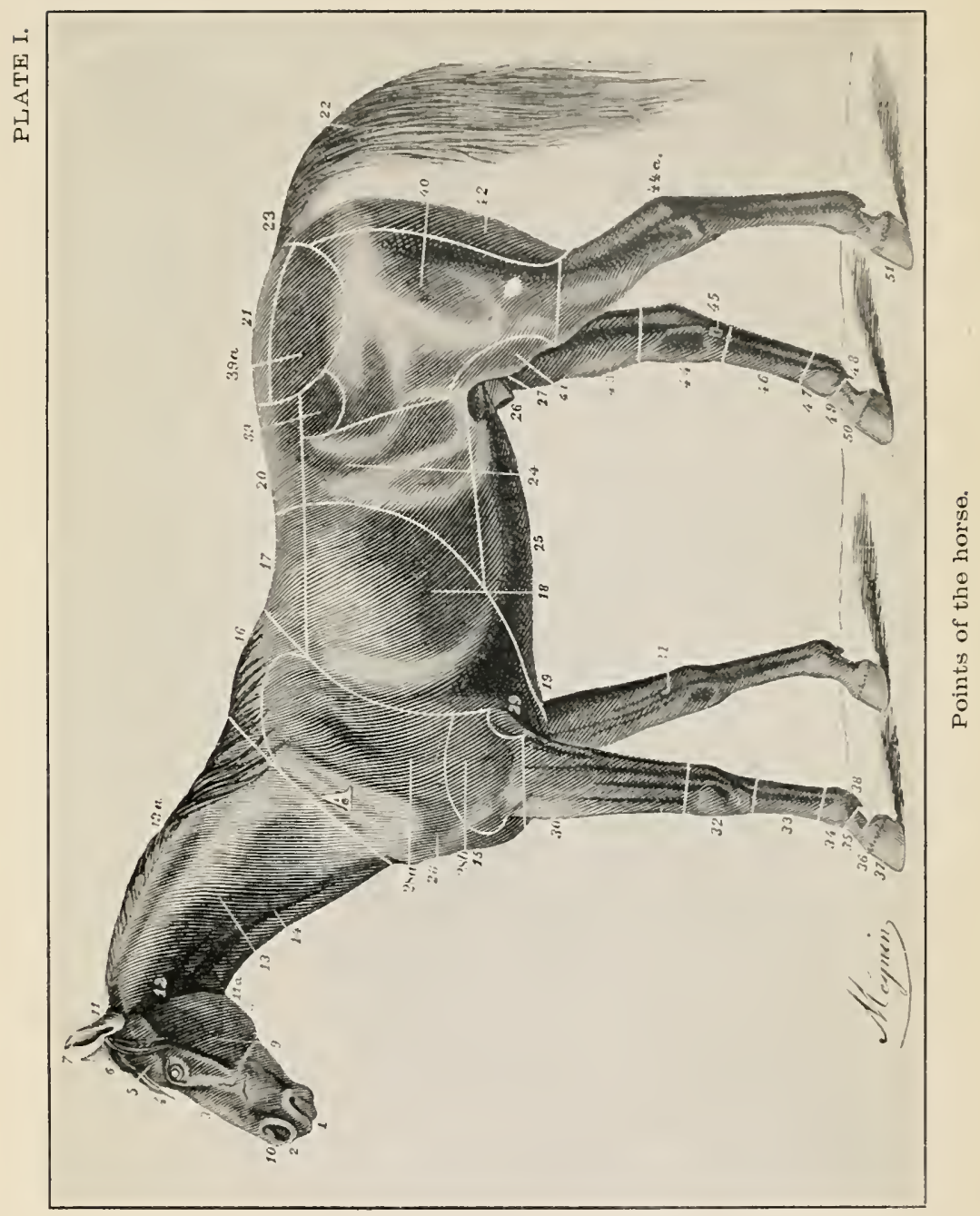




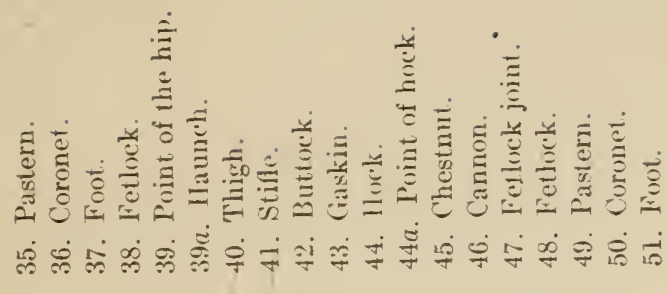
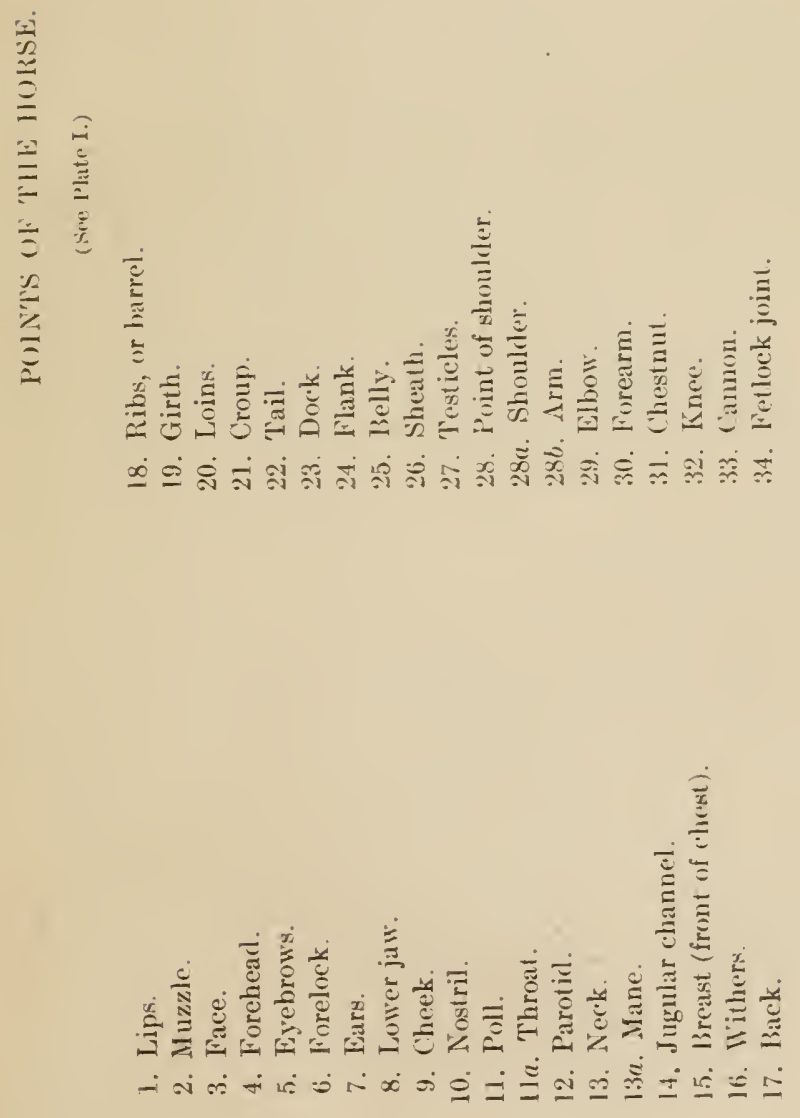



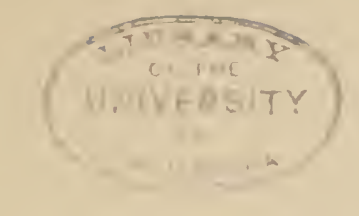

\title{
THE ARYY HORSE IN ACCIDENT ANI) DISEASF.
}

\section{CHAPTER T.}

\section{CONFORMATION AND POINTS-DEFECTS ANI BLEMISHES.}

\author{
CONFORMATION AND POINTS.
}

(Plate I.)

The forehead should be broad and not bulging; the eyes full, clear, and prominent, with a mild expression, and not showing any of the white; the muzzle not too large, as a coarse, large muzzle indicates ill breeding; the nostrils large and open; the face straight; and the lower jaw with ample width between the two sides, for the development and play of the larynx (Adam's apple) and windpipe, and, in addition, to allow the head to be nicely bent on the neek.

The ears should be of medium size, set well on the head and held erect.

The parotid and submaxillary regions should be free from large glands and without any loose skin at the lower part of the throat.

The neck should be of moderate length, clean and not too narrow at a point just in rear of the throat; a short, thick neck does not allow of free movement from side to side, and a long, slim neck is apt to be too pliable. A neek with concave upper border, known as "ewe neck" is unsightly. The jugular channel or furrow should be free from enlargements. The point of the shoulder should be wril developed. The point of the elbow should not be turned in, as the horse in that case is apt to turn his toes out; the opposite conformation results in the condition ealled "pigeontoed."

The forearm should be long and museular; the knee broad, and when looked at from the front, much wider than the limb above and below, but tapering off backward to a comparatively thin edge. A bending of the knee backward is called a "ealf knee," and is very objectionable. The opposite condition is known as "knee sprung."

The cannon should be of uniform size; if smaller just below the knee than elsewhere (a condition called "tied in"), weakness is to be expected. 
The fetlock joint slowuld be of grood size and clean; the pasterns of moderate length, and forming an angle of between fis and io degrees with the ground ar floor.

The foot should be of moderate size; a flat foot or one too narrow at the heels is objectionable.

The relative proportions of the shoulders and the exact shape desirable vary considerably in cavalry and artillery horses. Thus, when speed and activity are essential, as in the cavalry horse, the shoulder should be oblique (sloping), as this shape gives clasticity to the gait of the horse. For the artillery horse, working in harness, a more up)right shoulder bears the pressure of the collar more evenly, and when the collar is at right angle to the traces the horse exerts his strength to the greatest arlvantage. The front line of the shoulder must be clearly marked; an irregular surface or exeessive muscular derelopment in the region marked 1 (Plate 1) prevents a close fit of the collar.

The wither's should not be thin and high, ats this conformation will allow the saddle to slip too far forward and the pommel will rest upon the withers. The bar's of the saddle will be forced against the shoukler blades, causing irritation and inflammation, and preventing free motion of the shoulders; the constraint causes stumbling. On the other hand, the withers should not be low or thick, as the saddle is then apt to pinch them.

The breast and chest should be of moderate width and have considerable depth; the narrow ehest indicates weakness, and the wide, heary chest is suitable for heary-draft horses only.

The capacity of the lungs is marked by the size of the chest at the girth, but the stamina will depend upon the length of the back ribs. The barrel should not be broad back of the cinch, as it would cause the cinch to slip forward and chafe the body just back of the point of the elbow. The opposite conformation would allow the saddle and cinch to slip backward. The back should be short, with muscles well developed, and the upper lines of the back bending down a little behind the withers and then swelling out very gently to the junction of the loins, which can hardly be too broad and muscular.

The last rib should be placed ('lose to the point of the hip, as this is an indication of strength, and the lorse is more easily kept in good condition than one lating the opposite conformation.

A slighty arehed loin is essential to the power of carrying weight: the concave or "sway-back" is therefore a sign of weakness: the much arched or "roatch back" is almost sure to give uneasy action from its want of elasticity.

The hips shoukd be broad, smooth, and museular.

The eroup should be well rounded, should slope slightly downward and be of moderate length: both the straight, horizontal eroup and 
the drooping croup are unsightly; when the (roup droops and also becomes narrow below the tail, the conformation is known as "goose rump" and is a sign of weakness.

The dock should be large and muscolar; the tail carried firmly and well away from the quarters.

The quarter (thigh and buttock) and gaskin shonild be broad. The muscles of the two quarters should enme close together, leaving no hollow below the anus; the widely separated eonformation is an indication of a want of (onstitution.

The hock should be of good size, but dean and flat, and with a good clean point standing clear of the joint. The two hocks should stand well apart, but not emongh to give the horse the appenrance of being "bow-legged." "Cow-loncked," so called, is when the hocks stand close together and the hind fect wide apart, with the toes turned out.

If the hocks stand in, it will be noticed that the stifles stand out, and the reverse. "Straight hock" and "crooked hock" are terms used to express the shape of the hind leg as seen from the side; both shapes are objectionable. "Sickle hock" describes the curre which results from a crooked hock, a short cammon, and a sloping pastern.

The cannon should be short, not tied in below the hock, and the line from the point of the hock to the back part of the fetlock should he straight.

The fetlock when bent forward is an indication of weakness known as "eocked ankle." The hind fetlocks, pasterns, and feet should correspond to those of the fore extremity, but the pasterns are usually more upright.

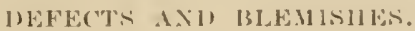

Defects and blemishes are those results of injuries (more or less serere) which show on the ontside of the body. They are regarded as external diseases, and may be classed as follows:

1. Discises of bones.

2. Diseases of srnorial membranes.

3. Diseases of muscles, temdons, ligannents. and skin.

4. Diseases of the foot.

\section{Hiserses uf hom!s.}

Bone spavin.-Location: Iower and inner part of the hock joint. splints.-Location: Usually appearing on the immer sile of the upper third of the front camnon; ocensionally foumd on the onter side of the upper third of the hind ('anmon.

Sidrbones (ossifiention of lateral artilagess). Lacations: Sides of the foot just above the eoronet.

Ringbone.-1 location: Between coronet and forlock joint. 


\section{Diseases of synovial membranes.}

Bog spmein.-Location: Front part of herek joint.

Thorough-pin.-loocation: lpper and back part of hock joint.

Wind puffs (windgalls).-Iocation: ()n the sides of the tendons just above the fetlock joints.

Other bursal enlargements (distender sinnorial sacs or pouches) may be found located on various parts of the legs, but no special name has been given to them.

i. Discases of the museles, tendons, ligaments, and skin.

Poll ril.-Iocation: In the region of the poll.

Fistulous withers.--Tocation: In the region of the withers.

Sweeny (atrophy or wasting of the muscles).-Location: Usually in the shoulder or the hip).

Broken knes.-Tocation: Front part of the kneejoint.

Capped elbor.-Location: Point of the elbow.

Capped hock.-Location: Point of the hock.

Curb.-Location: Lower and back part of the lock.

Sprung knees.-I ocation: Kinees.

Cocked ankles.--Tocation: Fetlock joints.

Bowed tendons.-Location: Flexor tendons below the knee and hock.

Breakdown.-Location: Sprain of the stispensory liganent.

Saddle galls.-Location: On the saddle bed.

("inch galls.-Location: On the parts coming in contaret with the cincll.

Collar galls.-Location: ()n the parts coming in contact with the (collar.

\section{INise (1.ses of the foot.}

Thrush-Location: Frog.

('anker.-I.ocation: Frog and sole.

Chroniclaminitis.-Iocation: Sensitive laminx.

Corn.--Location: Between the wall and bar.

False quarter and quarter cruck.-Location: Quarters of the hoof. Quittor--Toration: Topr of the coronet.

Contrected herels.-I ocation: Heels.

Toe cracks. I lacation: At the toe of the hoof.
Serdy tore. 


\section{CHAP'TER II.}

\section{STABLE MANAGEMENT OF THE SICK AND INJURED.}

\section{CARE OF THE SICK.}

The sick horse should, if practicable, be immediately removed to a large, clean, light and well-rentilated box stall, free from drafts and located as far as possible from other horses. Clean bedding should be provided, and the stall kept free from manure and moisture. If such a stall ean not be provided a double stall, with the kicking bar remored and ropes or bars placed across the front of it, will answer the purpose.

If the patient is suffering from a febrile disease (fever) during the cold season of the year, paulins or horse covers can be luung up in such a manner as to serve as a protection from drafts, care being taken to allow sufficient air to enter this improvised box stall. Such patients must be clothed according to the season of the year, the blanket drawn well forward on the neck and fastened in front, the legs, after hand-rubbing, bandaged with red flannels. The bandages should be changed several times daily, and the legs thoroughly rubbed to stimulate circulation.

Horses with diseases of the nervous system require to be kept absolutely quiet, and must be remored as far as possible from all noise. It is preferable that only one man be allowed to attend to their wants, as a change of attendants would very likely cause excitement and thus increase the severity of the disease. Animals suffering from debilitating diseases should be tempted with and fed any food that is rich in nourishment and easily digested. Salt should frequently be added. The food, etc., should be giren only in such quantities as the animal will readily eat, and any portion left over should be at once removed, as food constantly placed before a sick animal will have a tendency to deprive it of all appetite. Fool that is wet, such as bran mashes or steamed oats, will soon sour in warm weather and will get cold or may freeze during the winter; if eaten in these conditions it may cause diarrhea, colic, ete. Feed boxes. water buckets, and all parts of the stall must be kept dean and free 
from color: The hay shomld be dean and bright, and only the best given to the sick animal. Pure water should be provided, and placed in such a position as to enable the animal to reach it without difficulty; a sick horse witl frequently rinse the lips and mouth with water if griven the opportunity, even when not thirsty. The water shoubl be changed as often as necessary during the day to insure a pure and fresh supply at all times.

A horse suffering from colie requires suflicient sparer, woll berdederl, to prevent injuring himself by rolling during a spasm of pa mun should be constantly in attendance, as there is dangrer the animal may become cast and be unable to get up without assist anne.

Undicrested matter being the exciting cause in almost all 'an colice, food shoukl be withheld for about twelve hours after al $l_{2}$. .ul has disappeared, and then griven only in small quantities durinr the next twenty-four hours, after which the ordinary ration may be wsumed. I few swallows of pure water may be given at short intervals, but special care must be taken when the water is very eold.

The pulse is the beating of the arteries, usually felt at the jaw (the submaxillary artery), and is an important guide in determining the physical condition of the animal: the normal pulsations are abr $t 4 u$ per minute. The count is best taken by placing the fore or $\mathrm{n}$ t dle finger transtersely on the artery. The slightest excitement, when the horse is sick, will eause an alteration in the pulse; therefore the animal shouk be approached very quietly. I strong and full .... is an inclication of health.

In the first staces of fever the pulse is full and bounding, afterwards becoming small and weak. A very slow pulse denotes disease or injury of the brain or spinal cord. In imperceptible pulse indicates the approateh of death.

At rest the healthy horse breathes from $1: 3$ to 1.5 times per minute. Difficult or rapiel breathing is a prominent symptom of disease of the respiratory orerans; it may also be observed in some cases of flatulent colic. Abdominal breathing is the respiratory movement perfow - 1 with the ribs fixad as much as possible, owing to pain or mechanical obsturetion in the chest, and is a symptem of plemrisy and lre ? ? thorax (water in the chest).

Jorecrulal breathing is that eonclition where there is a want of harmonious correspondenee between the inspiratory and expiratory movements, and is observed in the disease commonly known as "broken wind" or "heaves." The inspiratory movement in this alfection is performed quickly and with jerky effort, while the expiratory movement is performed slowly and with a double action, more particularly of the abrlominal muscles. Irregular breathing often becomes spasmorlic or convulsive during the progress of the diseas". The condition and color of the visible mueous membranes 
should be closely observed; as will be learned in detail later, they are an important guide in determining the physical condition of the animal.

Tie normal temperature of the horse in the internal part which is riost easily accessible, the rectum, may be estimated at from $99^{\circ}$ to $101^{\circ} \mathrm{F}$. In very young animals the temperature is commonly about $101^{\circ}$, but in very old ones it has been known to be as low as $96^{\circ} \mathrm{F}$. The temperature of the external parts of the body becomes if according to their distance from the heart, and liable to much if frotion from the state of the surrounding atmosphere. Fever is an elevation of temperature.

The production of animal heat is due to certain chemical and vital $\checkmark$ ig fuges which are continually taking place in the borly; these changes consist in the absorption of oxygen by the capillaries in the lungs, and the combination of that oxygen with the carbon and hydrogen derived (first) from the disintegration of animal tissues and (second) from certain elements of the food which have not been converted into tissue.

This combination with oxygen, or oxidation, not only takes place in the blood, which may be looked upon as a fluid tissue, but in the tis ije cells also, in all parts of the body, the animal heat being maintaingl by the natural changes which are essential to a healthy condition.

As previously stated, oxygen is absorbed from the air by the capilis s of the lungs in respiration (breathing). Expired air is found to have lost about 10 per cent of the oxygen contained in pure air, and to have accumulated a like amount of a combination of carbon and oxygen, ealled carbonic acid gas. If we imagine the animal breathing and rebreathing the same air, it can be seen that the oxygen, so necessary for the purification of the blood, would soon diminish to a dangerous degree. Hence, we realize the importance of a large supply of air to draw on and the necessity of good rentilation. It each inspiration the horse draws about 250 eubic inches of air into tho lungs, and he therefore requires about 2 cubic feet per minute, or 1:20 per hour. It is customary, in building ordinary stables, to -allyw 1,600 cubie feet of air space (over twelve hour's' supply) for each animal, and to provide means of admitting fresh air without causing drafts. In infirmary stables the allowance is inereased to 1,900 cubic feet.

Without good air the blood is imperfectly purified, the vitality of the animal is lessened, he is more susceptible to discase, and will succumb more easily when attacked; consequently horses should nerer be kept in the vicinity of a marsh, the air from which contains an excess of carbonic acid gas and a diminished supply of the necessary oxygen.

$5417-09-2$ 
If the horse is seriously injured and stands with dilliculty, he should be placed in slings (Plate II) to partially support the woight of the body. The slings must be properly arljusted, fitting rlosely behind the elbows in such a manner as to support the weight of the boly on the elhest and not on the abdomen. This position is maintained by the use of the breast piece and brecching, which prevent the shifting of the sling. A single stall, having a level floor, free from bedeling, is more suitible than one allowing more motion to the animal.

If the horise is but slightly injured, there is no necessity of placing him in slings. An ordinary stall with a level floor is all that is required. After the injury has been dressed he should be allowed to stand without being disturbed. If very lime, and movement is painful, the more quict he is kept the more quickly will recorery take place. Absolute rest and perfect quietude are two very essential things, and when secured they will hasten the process of recorely without inflicting unnecessary pain upon the animal. In some surgical cases it is necessary to restrain the animal so that he can not injure himself hy rubbing or biting the affected parts. This can be accomplished by tying up the head or by the application of side lines. Bandages maty be applied to the lears of animals for different purposes: First, to give support to the hlood ressels and synorial bursa; second, to dry and warm the legs; third, to support packs used in applying hot and cold lotions; and fourth, when conditions are favorable, to check hæmorrhages.

\section{WATER SUPPLY.}

However harmless impure water may have been to animals in a wild state, the more we subject them to an artificial existence the more we remove them from the immunity they may have possessed against common causes of disease and the greater liability is there for the development of diseases which originally may never have existed. In other words, the domesticated animal should always have pure water; when the vitulity is further redued by sickness the necessity of absolute purity is even more imperative. 


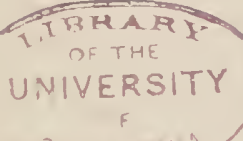




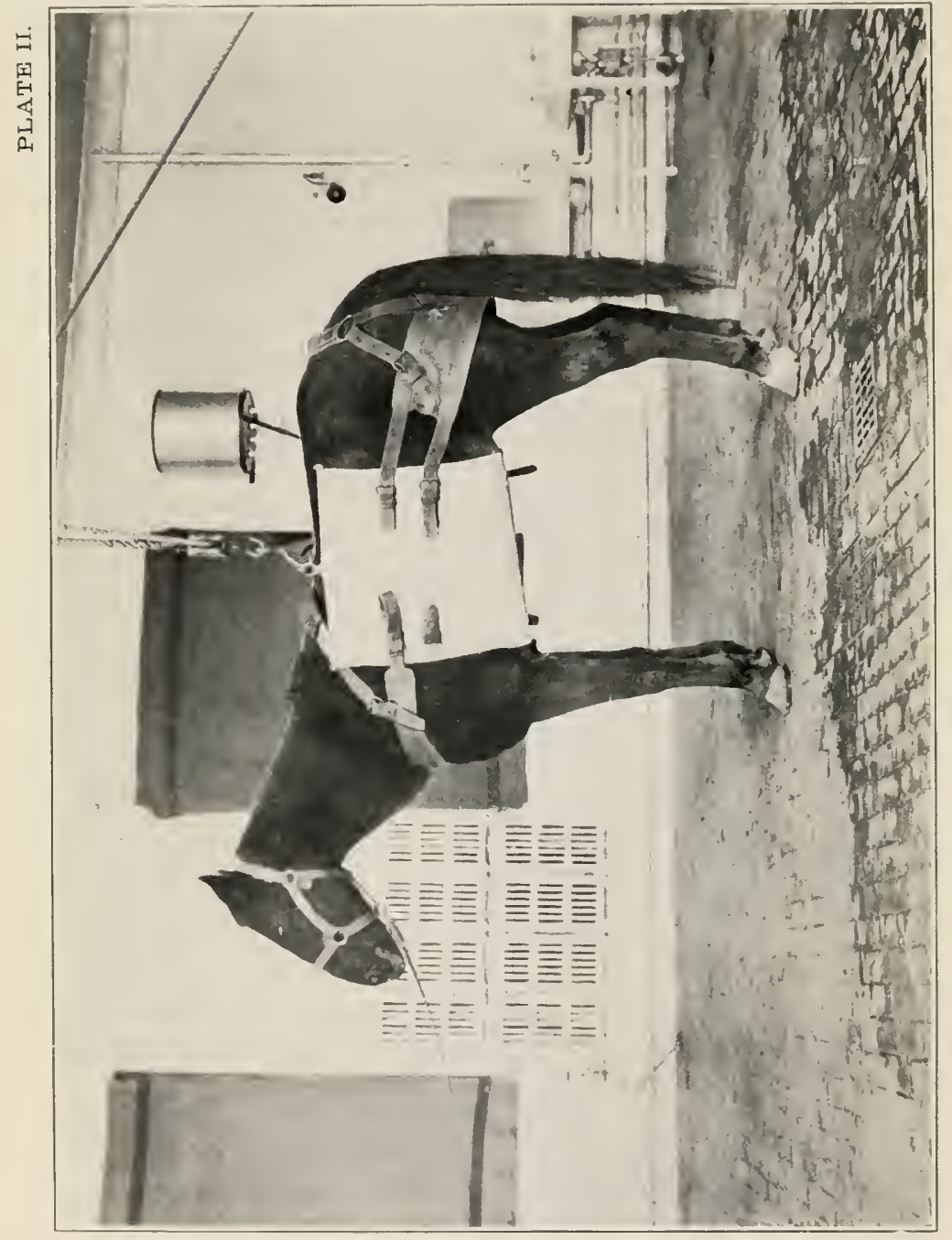

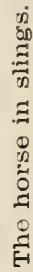




\section{CIIAP'TER III.}

\section{ANATOMY.}

Inatomy is a deseription of the struetures that make up the body.

THE SKELETUN.

(l'late III.)

The skeleton is the framework for the support of the softer structures, and is composed of 216 bones (exclusive of the teeth) of various sizes and forms.

Flat bones, such as the skull, ribs, and scapula, are found covering vital organs; long bones are found principally in the extremities, for the support of the body.

The spinal column is composed of bones of rery irregrular shape, which are divided into five groups according to their locintion, and are known as vertebra. Commencing at the back of the head, the first seven are called the cervical vertebra, or bones of the neck; of these the first is called athes, the second axis; the next eighteen are called the dorsal vertebra, forming the main part of the back; the next six, the lumbar vertebra, form the loins; the croup) or sacrum is composed of five bones, which in the adult animal are united together as one bone; and following this are found the coceygeal or tail bones, numbering from thirteen to twenty. All vertebra have irregular projections of varying length, called spinous processes; these are named, according to lociation, dorsill, cervical, at e.: the third to sixth dorsal spinous processes (often called dorwal spines) are very long and form the wither's.

The ribs are eighteen on cach side, attached above to the dorsal vertebre. The first eight (true or fixed rilss) are attached below, by cartilage, to the sternum or breastbone; the remaining ten (false or floating ribs) are attached by (artilage to one another and indirectly to the sternum; they form the wills of the chest and serve ats a protection for the heart, lungs, and large blood vessels. 

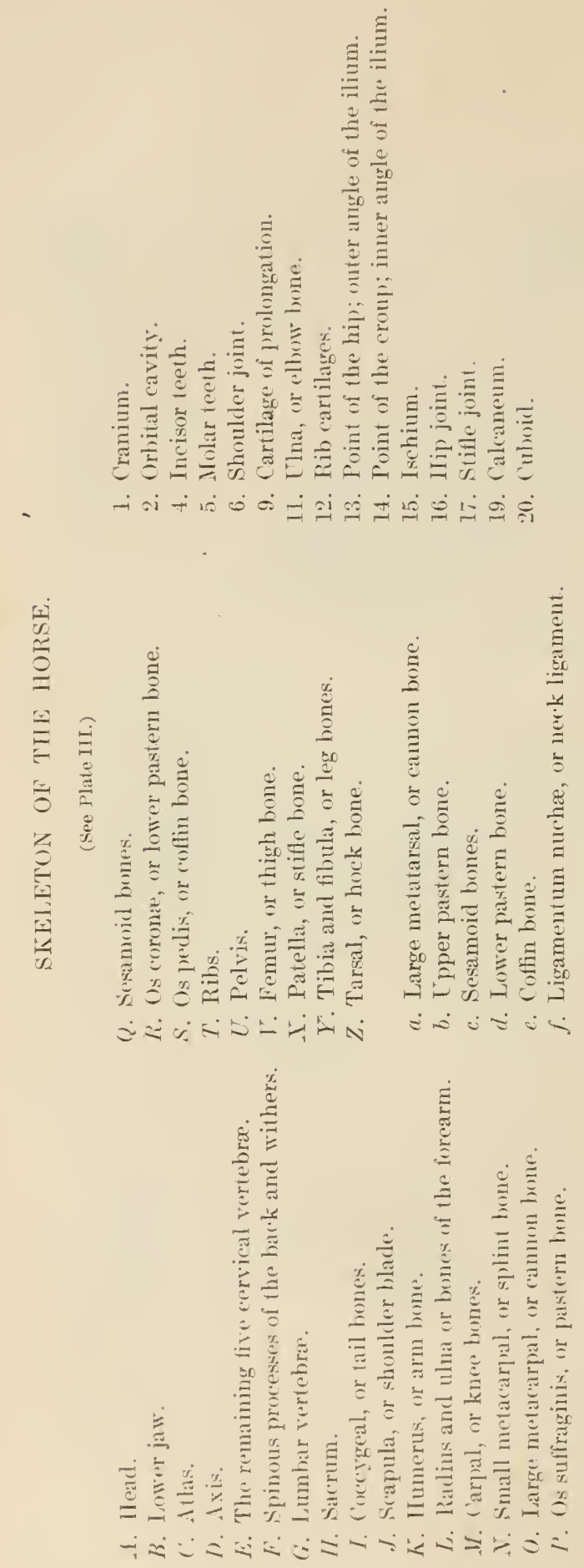


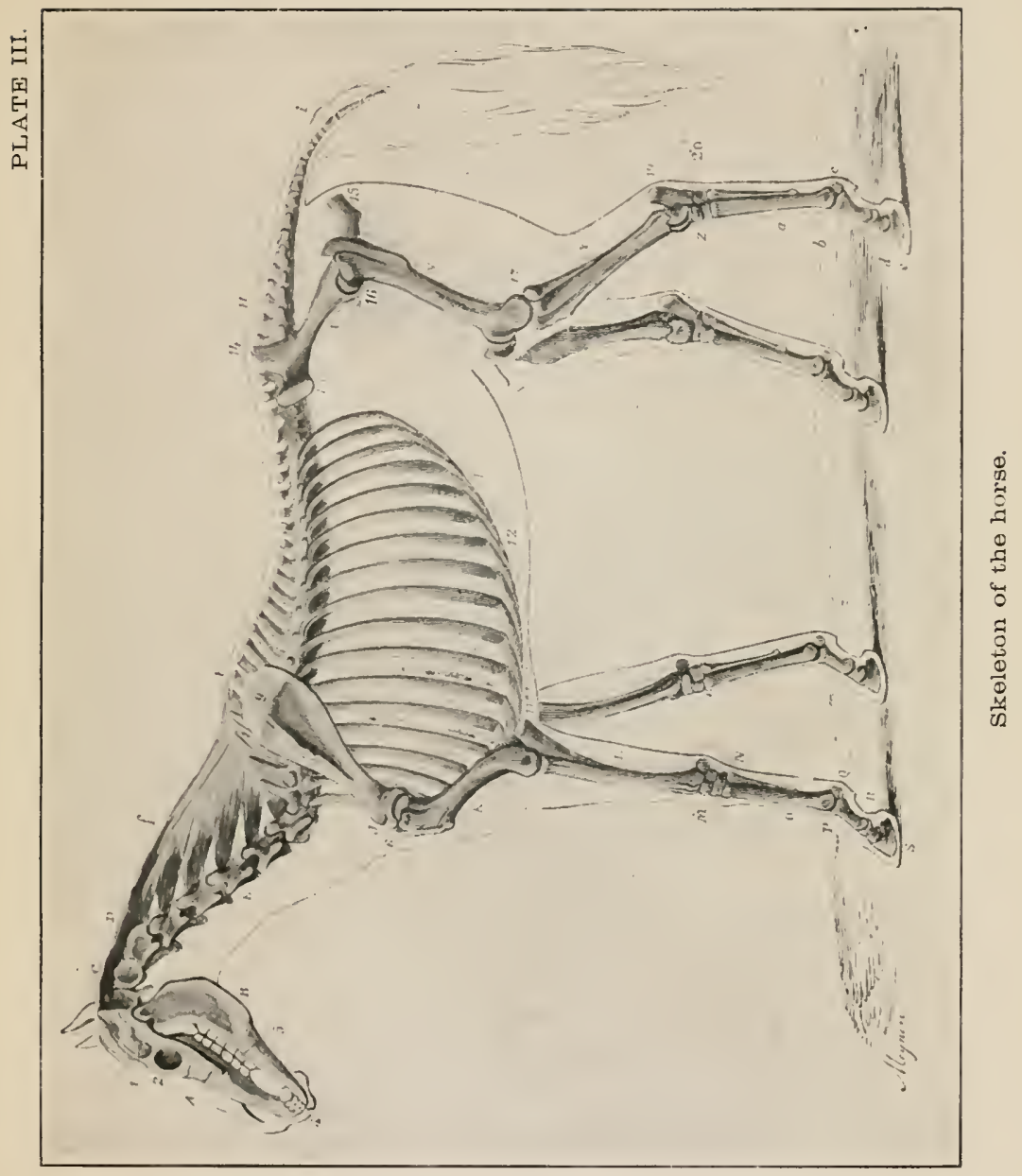




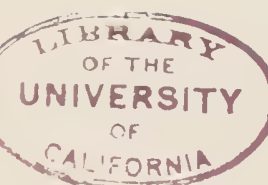


The skull, containing curitios (or chambers), is composed of irregularly shaped flat bones, the most important of which is the cranium, or brainpan, oceupied by the brain and communicating with the bony canal (eontaining the spinal cord), which passes through the center of the cervical, dorsal, lumbar, sacral, and sometimes the first two or three cocergeal vertelnat. The orbitul cavities (containing the eyes) communicate with the brain by narrow passages, through one of which the optic neme palsses.

On each side, below the eye, are two closed avities known as the superior (upper) and inferior (lower) maxillary sinuses; in the lower third of the skull are found the nasal chambers extending from the mostrils backward to the pharynx, and separated by a thin partition of bone and eartilage, called the septum nasi; the floor of these chambers forms the roof of the mouth. From the orbital carities the skull gradually becomes narrower and terminates a short distanee below the nostrils in the premaxilla, which contains the six upper incisor tecth; these six, with the corresponding teeth in the lower jaw, form the anterior (front) boundary of the mouth, which extends back to the pharymx. On the upper portion of the back of the mouth (avity are found six molar or grinder teeth on each side; that portion of the jaw between them and the incisors is called the interdental space. Situated on each sille near the incisor teeth in this space are found, in the male, and rarely in the female, the tushes or canine teeth.

The inferior maxilla or lower jaw is composed of two segments firmly united in front and spreading backward somewhat in the form of a letter $\mathrm{r}$. Each branch, at the end, turns upward and is united to the skull proper in a movable joint. The branches of the jaw include a space appropriately ealled the maxillary space. Located in the united or front part of this bone are the inferior incisors and ('anine teeth, and, in the branches, the inferior molar's, which correspond to those of the upper jaw. The space between the molars and incisor's is the same as that in the upper jaw.

The front leg is composed of the following bones, named in order from above downward: Scapula, shoulder blade; humerus, bone of the arm; radius, bone of the forearm, and ulna, bone of the elbow (radius and ulna are united in one bone); carmus, knce bones (seven small bones); large metacurpal, cannon bone; two small metacarpals, splint bones (the three metacarpal hones are joined together, forming the metacarpus); two sesamoids, pulley bones; os suffraginis, upper pastern bone; os coroner, lower pastern bone; os pedis, coflin bone, and os navicularis, shuttle bone. The scapula is extended by means of a thin plate of gristle, called the "cartiluge of prolongution." which offers additional attachment for the museles of the body. 
The peteis is composed of two segments. In ald secrment are three united, irregularly shaped, flat bones, namoly, ilium, ischium, and pubis (haunch bones). The ischium and pubis bones are also united in pairs, forming the floor of the polvic cavity oceupied by the bladeler and rectum. The two ilimm bones or beanches are triangular in shape. The outer angrle in each case is the proint of the hip. The two inner angles are close to each other, and together form the proint of the croup. Just below this point each branch is attached to the sacrum iny ligiments. That portion of the ilimm extending back to the hip joint is called the "shaft."

The hind log is composed of the following bones: Femur, thight bone; tibia, lecr bone: fibula, accessory licr bone; petella, stifle bone; tursus, hock (made np) of six small bomes, named calcuneum, astragalus, cunciform magnum, melium and pareum, and cuboid); large metatursal, eannon bone; two small metatarsals, splint bones. Below the cannon, the bones have the same name as in the fore leg.

\section{JOINTS.}

A joint is a morable union between two or more bones. Covering the adjacent surfaces in the joint is a thin and rery smooth layer of a peculiar lind of cartilage called articular curtilage. A lubricating fluid, synovia, joint oil, is required to reduce the amount of friction; this fluid is secreted or formed by the synovial membrane and the latter is confined and protected by the capsular ligament which completely surrounds the joint. Outside of the capsular ligament are binding ligaments holding the bones in position.

The joints of the fore leg are as follows: Shoulder joint, formed by the lower end of the scapula and the head of the humerus; flbow joint, by the raclius, ulna, and humerus; Fnee-joint, by the radius, seven small bones (carpals), and the upper end of the metacarpals: fotlock joint, by the large camnon, upper pastern bone, and the two sesanioids; pastern joint, by the upper and lower pastern bones; coffin joint, by the lower pastern, coffin bone, and shut tle bone.

The following joints make up the articulation of the hind leg: Hip joint, formed by the socket of the pelvis and the head of the femur; stifle joint, by the lower end of the femur, head of the tibia, and the patella; hock joint, by the lower end of the tibia, six small bones (tarsals), and the uppor ('nds of the motatarsals. The fetlock, pastern, and coflin joints correspond to those of the fore limb.

\section{I.IG MENTS.}

Ligaments are, generally spealking, strong bands of white fibrous inelastic tissue. Their principal use is to firmly lind joints together, thereby preventing vibration and diminishing friction. 
The suspensory ligament should be carefully studied on account of the numerous accidents to which it is liable. It is a long, strong band of fibrous tissue originating in the back part of the lower bones of the knee and in the upper part of the cannon bone; it occupies the space between the splint bones and passes down immediately behind the cannon bone, lying between it and the tendon (sinew) of the flexor pedis perforans: it bifureates (divides into two) opposite the lower third of the anmon bone and becomes attached to the sesamoids, whence the parts pass forward and downward, joining the tendon of the extensor pedis just above the pastern joint. It is thin and comparatively weak near the knee, but as it approaches the fetlock joint it almost equals the back tendons in substance, and its size and wiriness to the touch may be taken as some test of the power of any particular leg to resist a breakdown.

The suspensory ligament of the hind leg corresponds in erery particular to that of the fore leg.

The calcaneo-cuboid ligament stretches from the posterior (back) border of the calcaneum to the posterior part of the cuboid, ending on the head of the external (outer) splint bone. A sprain of this ligament is known as a "curb."

Capsular ligaments, as we have seen, are pouch-shaped, are found around joints, and are intended to protect the lubricating apparatus inside.

Some ligaments are made up almost entirely of yellow tissue, which is elastic. The ligamentum nuchæ, neck ligament, is an important example. It occupies the space in front of the dorsal spines, above the cervical vertebre, and is attached to the top of the skull. In this position it separates the neck muscles of the riglit sicle from those of the left. The object of elasticity in this ligament is to permit of great freedom in the motion of the head, although supporting its great weight in proper position.

\section{MUSCLES AND TENDONS.}

(Plate IV.)

The muscles are divided into voluntary and involuntary muscles; the former being under the direct control of the will, as, for example, the muscles of the neck, legs, tail, ete.; and the latter acting independently of the animal's will, as, for example, the heart, intestinil muscles, etc.

The muscles form about one-half of the entire weight of the body. With regard to their form they are divided into long, wide, and short. Long muscles are generally found in the limbs; wide muscles are stretched beneath the skin or around the great avities of the trunk, and short muscles are found chiefly around the irregularly shaped bones. 
Tendons are white, round or flattened cords affixed to the extremities of long muscles, attaching them to other structures, but themselves neither stretching nor contracting.

All lear muscles are longer muscles. Extensors are those that have the power of straightening the limb: flexors, of hending the limb.

The extensor pedis is the principal extensor of the fore leg; it originates at the lower extremity of the humerus, and its fleshy portion continues to the lower third of the radius; at this point it becomes tendinous, and, passing down over the knce, continues along the front of the legr and becomes attached to the upper and front part of the os pedis. Action, to extend the leg.

The extensor suffraginis has its origin from the external head and outer border of the radius and from the side of the uhna it is inserted (attached) to the upper and front part of the os suffraginis. Action, to extend the foot.

The extensor metacarpi magnus has its origin from the lower and external surface of the liumerus, passes down the front of the radius and kneejoint, and is attached to the upper end of the large metacarpal bone. Action, to extend the metacarpus.

The flexor brachii has its origin from the lower end of the scapula, near the shoulder joint, and passes down in front of that joint and the humerus and becomes attached to the upper front part of the radius. Action, to flex the elbow joint and extend the shoulder.

The flexor pedis perforatus originates from the inner and lower part of the humerus; it passes down the back part of the leg, becoming tendinous just above the carpus; behind the pastern it bifurcates, forming a ring for the passage of the tendon of the perforans and becomes attached to the sides of the os coronæ. Action, to bend or flex the knee, fetlock, and pastern.

The flexor pedis perforans originates with the perforatus; its fleshy portion passes down and is attached to the back part of the radius; its tendinous portion, beginning at the knee, passes down the leg between the cannon bone and the tendon of the perforatus, over the back of the fetlock, through the arch formed by the division of the tendon of the perforatus, and is attached to the under surface of the os pedis. Action, to flex the knee and all joints below.

The extensor pedis of the lind leg originates from the lower and front part of the femur; its fleshy portion extends downward along the front surface of the tibia to the hock, where it becomes tendinous; passing thence down the front of the leg it is attached in the same manner as the extensor pedis of the front lecr. Action, to extend the legr and flex the hock.

The peroneus las its origin from the external licrament of the stifle and from the onter part of the fibula, and is attached to the tendon 



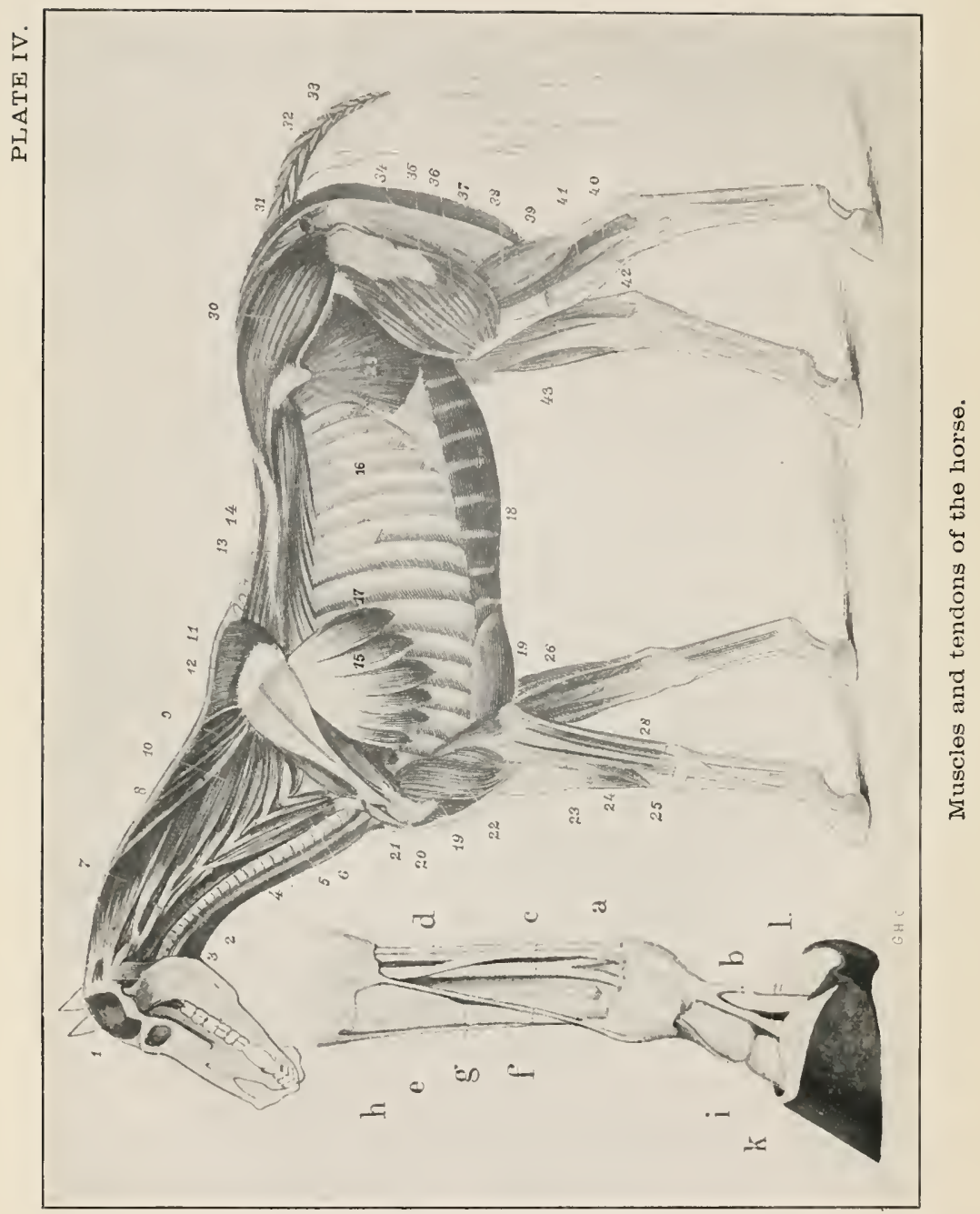




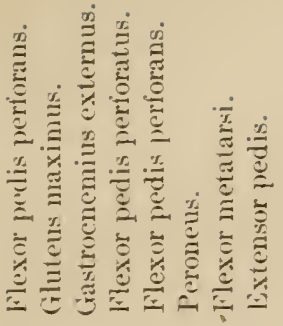

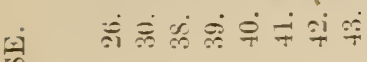

일

릴

כ)
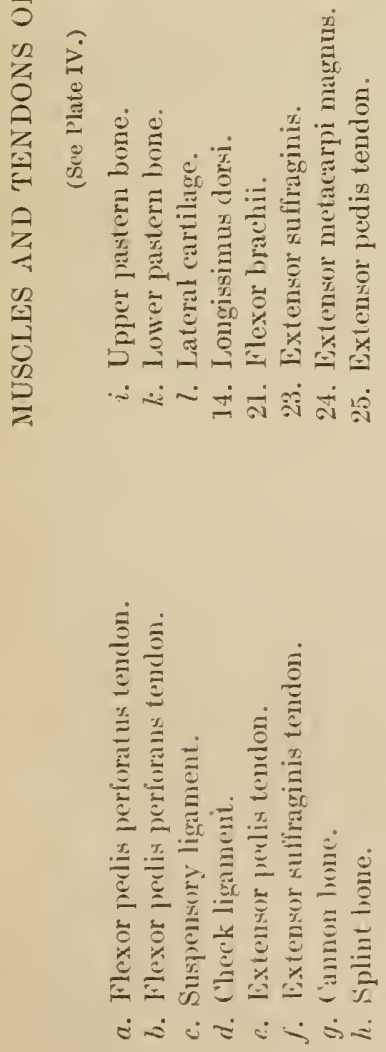
of the extensor pedis a short distance below the hock. Action, to assist the extensor pedis.

The tendon of the peroneus is cut in the operation for string halt.

The flexor metatarsi is divided into two portions-al muscular and a tendinous. The tendinous part is a strong pearl-white cord, situated between the museular portion and the extensor pedis. It commences at the lower extremity of the femur, and terminates in two branches-a latre one inserted in front of the upper extremity of the cammon bone and a small one deviating outward to reach the front surface of the cuboid bone. The fleshy portion originates on the front face of the tibia and is inserted by two tendons, one in the head of the large metatarsal bone, the other in the small euneiform on the inner side of the hock. Action, to flex the hock.

The flexor pedis perforatus of the hind leg originates at the back and lower part of the fenur. Its fleshy portion extends about halfway down the tibia, then becomes tendinous, and passes over the point of the hock, continues down the back of the leg, and is attached in the same manner as the perforatus of the front leg. Action, to extend the hock and to flex the fetlock and pastem.

The gastrocnemius externus has a double origin at the lower and back part of the femur and is attached to the point of the hock. At the back part of the leg the tendon of this muscle becomes closely associated with the tendon of the flexor pedis perforatus, the two forming the tendon of Achilles, or hamstring.

The flexor pedis perforans of the hind leg originates at the upper and back portion of the tibia. Above the hock it becomes tendinous and passing down over the inner and back side of the hock is attached to the os pedis in the same manner as the perforans of the front limb. Action, to extend the hock and to flex the joints below.

Wide muscles are attached to other struetures by broad bands of strong white tissue instead of by tendons.

The panniculus carnosus (fly shaker) is a wide flat musele situated on the imner surface of the skin and covering most of the neck, sides of the chest, and belly. Action, to shake the skin.

The principal muscles of the back, loins, and haunches are the longissimus dorsi, glutcus externus, gluteus maximus, and glutems internus.

The longissimus dorsi is situated on the upper part of the back and loins, and is the largest and most powerful muscle in the body, occupying the space on either side of the dorsal and lumbar spines. Is broad and fleshy at its origin in the loins and becomes narrower as it proceeds forward. It is attached to the front part of the pelvis (ilium), first two bones of the sacrum, all of the lumbar and dorsal vertebra, the external surface of the last fifteen or sixteen ribs, and to the last three or four eervical vertebrat. Action: It is lorought 



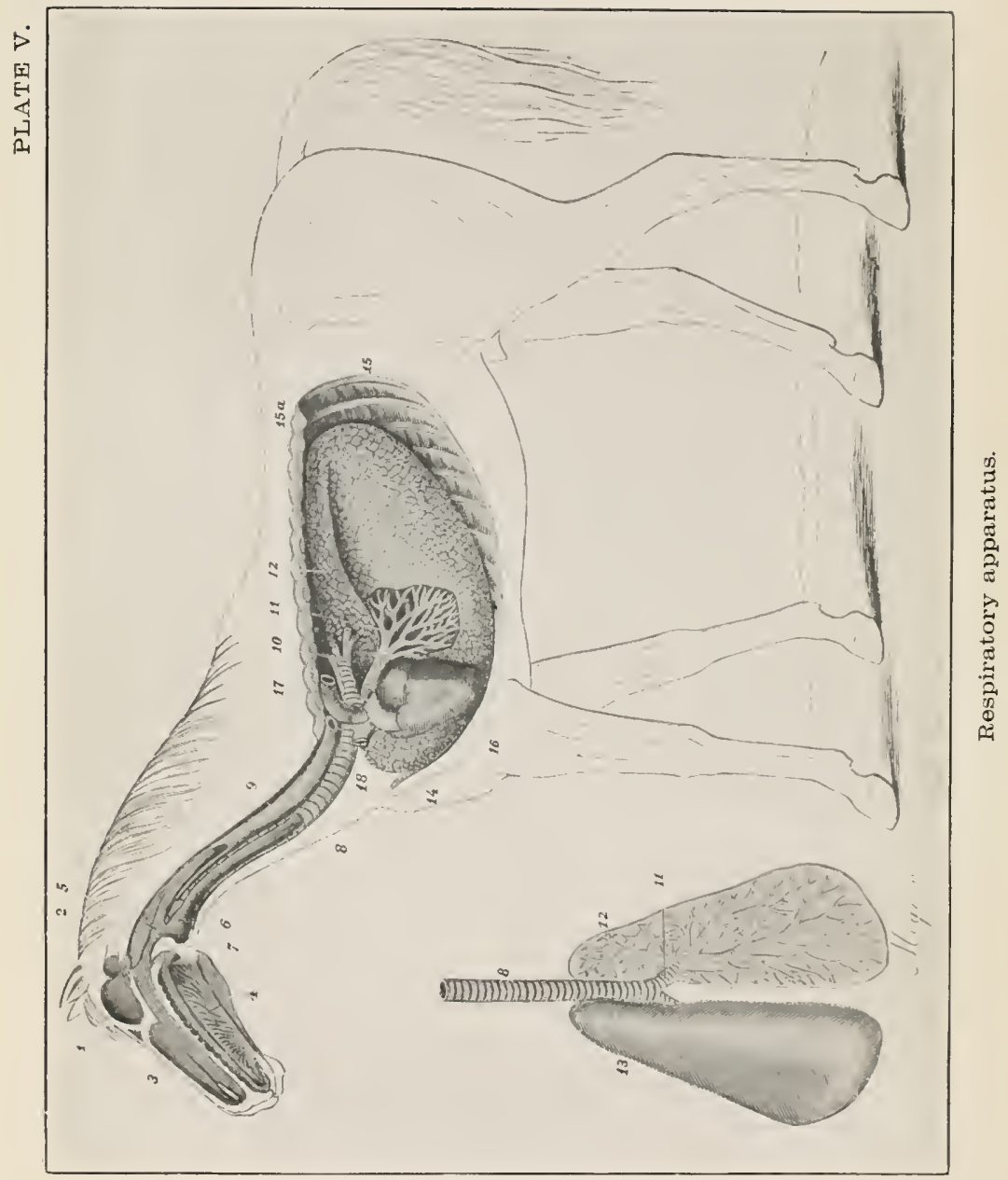



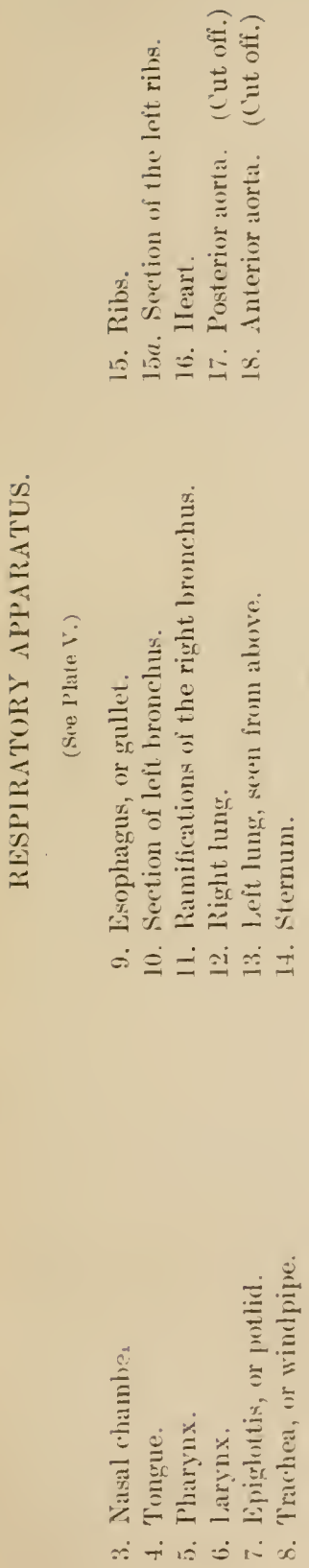
powerfully into play in kicking or rearing; it clevates the hind or fore quarters, according as the fore or hind limbs are on the ground. Aeting on one side only, it bends the back and loins laterally.

Glutens externus is a V-shaped musele situated on the upper and outer part of the haunch. It originates on the front part of the ilium and at the second and third sarral spines. Insertion, to the upper and outer part of the femur. Artion, to draw the thigh out warl.

Glutens maximus is a very large muscle, originating in the lumbar region: it is attached to the ilium and. sacrum and is insertod on the upper and auter portion of the fomur. Action, to extend the femur on the petris, and when the posterior limbs are fixed, to assist in rearing.

Glutcus internus is situated underneath the gluteus maximus and above the hip joint. It originates from the shaft (lower angle) of the ilimm and is inserted by a tendon to the upper part of the femur. Action, to draw the lege outward and rotate it inwart.

THF, RESTIRATORT SYSTEM.

(l'late V.)

The organs of respiration are the nostrils, nasal chambers, pharynx, larynx, trachea, bronchi, bronchial tubes, and air cells. All of these organs, except the air cells, are lined with a soft tissue called mucous membrane; where organs open to the external surface the mucous membrane and the skin are continuous. The nostrils are two oblong openings (right and left) situated in the front part of the muzzle. The nasal chambers extend from the nostrils to the pharynx and are separated from each other by the cartilaginous septum nasi; each chamber is divided by the turbinated bone into three passages, all lined with a delicate rose-colored mucous nembrane, called the Schneiderian membrane, which is continuous with the skin of the nostrils.

The pharynx is a muscular, membranous carity, common to the digestive and respiratory canals, somewhat cylinctrical in form, and extending back to the larynx and the esophagus.

The farynx (commonly known as "Alam's apple") is a complex musculo-cartilaginous box, situated in the back part of the maxillary space, and at the front part of the trachea or windpipe. It gives passage to air and at the same time is the organ of voice. The front extremity opens into the pharynx and the posterior into the trachea: the front opening is guarded by a valve called the epiglottis or "potlicl," which closes mechanically in the atet of swallowing and thus prevents the passage of food or water into the trachea and lungs. 
The trachea, or windpipe, is a cylindrical, flexible tube consisting of a series of incomplete cartilaginous rings, numbering from forty to fifty, according to the length of the neck. It suceneds the larynx, runs down the neck, enters the thornx or chest, and terminates at the base of the heart where it branches into the right and left bronchi, which enter the lungs and subdivide into branches termed bronchial tubes. These, becoming grarlually smaller as they divide, finally terminate in air cells. The entire ramification, when isolated, has the appearance of a tree, the trachea being the trunk, the bronchi and bronchial tubes the branches, and the air cells the leaves. Theso structures are accompanied throughout by arteries, veins, and nerves.

The thorax, or chest, is formed by the ribs, sternum, the borlies of the dorsal vertebre, the muscles between the ribs (intercostal), and the diaphragm. It contains the lungs, heart, large blook ressels, the trachea, esophagus, and a number of nerves. The thorax is lined by two serous membranes, the right and left pleura, each pleura lining onc-half the thorax and coreloping the struetures contained therein. A serous membrane is a thin glistening structure and lines a closed cavity.

The lungs, the essential organs of respiration, are light, spongy organs of a conical shape, situated in the thoracic eavity. (Itealthy lungs float in water.)

The diaphragm or midriff is the muscular partition which separates the thorax from the abdominal cavity or belly.

\section{DIGESTIVE OR(KANS.}

(Plate VI.

The digestive organs consist of the mouth, phurynx, isophague, stomach, intestines, and amus, all lined with mucous membrane. Together they form the alinentary canal through which the alinentary matter (food) is subjected to the special actions which adapt it to the purpose of nutrition.

The mouth is an irregular carity, containing the organs of taste and the instruments of masticution (chewing or grinding). It is situated between the jaws, its long diameter following that of the heal, and is piered by two openings-the anterior, for the introduction of food, and the posterior, through which the food passes into the pharym. It is bounded in front by the lips and laterally by the cheeks; the roof is formed hy the hard palute; the floor is occupied by the tongue, while the rear boundary is the soft paluts. Opening into the mouth are ducts leading from the salivary glands: the parotil, submaxillary, and sublingual glands. The mucous membrane covers the whole free surface of the mouth and its accessories 
except the teeth. The lips are the organs of touch as woll as of prehonsion (pieking up). The soft palate is a curtain suspended between the month and the pharyax, attached above to the poldetine arch (the back part of the hard palate); the lower border is free and rests on the floor of the pharymx. Owing to the great size of this eurtain, the horse is malble to breathe through his mouth.

The tongue is a movalble museular organ, situated on the floor of the month between the branches of the lower jaw. It is the speeial organ of taste and at the same time assists in mastication.

The pharymx has been previously described.

The esophagus, or gullet, is a museular tube connecting the pharynx to the stomach.

The stomuch is a pear-shaped organ situated in the abdominal cavity, close to the diaphragm. Its intermal, or mucous, coat is divided into right and left portions, the left is the cuticular portion and is continuous with the nucous membrane of the esophagus, which it resembles in structure and appearance, being of a pale white color. The right portion, the villous, or true digestive coat, is reddish in color, soft, very vascular (filled with blood vessels) and velvety looking; it contains the peptic glands which secrete gastric juice.

The eapacity of the stomach of the horse (from 3 to $3 \frac{1}{2}$ gallons) is small in proportion to his size.

The intestines are divided into large and small. The small intestines are continuous with the stomach, rather more than an inch in diameter and about 72 feet in length. The large intestines, measuring about 22 feet in length, extend from the termination of the small intestines to the anus, and may be regarded as consisting of four parts, the crecum, grent colon, floating colon, and the rectum.

The membranous lining of the intestines is covered with small projections called villi, which absorb the nourishing parts of the food. The villi are more numerous in the small intesines than in the large.

The intestines are supported thronghout their entire length by strong bands of fibrous tissue (the mesentery) extending from the backbone. The mesentery is a part of the peritoneum.

The amus is the posterior opening of the alimentary canal and lies below the root of the tail. It forms a romel projection, which beeomes less prominent with age.

The lier is the largest secreting organ in the body, weighing from 10 to 12 pounds. It is situated immediately behind the diaphragn and in front of the stomach. The liver secretes a fluid, called hile or gall, which is cmptied directly into the small intestines, as the horse is not provided with a gall bladder.

The pancrees (swerthreat) is situated behind the stomach and in front of the kichers. It is of reddish cream eolor, and weighs about 



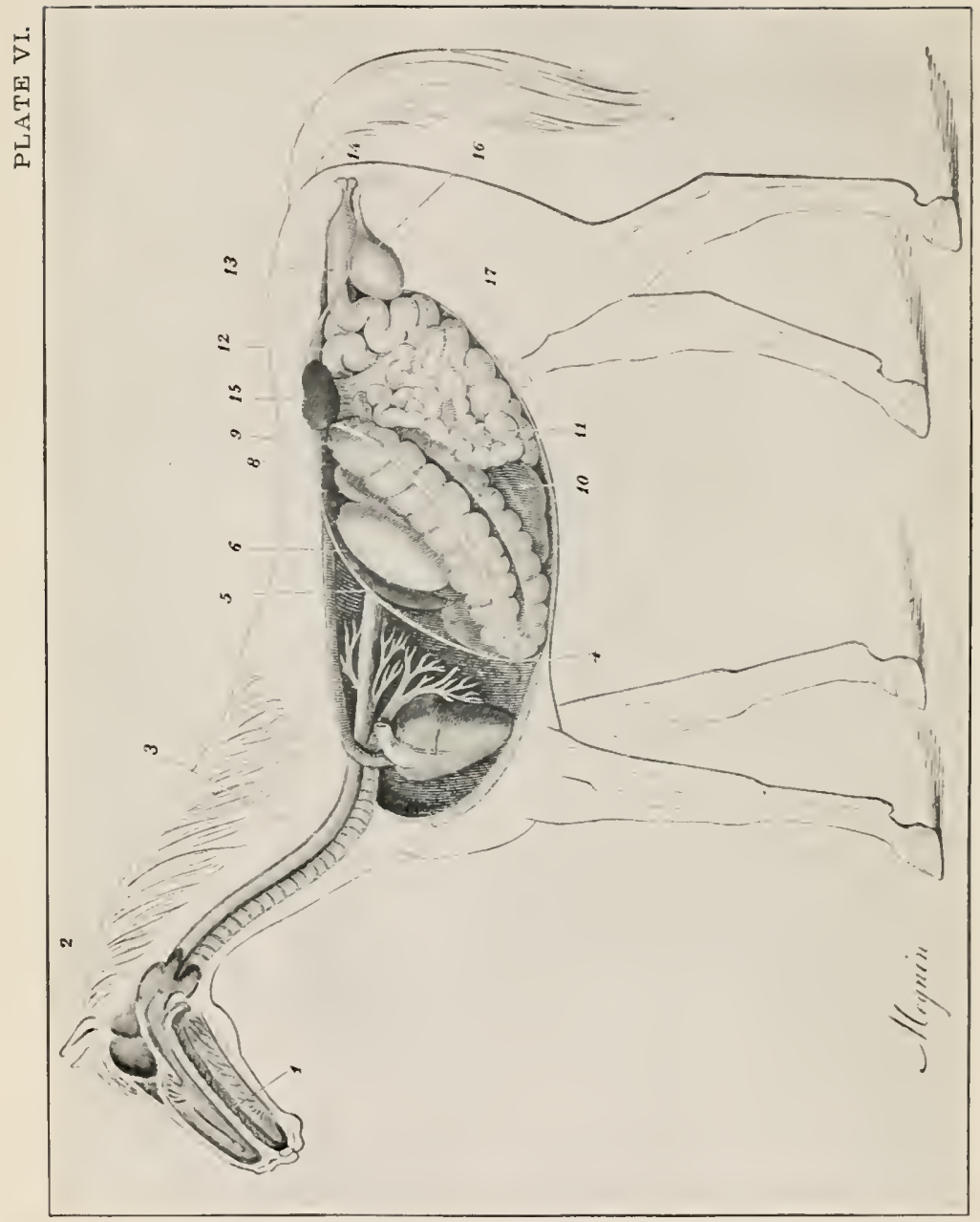

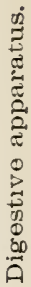



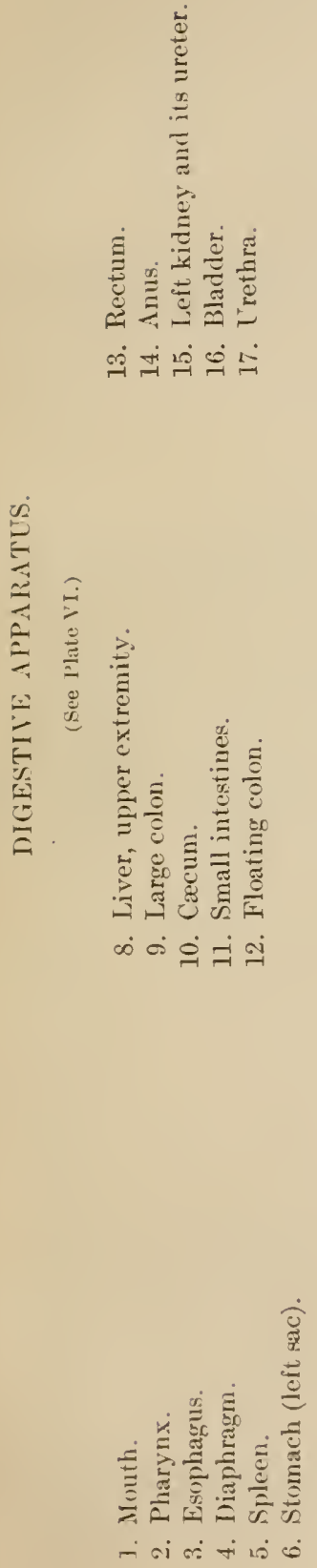
17 ounces. Its function is to secrete pancreatic fluid, which is poured into the small intestine.

The spleen is situated on the left side of the stomach. It is pointed at the lower end and gradually widens as it extends up to the region of the left kidney. The spleen is of a reddish-gray color and in the lealthy horse weighs from 2 to 4 pounds. In disease, however, it may reach an chormous size.

The function of the spleen is not positively known, but it is believed that this organ acts as a storehouse for the supply of bloorl to the stomach during digestion and that it effects some change in the blood, many authorities claiming that it forms the white blood corpuseles. (See "Blood.")

The abdominal cavity is a large, somewhat oval cavity, bounded above by the muscles of the back, below by the abolominal muscles, and in front by the cliaphragm; behind it is continuous with the pelvic cavity. The cavity is lined throughout by a serous membrane called the peritoneum.

\section{PIIYSIOLOGY OF DIGESTION.}

By physiology is meant a description of the functions or uses of certain structures. The plyysiology of digestion describes the functions of parts of the digestive apparatus.

Food, as it passes through the digestive or alimentary canal, is subjected to a series of mechanical and chemical agencies by which it is, in greater or less part, digested and worked up to a condition in which it can be absorbed by the appropriate vessels, and, while this portion is taken up by the circulation, the effete (worthless) remainder passes on and is clischarged.

The food is taken into the mouth by the lips (prchension), where it is ground up (mastication), and is mixed with saliva. Saliva, secreted by the salivary glands in different parts of the head, acts chemically upon the starchy components (parts) of the food and con verts them into sugar, which is more rearlily absorbed. This step is called insalivation.

Tho noxt step, deglutition or swallowing, is mechanically performed by the tongue, pharynx, and esophagus.

When the food reaches the stomach it is sulojected to the next step, maccration, a mechanical rolling, mixing, and soiking with the gastrie juice. During maceration the gastric juice acts chemically upon other components (nitrogenous parts), rendering them absorbable. Food in the condition in which it leaves the stomach is called chyme.

In the small intestines the villi take up the absorbable parts already prepared, and the remaining nourishing parts are imme- 
diately subjected to the chemical action of the bile and pancreatic fluid. Chyme, acted upon by these juices, becomes chyle. Passing through the great length of the small intestines, nearly all of the nourishing parts of the chyle are absorbed, and the residue (remainder) enters the cacum, which is the water reservoir. (Water remains in the stomach of the horse only a short time and then passes promptly through the small intestines into the ('iecum.)

The residue, soaked in water, gives up, in its passage through to the rectum, the small amount of nutritive matter that has not previously been absorbed. By means of muscular cross ridges in the floating colon the effete material is mechanically molded into pellets of dung, which are stored in the rectum, whence they are ejected, at intervals, through the anus. The ejection is called defecution.

TRINARY SYSTEAI.

(Plate VI.)

The organs of this system secrete eflete material in the form of a watery fluid, called urine, and expel it from the body (urination). They are the kidneys, ureters, bladder, and urethre, all lined with mucous membrane.

The kidneys are two in number, right and left, situated on either side of the spine, inmediately lelow the lumbar vertebre. Their action is to secrete the urine from the blood by a process of filtering. Each kidney has a tube or cluct, called the ureter, which carries the urine to the storage reservoir, the bladder. 'This muscular organ, by contraction, discharges the urine, at intervals, through a tube called the urethra, which extends to the head of the penis.

The normal amount of urine secreted in twenty-four hours and expelled through the penis varies from 3 to 6 quarts. The color in health is yellowish.

\section{CIRCU'IATTION.}

(Plate VII.)

The organs which conver the blood thromghout the body are the heart, arteries, capillaries, and reins.

The heart is a hollow organ, made up of involuntary muscles, and inclosed in a serous sac called pericardium; it is situated between the lungs, in the thoracie cavity, and averages about $6 \frac{1}{2}$ pounds in weight. It is divided into two parts, right and left, separrated by a muscular wall. Each part contains two cavities, one above the other, the upper called the auricle and the lower the wentricle. The arvities are connected by openings, which aro gruarded by valves to prevent at back flow of the blood.

$$
5417-0.9-3
$$


Arteries aro hollow structures or tubes, conveying the blood away from the leart, and veins are similar structures, bringing it back to the heart. 'The walls of the tubes are thicker in arteries than in veins. Teins have valves; arteries have none. Veins as well as arteries branch off and diminish in size as they extend from the heart.

The smallest arteries are connected with the smallest veins by minute ressels called capitlaries, which are to be found in the tissue throughout the body. They are too small to be seen with the naked eye.

\section{Blood.}

The blood is a fluid which is the medium by which nutritive material is conveyed to all tissues of the body. It is an opaque, thickish, clammy fluid, with a peculiar odor and sickly, saline (salty) taste. Its color varies in different parts of the same animal, that in the arteries being a bright red or scarlet, while that in the veins is a dark purple.

Blood is composed of red blood corpuseles, or cells, and white blood corpuseles, floating in a watery liquid ealled serum, which contains the nutrient material absorbed by digestion, and certain Salts.

The red cells convey the oxygen, and their presence in countless numbers gives the bright-red color to the fluid. The white corpuscles act as a protection to all parts of the body in case of disease or injury; they assist in the repair of injured tissue and destroy or check invading germs. Blood cells can be seen only with the aid of the microscope.

\section{Circuit of the blood.}

The heart, from the action of its involuntary muscles, may be likened to a force pump. The blood from the veins, venous or inpure blood, entering the right auricle of the heart, is pumped into the right ventricle and thence through the pulmonary artery (lung artery) into the lungs.

In the lungs the pulmonary artery branches into small arteries and then into eapillaries which surround the air cells. Here the blood gives off carbonic acid gas and receives its purifying supply of oxygen. The purified blood passes from the capillaries into the small veins, which unite in the pulmonary veins leading back to the left auricle.

The arterial, pure, or bright-red blood is then pumped into the left ventricle and thence into the arteries, small arteries, and capillaries. In these last vessels it gives up the oxygen supply to the tissues and receives the impure carbonic acid gas, which causes it to change 



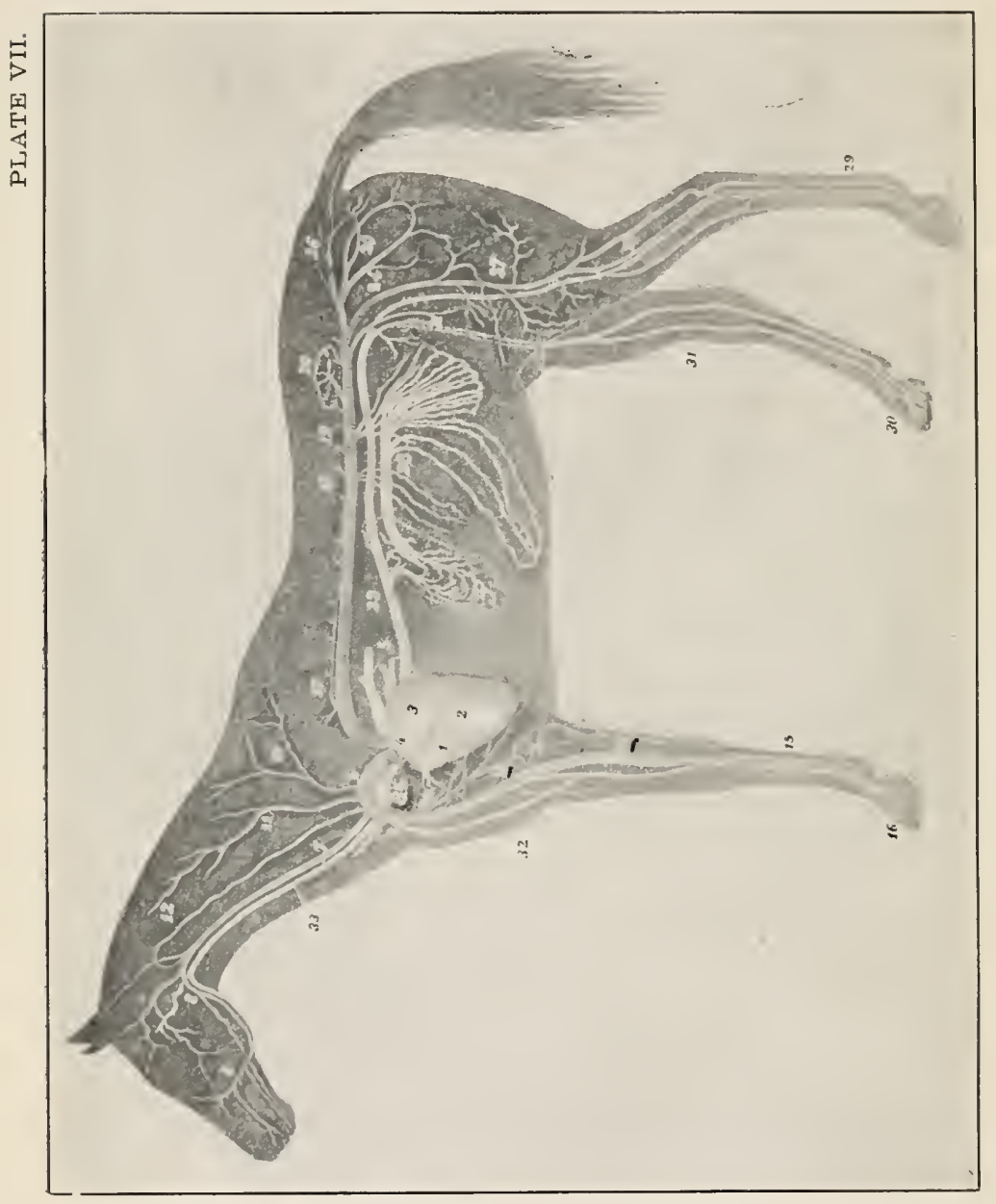




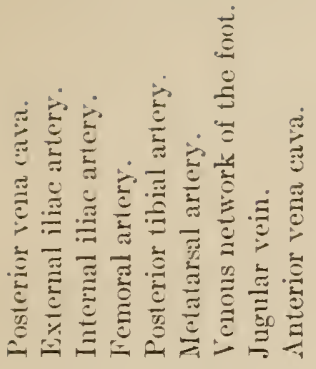

तों की
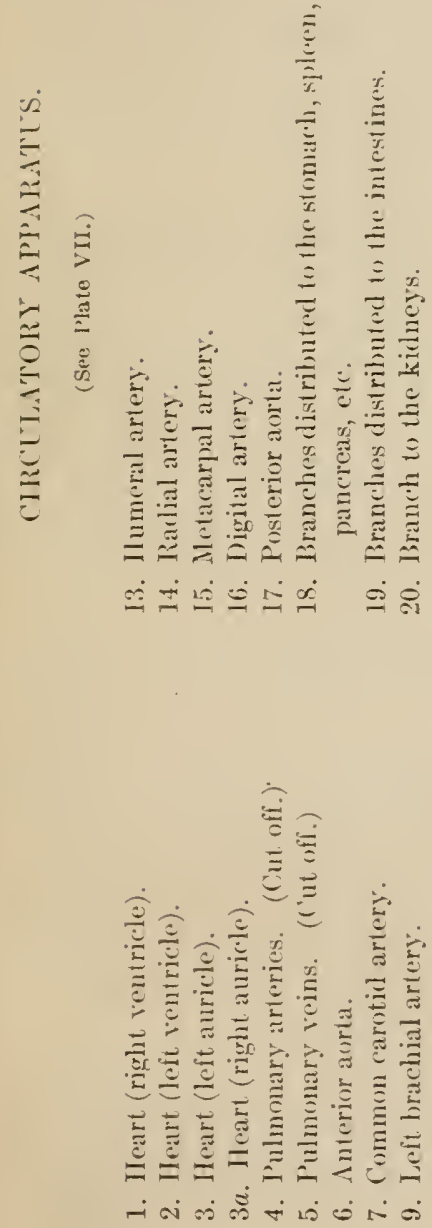
color. 'The dark impure blood is then collected through the small vejus into the larger veins and thence into the right auricle from which it started. 'This round or circuit, which is constantly going on, gives rise to the name circulation.

It has been stated that arteries convey the blool away from the heart and that veins return it. In supplying the boty, arteries eary pure blood and veius carry impure blood. When, however, the impure blood is sent to the lungs for purification, it is convered in an artery and the pure blood returis in a vein. These two important exceptions must be carefully noted.

\section{Arterial rumification.}

'The large artery given off from the loft ventricle of the heart is the common aorta, which passes upward and forward for 2 or 3 inches and divides into the anterior aorta and the posterior aorta, supplying, respectively, the fore and hind portions of the body.

The anterior aorta is very short (1 or 2 inches), passes upward and forward under the trachea and between the lungs, and divides into the right and left brachial arteries, eash supplying blood to one of the fore limbs and its neighboring muscles.

The right brachial artery gives off a la rge branch, called the common carotid. There is no corresponding branch of the left brachial. The common carotid is short and immediately divides into two branches, right and left carotids, which pass up the neck, at first under the trachea and then on either side; they follow the trachea to the throat, where they divide into branches, supplying the head.

The brachial arteries continue toward the front part of the thorax, winding around the first ribs, and divide into branches, supplying the fore limbs. The main branch of each is here named the humeral artery.

'The humeral artery descends along the inner side of the humerus, and just above the elbow joint divides into the anterior and posterior radiul arteries.

The anterior radial descends over the front surface of the elhow joint, passes down in front of the radius, and apploaderes the knee below the extensor pedis muscle, where it divides into numerous branches, supplying blood to the surromnding tissues. The posterior radial is a continuation of the humeral antery, passing down the inner side of the fore lesr, inclining batek and dividing at the lower end of the dadius into the large and small metacarpal arteries.

The small metacarpal passes outward from the immer and back pant of the knes and, lunniner downward, supplies nourishument to the surounding tissues. The large metacarpal is a contimution of the posterior radial. It runs down the back of the knee, in company with the flexor tendon; above the fetlock it passes between the 
tendon and the suspensory ligament, dividing into the external and internal digital arteries, which supply the foot.

The study of the digital arteries will be taken up later, when the student has a more extended knowledge of the bones and of the elastie and sensitive structures of the foot.

We will now return to the posterior aorta. 'The posterior aorta is larger and longer than the anterior. It begins at about the level of the fourth dorsal vertebra, passes upward and backward, and reaches the left side of the spine just below the sixth or seventh dorsal vertebra. It then passes straight back into the abdominal carity and terminates in the lumbar region below the last lumbar vertebra. During its passage to this point it gives off branches to the muscles of the ribs, to the lungs for their nourishment, to the abdominal organs, and to the muscles of the loins. Below the last lumbar vertebra it divides into four branches, the right and left external and internal iliacs, which supply blood to the hind extremities.

The internal iliacs are short thick trunks which soon break up into several branches to the muscles of the hind quarters. The external iliacs, with their continuations, are the main arteries of the hind lecrs. Each, as previously stated, begins below the last lumbar vertebra, curves obliquely outward and downward, giving ofl branches, and, near the head of the femur, receives the name of femoral artery.

The femoral artery is the artery of the thigh. Just above the back of the stifle joint it divides into two branches, the anterior and posterior tibial, the latter supplying the hack part of the gaskin and hock with nourishment, while the former winds forward between the tibia and fibula to the fore part of the leg, gaining it midway between the stifle and the hock. At the hock it passes obliquely outward, crossing the joint, and becomes the great metatarsal artery at the upper and outer part of the metatarsus. The great metatarsal passes under the small splint bone and gains the back part of the camnon, then, passing down the leg, it divides just below the fork of the suspensory ligament into two branches, the external and internal digitals, which will be studied later.

The involuntary muscles of the heart receive their hlood supply from two small arteries, right and left coronary, which branch off at the begimning of the common aorta.

\section{Teins.}

Veins are usually found accompanying the arteries of the body and bearing similar names; there are several important exceptions, three of which will be here noted, namely, the anterior vena cava, jugular, and posterior vena cava.

The anterior vena cava is the large, short vein, formed by numerous branches, returning the blood from the heal, the neck, the fore leg, 
and part of the chest. It is located in the front part of the thorax, bolow the tachea, and hetween the right and left pleurae, and empties into the right aluricle.

The jugular veins (right and left) are the largest branches of the anterior vena cav'a and collect the blood from the head and neighboring parts. Just below and back of the lower jaw they approach the carotid arteries and run down the neck in their company. Each jugular is outside of the corresponding earotid and the two are separated by a thin muscle. 'The jugular veins in their deseent follow grooves at the side of the neek (jugular furrows), and at first are close to the surface and easily felt; they soon take a decper course, rumning beneath the panniculus armosus muscle. They enter the front part of the thorax, where they empty into the anterior vena cavia just in front of the heart.

The posterior vena cava is the main vein returning the blood from the hind parts and from the abdominal and pelvic organs. It corresponds to the posterior aorta, which, as has been seen, is the main artery carrying the blood to these parts. This vein is formed at the front part of the pelvis and runs forward under the lumbar vertebra, accompanying the posterior aorta, which is at its left. When it reaches the upper border of the liver it inelines downward and passes through a notch or fissure of that organ. Thence it passes through the diaphragm into the thoracic eavity; here it follows a groove on the upper surface of the right lung and then enters the right auricle of the heart.

The important veins of the foot will be discussed later.

ANATOMY AND PIYSIOLOGY OF TIE LYMPIATIC SYSTEM.

The lymphatic or absorbent system resembles the system of blood veins with which it is connected. The main part of the system collects surplus tym ph (to be deseribed later) and returns it to the blood; a smaller part has the same function, but, in addition, absorbs and collects chyle and adds it to the blood.

When the blood in its circuit reaches the eapillaries the semm oozes through their thin walls into the minute spaces in the surrounding tissues and there receives the name of tymph. This colorless fluid bathes and nourishes the tissues and takes up worn-out material. The spaces in the tissues assemble into minute, delicate, and transparent vessels (lymplaties), which are remarkable for their knotted appearance, due to numerous valves. The vessels join and increase in size, like veins, and through them flows the surplus lymph with its collected waste material.

The vessels of the right fore extremity, the right side of the head, neek, and thorax, form tubes uniting in at main trunk, callod the right lymphatic vein, which leads into the anterior vena cava; the 
vessels from the remainder of the body unite in a trunk called the thoracic duct, which begins in the lumbar region, passes forward beneath the lumbar and dorsal vertebra, and empties into the anterior vena cava just in front of the heart.

Each of the villi of the intestines contains a minute vessel called a lacteal, which absorbs chyle and receives its name from the lacteal or milky appearance of that fluid. These vesesls of the smaller lymphatic system unite and form larger tubes which empty into the receptaculum chyli (chyle reservoir), which is a part of the thoracic duct of the larger system.

It will thus be scen that the lymph with its waste material and the chyle with its nutrient material are mixed and poured into the impure blood. The lymph and chyle are taken up into the serum and the waste material is thrown off from the circulating blood by the lungs, skin, and kidneys.

Lymph, therefore, makes a circuit very much as blood does.

To simplify the explanation of the system, the lymphatic glands have not been mentioned.

Glands are organs, the function of which is to separate certain substances from the blood, which are either to be used in the animal's system or to be thrown off as waste material.

The lymphatic glands are so placed that the lymphatic. vessels pass through them in their course toward the main trunks. These glands act as filters and remove any infective material from the lymph and also supply lymph corpuscles, which are identical with the white corpuscles of the blood.

When the glands are situated near diseased structures, an amount of infected material lodges in the glands, greater than can be overcome by the lympl corpuscles, and, in consequence, inflammation and swelling of the glands result.

\section{A.ATOMY OF TIE NERYOLS SYSTEM.}

A nerve consists of a bundle of tubular fibers, held together by dense connective tissue; the nerve fibers form a conducting apparatus, to convey impulses of sensation and to transmit impulses of motion.

The nervous system is divided into two minor systems, the cerebrospinal, which is to a considerable extent influenced by the will of the animal, and the sympathetic, which is not directly influenced by the will.

In the first the center is made up of two portions, the brain and the spinal cord.

The brain is situated in the cranial cavity; the spinal cord is elongated and continuous with the brain and is situated in the canal of the vertebral column. 
The communicating portion of this system consists of the cerebrospinal nerves, which leave the brain and spinal cord in symmetrical pairs, and are distributed to the roluntary muscles, to the organs of common sensation, and to those of special sense.

The sympathetic system consists of a double chain of ganglia (small brains), extending from the head to the coccyx, one chain along each side of the spine, and the two chains connecterl by nerve eords. The ganglia are also eomected to branches of the cerebrospinal nerves, thus uniting the two systems. The nerves of the sympathetic system are distributed to the involuntary muscles, mucous membranes, internal organs, and blood ressels.

\section{ANATOMY OF TIIE EYE.}

(Plate VIII.)

The eye is the organ of sight and is situated in the orbital cavity. It is spherical in shape and is filled with fluid. The front portion,

\section{PLATE VIII.}

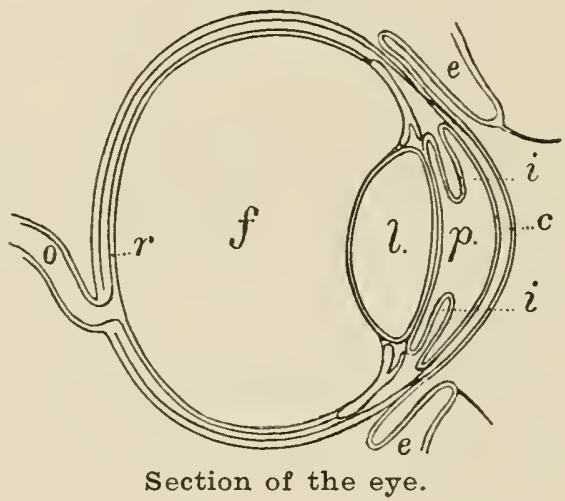

$c$, Cornea; $e$, eyelids; $f$, fluid; $i$, iris; $l$, crystalline lens; $o$, optic nerve; $p$, pupil; $r$, retina.

ealled the cornea, is perfectly clear and admits the light to the back part of the ere, where it strikes the retina, an expansion of the optic nerve; through this nerve impressions are conveyed to the brain. The colored portion or iris, situated behind the cornea, acts as a eurtain, regulating the amount of light admitted through the central opening, which is ealled the pupil. The crystalline lens is a small transparent body situated inmediately behind the pupil; it is thick in the center and tapers towarl the edges. Its function is to draw the rays of light to a focus on the retina. When the lens is diseased and no light can pass through, the animal is said to liave a cataract. The eyelids are two movable curtains, superior and inferior, which protect the eye. The membrana nictitans, or accessory eyelid (haw), is situated near the inner angle between the lids and the eyeball. 
This membrane acts like a finger in the remoral of foreign bodies from the eye. The conjunctiva is a continuous mucous membrane covering the cornea and haw and lining the eyelids.

The fluid between the lens and the cornea (called "aqueous") is watery, while that hetween the lens and the retina (called "vitreous") is thicker and like the white of a raw egg.

The outer covering (seen when the animal shows the white of the eye) is a fibrous tissue called the sclorotic cout. Between it aud the retina, is a delicate, dark colored tissue containing the blood ressels and known as the choroid coat.

\section{ANATOMY OF THE SKIX.}

The skin consists primarily of two parts: The outer, nonvascular layer, called the cuticle or epidermis, and the deep vascular layer, called the corium, dermis, or true skin.

The epidermis is a scaly covering. The true skin or dermis lies immediately under the epidermis, is much thicker, and contains the roots of the hair, the sweat glands, and the sebacrous glands.

Sweat glands are simple tubes extending from the deeper layers of the skin to the surface of the body and pouring out perspiration, which carries with it certain waste materials from the system. The evaporation of sweat cools the body and assists in regulating its temperature.

Sebaceous glands secrete an oily fluid. On parts of the skin which are subjected to much friction these glands pour their oil directly upon the outer surface, as in the sheath, the back of the pastern joints, etc. Usually, however, the glands open into the hair follicles or sacs, and the oily secretion gives gloss to the hair, prevents it becoming dry and brittle, and keeps the surrounding skin soft and supple.

ANATOMY AND PIISIOLOGY OF THE FOOT.

(Plate 1.)

The horse's foot is composed of three parts, riz: The bony framework or skeleton, completed by certain elastic structures of eartilage and fat; the layer of highly sensitive flesh (quick), which corers the framework; and the box or case of horn, called the hoof, which incloses and protects the above-mentioned structures.

\section{Bones of the foot.}

The bones of the pastern region and foot form a column extending downwarl from the fetlock into the hoof, and, as previously stated, are named as follows: Os suffraginis (long pastern bone), os coronx (short pastem bone), os pedis (eoffin bone), and os navicularis (shuttle bone). 

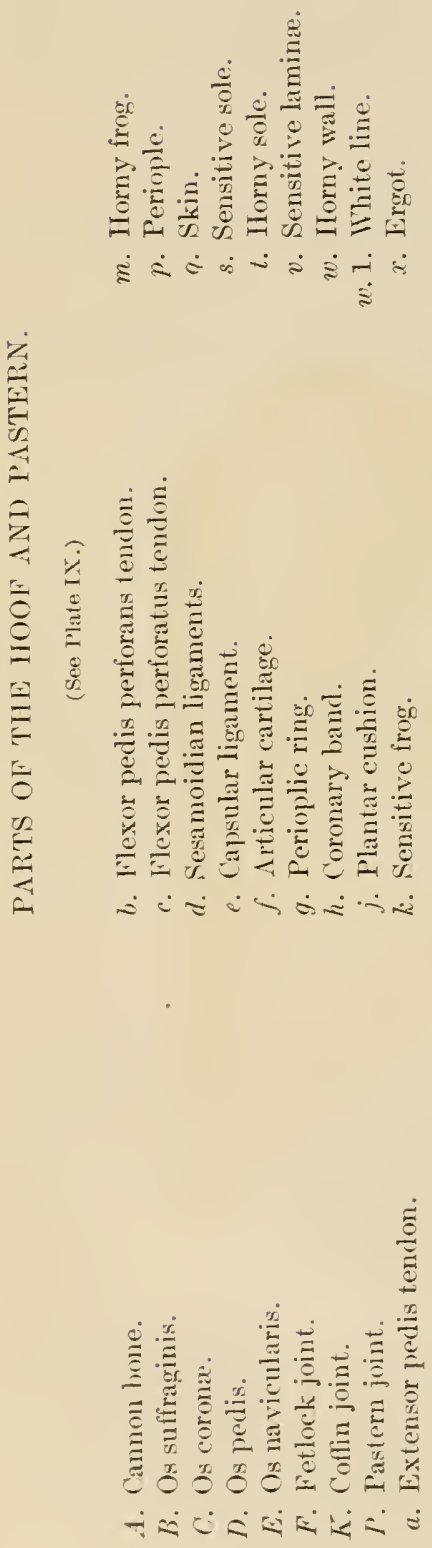


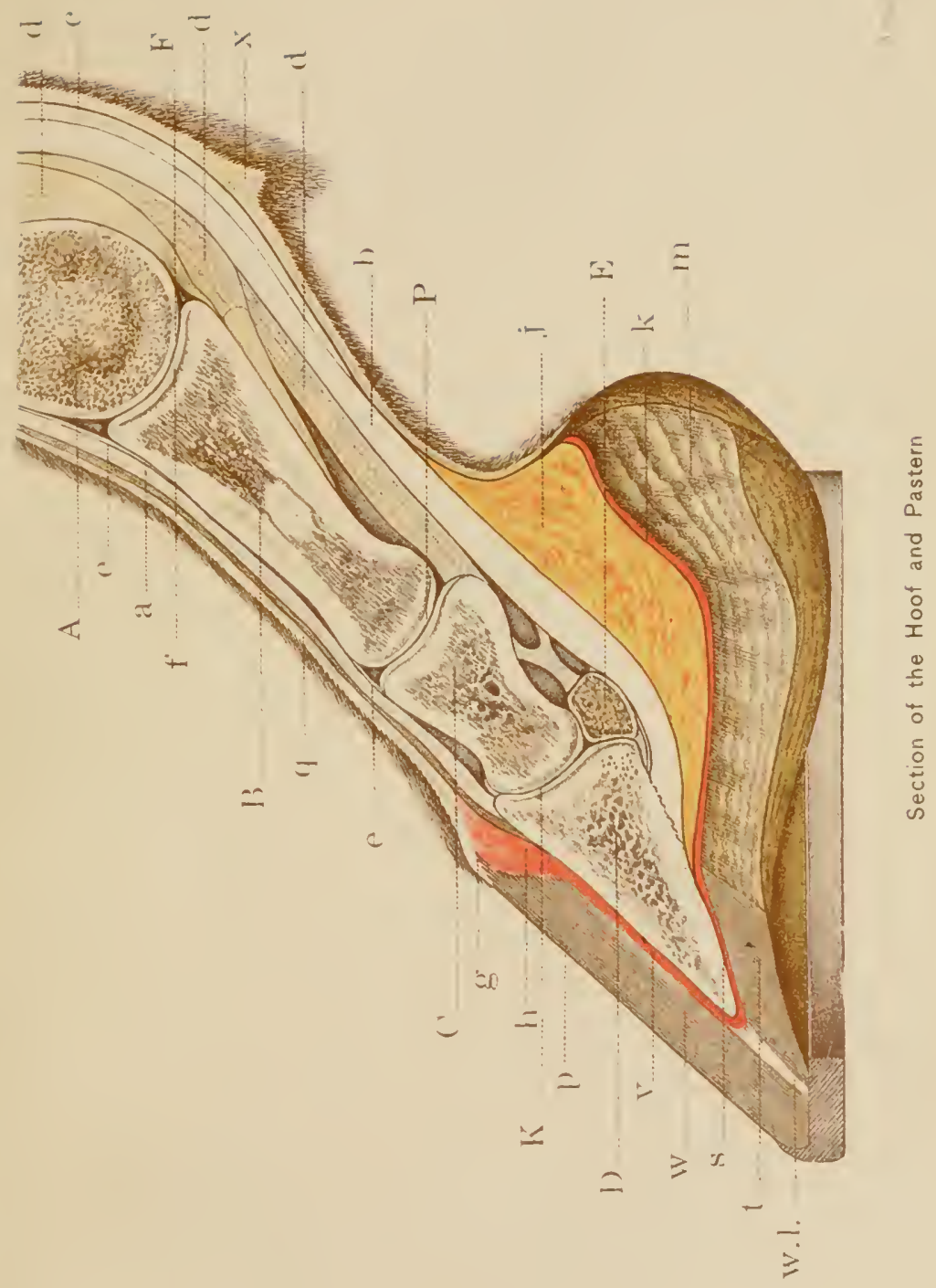



The os suffraginis is about one-third as long as the cannon bone (the bone extending from the knee or hock to the fetlock) and reaches from the fetlock joint above to the pastern joint below; its superior extrenity shows a shallow eavity on each side, separated in the micldle by a deep groove, and into this surface fits the lower end of the camnon bone. 'The inferior extremity is much smaller and narrower than the upper; on each sile is a small convex surface, the two surfaces separated in the midclle by a shallow groove. This extremity meets the upper end of the os coronie and forms the pastern joint.

The os coronx follows the direction of the os suffraginis downward and forwarl and lies between the pastem and coffin joints, its lower end being within the hoof.

Its superior surface shows a shallow cavity on each side, with a ridge between them to fit the lower end of the os suffraginis. The lower surface of this bone shows a convex part on each sille, separated by a groove, to fit the upper surface of the coffin bone in the coffin joint.

The os pedis is an irregular bone, situated within the hoof and is similar to it in shape.

The anterior surface is known as the wall surface; it shows a number of small openings, called foumina for the passage of blood ressels and nerves, and is roughened to gire attachment to the soft parts (sensitive laminx) covering it. At the top of this surface, in front, is a ridge called the myramidal process, to which is attached the extensor pedis tenton.

The lower surface, called the sole, is half-moon-shaped, concave and smooth, and is covered by the sensitive sole. The upper surface helps to form the coffin joint and is ealled the articular surface; it shows two shallow eavities, separated by a ridge.

Just back of the articular surface is a small triangular surface to fit the narieular bone behind.

Just back of the sole is a rough surface, to which is attached the flexor pedis perforans tendon; it is called the tendinous surface.

On each side of this surface is a groove rumning forward and terninating in an opening, called the plantar foramen: an artery and a nerve enter the bone and a rem leaves it through this opening.

On each side of the os perlis, extending backward, is a prolongation, called the wing. Each wing is divided by a noteh and then by a groove, which runs forward on the outside of the bone; an artery lies in the noteh and erroove.

The os navicularis is an irregular bone situated behind and below the os coronse and behind the os peelis, articulating with both bones. Its long axis is perpendieular to the axis of the foot. The extremities of the bone are attached to the wings of the os pedis; the inferior 
surface is covered with cartilage, which forms a smooth surface for the movements of the tendon of the flexor pedis perforans muscle.

\section{Elastic structures of the foot.}

All of the parts of the foot, except the bones, are more or less elast ic or "springy" and yicld when pressure is applied; but certain parts have a very high degree of elasticity, their special use heing to orercone the eflects of concussion or jar when the foot strikes the grround and to prevent injury, and these parts are referred to as the elastic structures of the foot. They are the lateral cartilages and plantar custion, or fatty frog, as it is sometimes called.

The lateral cartilages are thin plates of eartilage, one attached to the top of each wing of the os pedis, and extending backward and upward so far that their upper borders may be felt under the skin above the coronet at the heels.

'The plantar custion is a very elastic werlge-shaped pad, which fills up the space between the two lateral cartilages on the sicles, the sensitive frog below, and the flexor pedis perforans tendon above.

The point or anterior part of the plantar cushion extends forward to the ridge which separates the sole from the temdinous surface of the os pedis. The base is covered by the skin above the heels.

\section{Sensitive structures of the foot.}

Over the bones and elastic structures of the foot is found a complete covering of very sensitive flesh, and from each part of this corering some part of the hoof is secreted or formed. The divisions of this layer of flesh are called the sensitive parts or structures of the foot. They are the coronary band, sensitive lamine, sensitive sole, sensitive frog, and the coronary frog band.

The coronary band is a thick convex band of tough flesh, about fourfifths of an inch wide, and extends entirely around the top of the hoof from one bulb of the heel to the other; in front it is attached to the extensor pedis tendon, and on the sides to ligaments of the coffin joint, to the lower end of the os corone, and to the lateral cartilages. The surface of the coronary band is covered with small pointed projections or villi. The coronary band secretes or forms the principal part (midrlle layer) of the wall of the hoof.

The sensitive laminx (fleshy leaves) cover and are firmly attached to the anterior or wall surface of the os pedis and to the lower part of the outer surface of the lateral cartilages. These delicate leaves of the flesh dovetail into the horny lamine which they secrete and, with them, serve to fasten the wall of the hoof to the os perlis and to the lateral cartilages.

The sensitice sole covers the sole surface of the os pedis, is covered with villi, and secretes the horny sole. 
The sensitive frog covers the lower face of the plantar cushion, and from its villi the horny frog is secreted.

The coronary frog band or perioplic ring is a narrow band of flesh rumning around just above the coronary band and separated from it by a faint groove. From the fine villi on the surface of this ring the delicate fibers grow which form the periople.

\section{The hoof.}

The box or case of horn, called the hoof, which incloses and protects the other structures of the foot, is divided into three parts - wall, sole, and frog. In a healthy foot these parts are solilly united.

The wall is the part seen when the foot is on the ground; it extends from the edge of the hair to the ground and is divided into the tor, quarters, heels, and bars; it has an internal surface, an external surface, and an upper and a lower border.

The toe is the front part of the wall. It is steeper in the hind foot than in the fore. The quarters extend backward from the toe to the heels. The heel or buttress is that part of the wall where it bends inward and forward, and the bar is the division of the wall running from the heel to within about 1 inch of the point or apex of the frog. It lies between the horny sole and the frog.

The external surface of the wall is covered by a thin varnish-like coat of fine horn, called the periople.

The internal surface of the wall is covered by from 500 to 600 thin plates or leaves of horn, called the hormy laminx. Between the horny laminx, which rtin parallel to each other and in a direction downward and forward, there are fissures into which dovetail the sensitive laminxe, and this union, as previously stated, binds the wall of the hoof to the os pedis and lateral cartilages.

The upper border of the wall shows a deep groove (coronary groove) into which fits the coronary bankl.

The lower border is called the "bearing edge" (or "spreal " in the unshod foot) and is the part to which the shoe is fitted.

The hormy sole is a thick plate of horn, somewhat half-moon-shaped, and has two surfaces and two borders.

The upper surface is convex (round or bulging upward) and is in union with the sensitive sole from which the horny sole grows. The lower surface is coneave or hollowed out and is covered with scales or crusts of lead horn, which gradually loosen and fall oft.

The outer border of the sole joins the imner part of the lower border of the wall by means of a ring of soft horn, called the white line. This mark or line is sometimes called the guide line, as it shows where the nail should be started in shoeing.

The inner border is a V-shaped noteh and is in union with the bars, except at its narrow part where it joins the frog. 
The horny sole protects the sensitive sole and does not, in a healthy foot, bear weight, except a very narrow border at the white line, an eighth or tentle of an inch in width.

The homy frog is the wedge-shaped mass of horn filling up the triangular space between the bars. The lower face shows two prominent ridges, separated behind by a cavity, called the eleft, and joining in front at the a pex or point of the frog; these ridges terminate behind in the bulbs of the frog. Between the sides of the frog and the bars are two cavities, called the commissures. The upper surface of the horny frog is the exact reverse of the lower and shows in the middle a ridge of horn, called the frog stay, which assists in forming a firm union between the horny and sensitive frog. The horny frog serves to break the jar or concussion by acting as a cushion or pad; it protects the sensitive frog and prevents the foot from slipping.

\section{Structure of horn.}

The horn of the hoof presents a fibrous appearance and consists of rery fine horn fibers or tubes, similar to hairs, running downward and forward and held together by a cementing substance. The horn fibers of wall, sole, and frog all run in the same direction, downward and forward, the only difference being that those of the frog are much finer and softer and run in wary lines, whereas the fibers of wall and sole are straight.

The horn fibers grow from the small villi, which cover the surfaces of the coronary band, sensitive sole, and sensitive frog.

\section{Circulation of blood through the foot.}

In previous study of the arteries we have seen that the large metacarpal of the fore leg and the great metatarsal of the hind leg each divides just above the fetlock into two branches. These branches are called the external and internal digital arteries, one on the inner and one on the outer side of the fetlock joint. They follow the borders of the flexor tendons downward and terminate inside of the wings of the os pedis. Each of the internal and cxternal digital arteries gives off five branches-the perpendicular, transverse, artery of the frog, preplantar ungual, and plantar ungual.

The perpendicular artery is given off at right angles about the midldle of the os suffraginis, descends on the side of the pastern, bends forward and joins with the artery of the same name from the opposite side and forms the superficial coronary arch. From this arch branches descend to the coronary band.

The transierse artery comes ofl under the upper border of the lateral cartilage, runs forward; and joins its fellow from the opposite side between the extensor pedis tendon and the os coronx. The deep 
coronary arch is the name given to this arrangement of the arteries, and branches from this arch also supply the coronary band.

The artery of the frog rises behind the pastern joint at the upper border of the lateral cartilage. It has two branches-a posterior, which runs back and supplies the bulb of the heel, and an anterior, which runs forward and downward through the plantar eushion and supplies the sensitive frog.

The preplantar ungual artery is griven off inside the wing of the os pedis, passes through the preplantar notch, and runs forward along the preplantar groove on the side of the bone. It helps supply the sensitive lamina with blood and sends some small branches into the bone to join branches from other arteries.

The plantar ungual artery is the terminal or last branch of the digital artery (is a continuation of that artery) and enters the os pedis at the plantar foramen.

The two plantar ungual arteries run forward within the bone and unite to form the circulus artcriosus. From this circle spring ascending and descending branches. The ascending branches, called the anterior laminal arteries, leave the bone through the small openings (foramina) and supply the sensitive laminæ in front. 'The descending branches, called the inferior communicating arteries, are about fourtcen in number and emerge from the bone by the openings just above its lower edge; they unite to form a large trunk, running around the toe of the os pedis, called the circumflex artery, and this artery gives off ascending and descending branche's. The ascending branches pass into the sensitive laminix, and the descending branches, called the solar arteries, numbering about fourteen, run backwarl through the sensitive sole to form a second circle, called the inferior circumflex artery.

The veins of the foot are arranged in networks, each network or plexus named from the parts in which it is located. The solar plexus is found running all through the sensitive sole. The laminal plexus runs through and under the sensitive laminx. The coronary plexus surrounds the os corone and upper part of the os pedis, just under the coronary band.

The veins of the frog are those found in the plantar cushion and sensitive frog; the interosseous veins form a network within the os pedis. The veins of the foot all unite above to form a large trunk, called the digital vein, which runs along the digital artery and earries the blood back toward the heart. The veins of the foot are valveless below the middle of the pastern, an arrangement which allows the blood to flow in either direction when pressure is applied and thus prevents injury. 


\section{Nerves of the foot.}

The nerves of the foot supply feeling or the sense of touch to the parts. The large nerve eord on either side of the limb diviles at the fetlock joint into three branches, ealled the digital nerves-the anterior, the posterior, and the midlle.

The anterior digital nerve passes downward and forward and supplies the anterior or front part of the foot.

The posterior digital nerve, the largest of the three, passes down behind the digital artery to supply the structures in the posterior part of the foot. It gives off a branch which passes through the noteh in the wing of the os pedis (in company with the preplantar ungrual artery) to supply some of the sensitive lamine; it also sends branches into the os perlis with the plantar ungual artery.

The middle branch is very small, is said to always join the anterior branch, and supplies the sensitive sole and fetlock pad.

The functions of most of the parts of the foot have been mentioned in passing. but there are some points in connection with the physiology of the foot which need to be explained more in detail.

\section{Expansion and contraction.}

When weight comes upon the leg, the os pedis descends slightly and causes the sole to descend and flatten. The plantar eushion and horny frog are compressed between the ground below and the structures above; this compression eauses them to spread out sidewise, carring outward the lateral cartilages and bars and the wall at the quarters. This is ealled expansion. When weight is removed from the leg, the plantar cushion becomes thicker and narrower, and the Iateral cartilages and quarters move inward to where they were before expanding. This is called contraction. The elastic lateral cartilage is merely a flexible extension of the wing of the os pedis and would appear to have been specially designed for expansion and contraction at the quarters. It is also to be noted that the bars are a provision for this same purpose, since expansion and contraction could not take place if the wall formed a solid unbroken ring around the hoof.

In adclition to breaking the jar when the foot comes to the ground, the plantar cushion has another important use. It assists in the circulation of the blood through the reins of the foot. When weight is placed upon the foot the pressure on the plantar cushion forces the blood upward through the veins; then, when the foot is lifted and the pressure is removed from the horny frog and plantar cushion, the veins of the frog again fill with blood, and this pumping action is repeated with each step. Proof of this statement is seen when a digital rein is cut, by accident or in experiment. If the horse is walked, a jet of blood spurts out each time he puts the foot to the ground; but if he is allowed to stand the blood flows in a steady 
stream from the vein. Great injury to the foot results from starting the horse off suddenly at a fast gait on a hard road after he has been standing for some time or when he first comes out of the stable. The circulation (just explained) and the structures of the foot should have time to gradually adapt themselves to the change from rest to severe work.

\section{Moristure.}

The wall of the healthy hoof, is, by weight, about one-fourth water, the sole more than one-third, and the frog almost one-half. This water is supplied by the blood and preserves the horn in a tough and elastic condition. The hoof, particularly the frog, is capable of absorbing moisture from the ground. The periople, which covers the wall, prevents the evaporation of water, and therefore should never be rasped. As there is no similar covering for the sole and the frog, the layers of horn on their exposed surfaces dry out and die. The dead layers are liard and brittle, and gradually fall or flake off; but, as they preserve the moisture in the layers of live horn beneath, they should not be removed in preparing the hoof for shoeing.

\section{Shoeing.}

Shocing is a necessary evil, but by remembering the functions of the various parts of the foot the damage resulting may be limited to a comparatively small amount.

The following rules may serve as a guide for the shoeing of healthy feet:

1. The wall, being the weight bearer, should be rasped perfectly level or the foot will be thrown out of its true position, causing extra strain on some of the ligaments.

2. Fit the shoe accurately to the outline of the foot; do not alter the latter to fit the shoe. Rasping away the exterior of the crust to fit the shoe not only renders the horn brittle but is so much loss of bearing surface.

3. The sole should not be touched with the knife; loose flakes may be removed with a blunt instrument.

4. The bars should not be cut away; they are a part of the wall and intended to carry weight. The shoe should rest on them.

5. The frog should not be cut, but left to attain its full growth. No frog can perform its functions unless on a level with the ground surface of the shoe.

6. The shoe should have a true and level bearing and rest well and firmly on the wall and bars.

A plain light-weight shoe is the best-plain on both ground and foot surface.

7. High nailing is injurious; do not use any more nails than are absolutely necessary, as the nails destroy the horn. 


\title{
CIIAP'TER IV.
}

\section{ADMINISTRATION OF MEDICINES-WEIGHTS AND MEASURES.}

\author{
ADMINISTRATION OF MEUICINES.
}

Melicines may enter the body through any of the following designated chammels: First, by the mouth; second, by the lungs and upper air passages; third, by the skin; fourth, undel the skin (hypodermically); fifth, by the rectum; and sixth, by intravenous injection.

By the mouth. -Medicines can be given by the mouth in the form of powders, balls, and drenches.

By the air passages. - Medicines are administered to the lungs and upper air passages by inhalations and nasal douches.

By the skin.-Care must be taken in applying some medicines over too large a portion of the body at any one time, as poisoning and death may follow from too rapid absorption through the skin. For domestic animals medicines are to be applied to the skin for local purposes or diseases only.

By the rectum. - Medicines may be given by the rectum when we can not give or have them retained by the mouth; when we want local action; to destroy the small worms infesting the large bowels; to stimulate the natural movement of the intestine and cause an evacuation; and to nourish the body.

\section{WEIGHTS AND MEASTRES.}

Solid measure. ${ }^{2}$

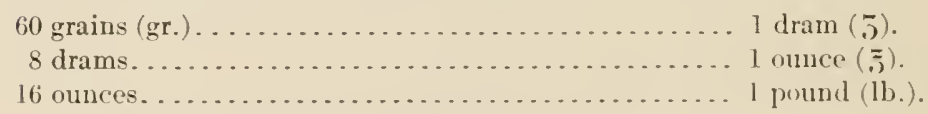

Liquid measure.

60 minims (min.)........................ I fluid dram (i. 5).

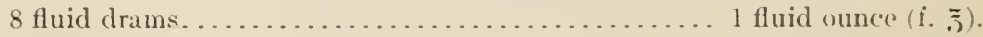

16 fluid ounces............................. 1 pint (O.).

32 fluid ounces.......................... 1 quart (Oii.).

4 quarts.................................... 1 gallon (Ci.).

a The difference in weight between the apothecaries' ounce ( 480 grains) and the ounce avoirdupois ( 437.5 grains) is neglected in handling veterinary or lulky meciicines. 
PRESCRIP'TIONS.

In writing prescriptions, Roman numerals are used instead of Arabic (ordinary figures) and the numerals follow the symbols, thus: 5 vii for 7 drams; f 5 xii for 12 fluid drams, ete. S. S. signifies one half, thus: 5 ii s. s. for $2 \frac{1}{2}$ drams.

\section{FIELD EXPNDIENTS.}

In garrison, doses must be accurately measured by scales or grarluates, according to the tables of dry or liquid measure, but in the field the following rough expedients may be used:

Dry measure.

In orluance spoon...................

()rlnance tin cup................. $\frac{7}{8}$ of a quart.

Full day's ration of medium-weight oats. 14 cups.

Liquid measure.

$\Lambda$ (lrop ....................... 1 minim.

I teaspoonful..................... 1 fluid dram.

A tablespoonful..................... $\frac{1}{2}$ fluid ounce.

Tin cup...................... 28 ounces $=\frac{7}{8}$ of a quart. 


\section{CHAPTER V.}

\section{WOUNDS, SPRAINS, BRUISES, ABRASIONS, AND ABSCESSES.}

\section{WOUNDS AND TILEIR TIEATMENT.}

Wounds (separations of the soft tissues) are classed as: Ineised wounds, or cuts; lacerated wounds, or tears; and punctured wounds, or holes.

A dressing is a local, periodicaliy repeated treatment, producing a continued action, and often following the performance of an operation. It is the application upon the surface of the wound of healing substances, which, in some cases, are mechanically held in place by bandages, stitches, ete.

Before applying a dressing the wound should be thoroughly cleansed and freed from blood, pus, the remains of previous dressing, and, in a word, of any foreign or other substances capable of becoming sourees of irritation. This is best done with water, but the effect is frequently greatly improved by combining with it some of the antisepties, such as carbolic acid, creolin, bichloride of mercury, ete.

Antisepties are remedies which prevent putrefaction, or rotting, and their combinations with water are called solutions.

The solution may be applied by carefully passing a saturated ball of oakum over the surface of the wound, or it may be used more freely in larger ablutions (washings). Crusts or scabs, if present, may be removed with the scissors or scraped away with the knife, but the finger nails must never be used for such a purpose, for the practice is both filthy and dangerous. The wound is to be handled only when necessary; all needless handling irritates. If the wound is deep, it should be cleansed by syringing.

The essential condition of cleanliness applies not only to the wound but also to the materials used for dressings, and soiled eloths or bandages and dirty oakum must be rigorously rejected; ererything coming in contact with a wound must be absolutely clean, hands as well as instruments and dressings. Instruments, however, slould never be immersed in the bichloride solution, which rapidly corrodes metal. 
In the treatment of all wounds cleanliness is of more importance than medication, but the two in combination, when thoroughly and intelligently carried out, will leave no room for the propagation and ravages of those germs that eause the formation of pus and retard the healing process. The farrier, or the man who is to care for the injured animal, should have his hands thoroughly clean, and should procure in a clean can or bucket a solution of creolin or other antiseptic, and several clean pieces of cotton, gauze, or oakum. Sponges are cleaned with difficulty and should not be used.

If hemorrhage (bleeding) is profuse the first step is to arrest the flow of blood by ligating (tying) the blood ressel or ressels with a piece of silk, or if none is at hand, with a elean piece of string; if the blood ressels ean not be tied, a thick pad made of cotton or of several layers of gauze or clean cloth, folded so as to corer the wound, and held firmly in place by one or more cotton bandages, will check the flow of blood. This arrangement, ealled a compress, should be left on until the hemorrhage ceases, and the wound treated as deseribed later.

In applying dressings (except eompresses) unnecessary pressure should be avoided, especially on the soft tissues.

Incised wounds.-If the injury is one that can be sutured (sewed) a needle and silk should be immersed in a solution of creolin-creolin 1 part, water 50 parts; the hair around the wound should either be shaved or be clipped with a pair of shears, and the wound thoroughly cleansed by washing it with cotton saturated with the ereolin solution; all dirt and hair must be removed, all ragged edges, if any, cut away, and the edges of the wound placed in contact with each other if possible and held in place by the aid of sutures, care being taken to allow free drainage; the wound should then be wiped dry with a fresh piece of cotton or gauze, and orer the surface should be dusted some iodoform or acetanilid. If the location will permit, the wound should be covered with a pad of gauze or absorbent cotton, and a cotton bandage wrapped around the parts to hold the pad in place. The wound should be dressed once or twice a day until the formation of pus ecases; when the wound is dry, only the powder should be used.

Lacerated wounds.- If the wound is a large one, with the skin and tissues so badly torn and lacerated as not to admit of the use of sutures, the torn and ragged edges (espeeially if the lower part of the wound hangs down) should be removed with the knife or scissors and the wound dressed as above directed. When the wound begins to granulate (fill with new tissue) (are should be taken that the granulations are not allowed to grow out higher than the skin, (ausing the condition known as proud flesh. 
The treatment of proud flesh consists in the removal of the unhealthy tissue by the use of the knife or by the applieation of a redhot iron; burnt alum or salicylic acid dusted upon the surface of the wound will also destroy the unhealthy granules.

Punctured wounds.-Punctured wounds (except those around joints) should be explored with a probe to ascertain if any foreign bodies are in the channel; if so, they should be removed, and if necessary a dependent opening be made to allow perfect drainage. 'The parts should then be syringed out thoroughly with a solution of creolin, 1 to 50 ; carbolic acid, 1 to 20 or 30 ; or bichloride of mercury, 1 to 1,000 , and the outside opening sprinkled with iodoform. 'This treatment shonld be applied twice daily.

For a few days the wound should be swabbed with tincture of iodine or packed with strips of gauze saturated with this drug in order to destroy infection, check the formation of pus, and promote the growth of healthy tissue.

Wounds of the lips, nostrils, and eyelids heal very rapidly; if of several days' standing, they should have their edges scraped and then be sutured, and iodoform or acetanilid dusted over the surface twice daily.

An excellent antiseptic solution for the treatment of wounds during fly time is marle by dissolving 8 ounces of gum camphor in 3 ounces of carbolic acid. Apply with il clean swab several times daily. One ounce of creolin to 8 ounces of olive oil is a good substitute.

\section{Punctured wounds around joints.}

Open joint is a wound situated on a joint and extending through the capsular ligament, allowing the joint oil to escape.

Treatment.-Remove the hair and thoroughly dean the parts around the wound with a solution of bichloride of mereury, 1 to 1,000; unless a foreign body is known to be lodged in it, do not probe or explore, as the introduction of any instrument, even if thoroughlly rlean, will be the means of setting up ronsiderable inflammation. Apply a blister of biniolide of mereury 1 part, cosmoline 4 parts, for the purpose of rlosing the opening, limiting motion, and relieving pain. Use the slings if the wound is very painful. If the wound is so large that a blister will not close it, the treatment should be as preseribed for an open wound.

A punctured tenclon sheath is treated like a punetured joint.

(AUSE ANI) TREATMENT OF SPRAINS.

Sprains affect muscles, tendons, and ligaments. The fibers of which they are composed are severcly stretched, sometimes torm in serious cases, causing inflammation and subsequent contraction, and, in case of muscles, atrophy or sweeny (wasting away). 
$=$ 
PLATE X.

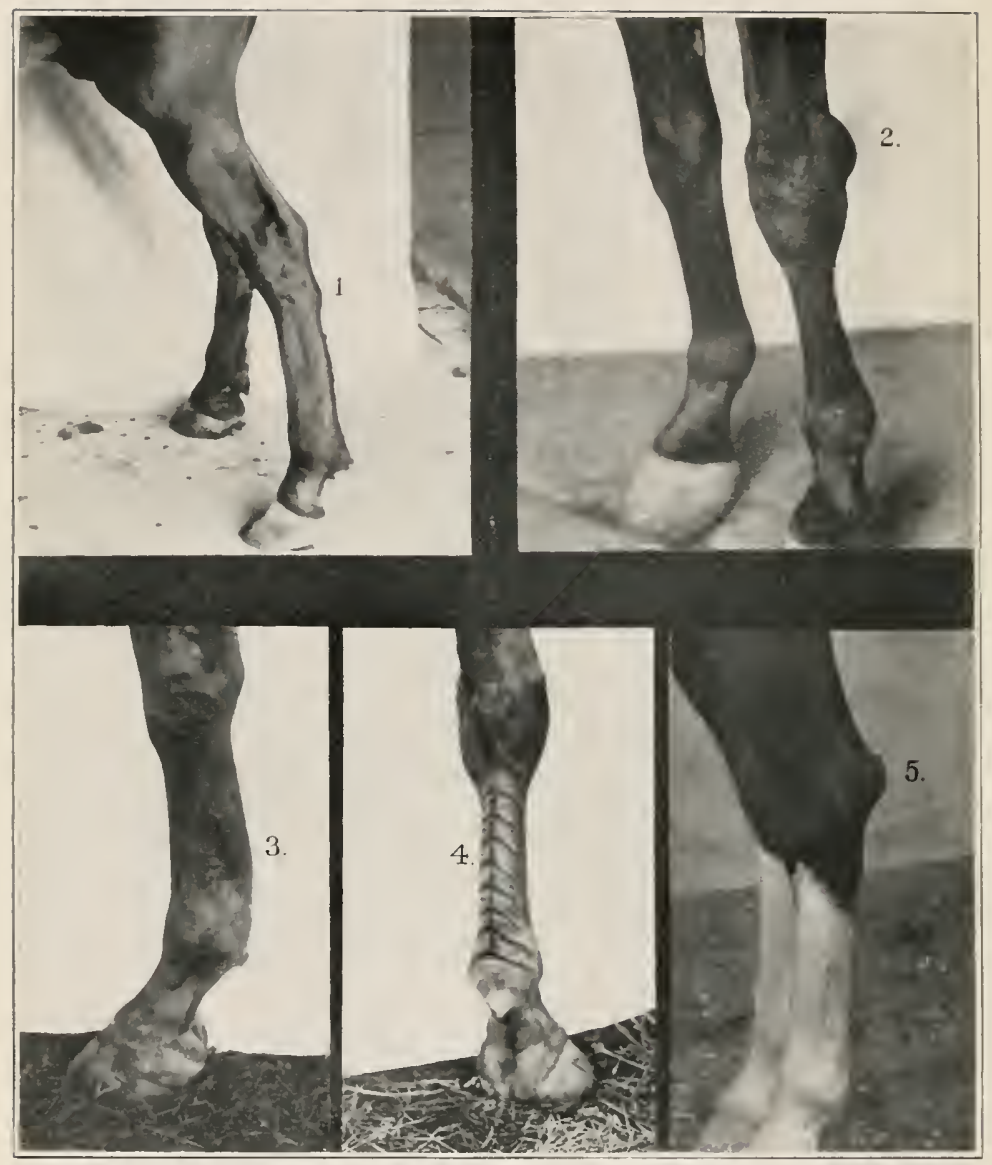

Fig. 1, Curb. Fig. 2, Bursal enlargement. Fig. 3, Sprain of the flexor tendons (bowed tendons). Fig. 4, Line firing. Fig. 5, Capped hock. 
Strains of the muscles.

Muscle strains oecur in various parts of the trunk and limbs; thus, a horse may strain the neck muscles, as a result of falling on the head; the muscles of the dorsal region may be strained by the hind feet slipping backward. When a muscle is strained the injury is succeeded by pain, swelling, heat, and loss of function.

An inflaned muscle ean no longer contract; hence in some strains the symptoms resemble those of paralysis.

\section{Sprains of the suspensory ligament and flexor tendons.}

\section{("Breakdown" and "Bowed tendons.")}

The fibrous structures situated behind the cannon bone, both in the front and hind legs, are often the seat of lacerations or sprains resulting from violent efforts or sudden jerks. The injury is easily recognized by the changed appearance of the parts, which become more or less swollen; the swelling usually extending from the knee down to the fetlock and occasionally even farther. It is always characterized by heat and is variously sensitive, ranging from a mere tendermess to a degree of soreness which shrinks from the lightest touch. The degree of lameness corresponds to the severity of the injury. Sprain of the flexor tendon is shown in Plate $\mathbf{X}$, figure 3.

\section{Sprains of ligaments.}

The ealeaneo-cuboid ligament, situated at the back part of the hock and uniting the calcaneum, the cuboid, and the external splint bones, is frequently sprained. This condition is known as a "curb" (Plate X, Fig. 1).

The various ligaments entering into the formation of joints are subject to sprains and injuries. This condition is indieated by lameness, accompanied by pain, heat, and swelling.

The eapsular ligament when sprained rery often becomes weakened, resulting in distention of the synovial sac (Plate $\mathrm{X}$, Fig. 2). Bursal enlargements recive different names, according to their location. Bog spavin is a characteristic bursal enlargement. It is found on the front and inner side of the hoek joint and varies in size with the amount of cistention of the capsular ligament. The trouble is usually caused by slipping, hard and fast work, irregular exereise, and high foeding. Draft animals, pulling heavy loads over rough or slippery ground, are particularly subject to this injury, which is also more commonly seen in young than in mature animals. The swelling can be readily detected; under pressure it fluctuates; heat may or may not be present; lameness rarely results unless the injury be accompanied by complications, such as bone spavin or bony deposits. 
In sprain of the stifle joint, the liganents holling it in position are severely stretched, in some cases sprained or ruptured, and even dislocation of the patella may ocenr. In this trouble the patella is forced outward and thus makes the joint inmovable, the leg being extended backward and the foot resting on the toc. If the animal is forced to move, he drags the leg, being unable to bring it forward in the nat ural manner on account of the dislocation. The bone is returned to place in the following manner: A rope having been placed about the pastern, the leg is steadily drawn forward by one or more assistants, while the operator stretches the patella forward and inward. When the bone regains its proper position, the animal has proper control of his leg. Reduce the inflammation promptly and blister as explained below. In case the patella persists in slipping out again, a rope should be fastened to the pastern and attached to the collar about the horse's neck: the rope should be drawn tight enough to prevent the horse extending his leg to the rear, but allowing him to stand upon it; keep the rope on until the blister has worked.

General treatment of sprains.-Perfect rest is absolutely necessary and must never be overlooked in the treatment of all sprains; therefore the injured animal should be at once remored to a level stall where it can remain until complete recovery has taken place. Hot or cold applications should be applied to the injured parts. These applications should be in the form of fomentations (bathing), or bandages saturated with water. Flannel bandages must not be allowed to dry while in contact with the injured parts, as flannel applied wet, shrinks in drying, and will not only retard the reparative process, but cause unnecessary pain. Cold water is often materially assisted in accomplishing the desired results br the addition of acetate of lead or sulphate of zine, witch-hazel, or nitrate of potash. A conrenient solution is made as follows: Acetate of lead and sulphate of zine, each 1 ounce; water, 1 quart; or, 1 pint of witch-hazel, 1 ounce of acetate of lead, and water enough to make 1 quart. If pain is very severe the following may be used: Tincture opium, 4 ounces; acetate of lead, 2 ounces; water to make 1 quart: this application is of more benefit when applied warm. All applications should be used several times daily.

If, after the inflammation is reduced, the parts remain large and swollen, benefit will result from the application of tincture of iodine, well rubbed in, twice a day. If this treatment fails to restore the parts to their normal condition in a reasonable length of time, a blister should be applied. It is made an follows: Cantharides (powdered) 1 part, cosmoline 4 to 5 parts: or, cantharides (powiered) 1 part, biniodide mercury 1 part, cosmoline 4 to 6 parts.

Before applying either the blister or the iodine the hair should be clipped from the parts to which the medicine is to be applied. To 
obtain the best results from the blister it should be well rubbed in for at least fifteen minutes. The animal must be tied in such a manner that he can not reach the blistered part with his mouth; the blister should be left on for a period of twenty-four to lorty-eight hours; it must then be removed by washing with warm water and castile soap. After the blister has been removed the animal may be untied. The parts should be kept clean, free from scabs, and soft from the use of cosmoline, olive oil, or grlycerin.

Rest is necessary throughout the treatment, and even to test his soundness the animal should not be moved more than is necessary.

If the disease does not yield to blisters, the parts must be fired. For this operation, two kinds of instruments are used: The thermocautery, which generates its own heat, and the more common form, the iron heated in the fire. Two methods of firing are in general use: Line firing, for diseases of the tendons, ligaments, etc. (Plate $\mathrm{X}$, Fig. 4), and puncture firing, for diseases of the bone (Chapter XI).

\section{BRUISES.}

In the cavalry horse the most frequent bruises are saddle and cinch galls, and bruises of the withers.

Certain horses suffer more than others, on account of the presence of old sores, scars, or scabs, or because of peculiarities in confornation.

The principal defects in conformation (previously noted) are: Abnormally high or abnormally low and thick withers; the keelshaped breast, accompanied by flat ribs and light flanks, and the broad or bulging barrel.

Old horses sometimes have the muscles in the saddle bed atrophied, and are therefore more liable to contract saddle galls.

All horses, whatever their conformation, are subject to saddle and cinch galls, produced mechanically by three causes: First, unequal distribution of weight; second, faults in saddling and cinching; third, poor riding.

After a long ride, the blood vessels under the saddle and cinch are compressed and almost empty. If it is suspected that saddle or cinch galls math have been formed, it is advisable to leave the saddle on for a half hour to an hour after dismounting; the cinch should be loosened very slightly.

If pressure be suddenly and completely removed, blood is vigorously forced into the paralyzed vessels, and may rupture their walls. On the other hand, if the saldle is allowed to remain some time in position, circulation is gradually restored without injury.

Treatment.-As soon as a swelling is noticed, application of cold in the form of pads kept saturated with cold water and massage in the form of gentle stroking with the fingers will aid in the absorption of the fluids causing the swelling. 
Lnjuries to the withers require different treatment-cold applications without pressure and without massage, on areount of the danger of the fluids burrowing.

A solution made of the following is a very good application for bruises: Sugar of lead 2 ounces, laudanum 4 ounces, water to make 1 quart. To be applied several times daily. Or a poultice made of flaxseed meal, to which has been added an antiseptic, such as creolin, carbolic aciel, etc.

Bruises caused by kicks or running against an obstacle slould be treated by applications of water, and if painful, an anodyne (pain reducing) liniment. The following makes a grood anodyne: Witchhazel 2 parts, tincture opium 1 part, tincture aconite $\frac{1}{4}$ part, water 2 parts. Apply locally with the hand.

Artillery horses are subject to the same injuries, produced by the saddle and einch, as are cavalry horses, and, in addition, may be bruised about the neck and shoulders by the collar. If the collar has not broken or chafed the skin (see "Abrasions") treat the bruises as previously directed.

The white lotion, composed of 1 ounce each of sugar of lead and sulphate of zinc, water 1 quart, is a most excellent remedy for bruises and also for abrasions.

\section{Bruises of the sole and heel.}

These are quite frequent, and should be treated by hot or cold applications, accomplished by holding the foot in a tub or pail of water, or by incasing the foot in a hot flaxseed-meal poultice. If pus forms, the underrun horn must be removed and the parts kept clean and covered.

\section{Capped elbow-shoe boil.}

This is a bruise at the point of the elbow, and is caused by the horse lying on the heels of his shoe; to prevent further injury, place a large roll around the pastern at night, and apply tincture of iodine twice daily, until the swelling is removed. In case of great swelling and heat, apply hot and cols water, or the white lotion, until the heat disappears; then proced als above.

\section{Capped hock.}

(Plate X, Fig. 5.)

Capped hock is a swelling, more or less soft, found on the point of the hock, and usually caused by kicking in the stall, or by bruising the parts during transportation by rail or sea. Tincture of iodine is a very good remedy for this injury.

Only in extreme cases is it advisable to use the knife in the treatment of shoe boils and capped hock. As soon as the parts are opened 

PLATE XI.

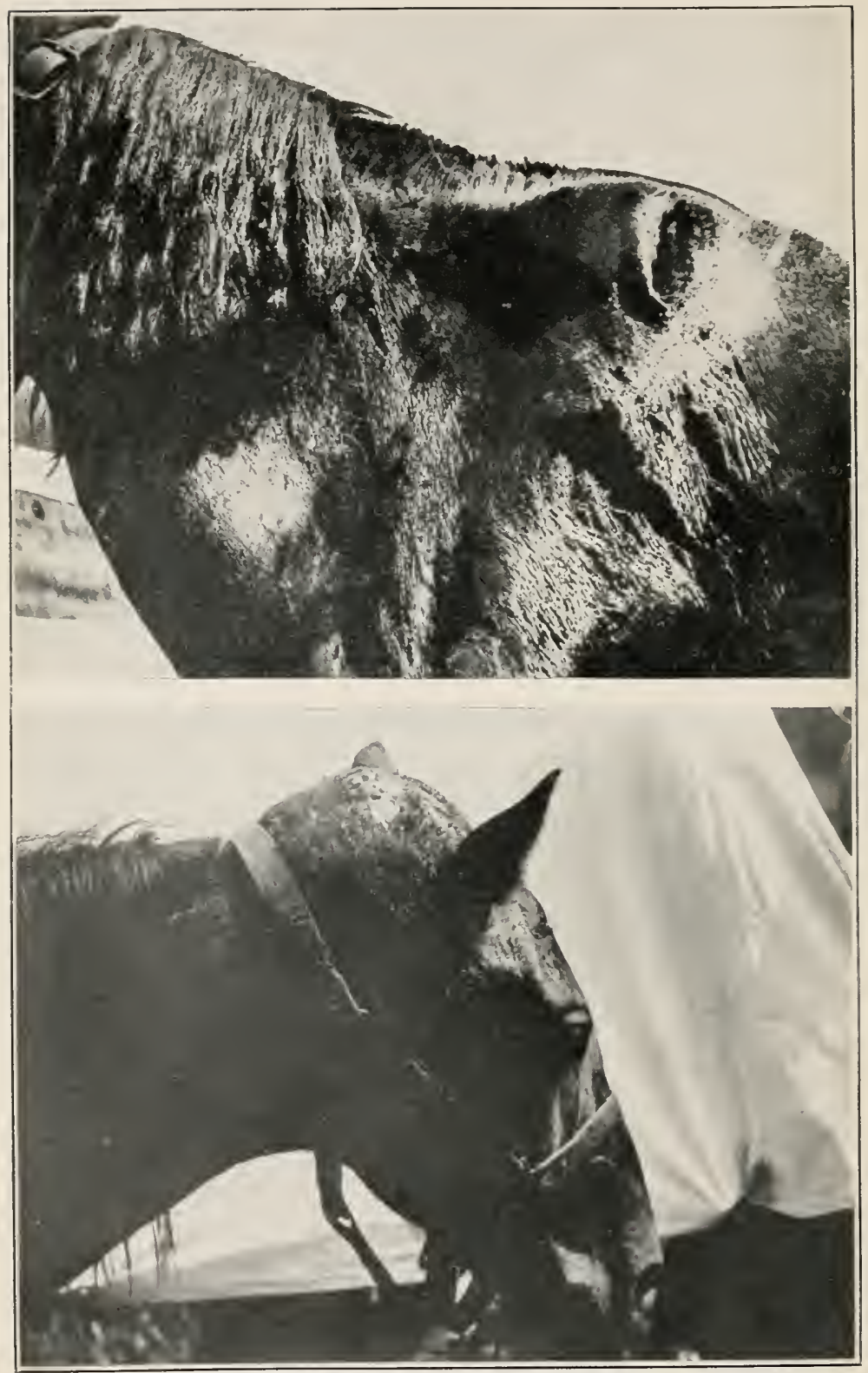

Fig. 1, Fistulous withers. Fig. 2, Poll evil. 
pus rapilly forms, and the inflammation (infection by germs) may extencl to the inner structures, causing a condition that will not readily yield to treatment.

\section{Sitfast.}

Sitfasts are patches of dry, dead skin, and may involve the deeper tissues; they are caused by continuous pressure of the saddle, cinch, or collar, and may be situated on the side of the body, back, side of withers, shoulder, or neck.

Treatment.-With the knife remove all dead and bruised tissue, stimulate the sore at the sides by the use of lunar caustic, and treat as a common wound. When there is no more formation of pus, and the parts are perfectly dry, do not apply liquids, but use iodoform until well.

\section{Fistulous withers.}

(Plate XI, Fig. 1.)

Fistulous withers is an abscess (gathering) having a more or less chronic discharge of pus from one or more openings situated in the inmediate vicinity of the withers; it may involve only the soft structures, or the bones may also be affected; it is caused by a bruise, and generally, in the army, by a bruise from an ill-fitting saddle.

Treatment.-Treat as explained under "Abscesses." If, after a reasonable length of time, results are not satisfactory, a surgical operation is necessary.

\section{Poll eril.}

\section{('llate XI, Fig. 2.)}

Poll evil is the result of a bruise on the poll. It is similar to fistulous withers, and should receive the same treatment.

\section{ABRASIONS.}

An abrasion, or chafe, is an inflummation of the skin, resulting from friction. Parts of the equipment frequently wear away the hair and leave the skin raw and tender.

Treatment.-One ounce of tannic acid in a pint of witchlazel is especially valualle for collar chafes; zinc oxicle as a dusting poweler is eflective, and the white lotion is always beneficial. In emergencies, bathe the parts with cold water to which a little salt has been added.

\section{Rope burn.}

Rope burn is an abrasion, usually at the back of the pastern, and caused by the animal becoming entangled in the halter shank, picket line, or lariat. The injury may be simply a chafe of the superficial 
layer of the skin or it may involve the deeper structures. In the lat ter caise it is of a serious nature and requires careful at tention.

Tratment.-If possible, grive the animal complete rest. (lip the hair from the injured parts, at the same time removing any torn skin; wash with some good antiseptic, such as solution of reolin or carbolic acid, and apply a dusting powler, such as zinc oxide or ioctoform, the former preforably. Apply a pad of clean cotton and serure with a cotton bandage; change the dressing daily. Should the parts be slow in healing, an occasional dressing of tincture of iodine is beneficial, and good results are often obtained by alternating this with a dressing of olive oil 3 parts and creolin 2 parts. Should proud flesh appear, the three sulphates (iron, copper, and zine) may be used, or powdered eopper sulphate alone. Use until the granules clisappear. When the wound begins to heal nicely, it is better to dispense with the pad and bandage.

\section{A BSCESSES.}

An abscess is an unnatural collection, in the tissues, of fluids, such as pus or serum. It is the result of inflammation caused by an injury or by the infection of pus germs. The swelling usually softens at some point, unless it be filled with serum, in which case it is soft and fluctuates at all points, and lies direetly beneath the skin.

Soft, pufly swellings in the neighborhood of joints and tendons should not be mistaken for abscesses, as they are usually bursal enlargements, filled with synovia, and requiring different treatment. (See "General treatment of sprains.")

Treatment.- I pus abscess, if slow in derelopment, should be poulticed until it softens at some part where it can be opened by cutting through the skin; then insert a blunt instrument through the wall into the pus carity, thus avoiding any danger of injury to blood ressels or other structures. When freely opened, the eavity should be flushed out twice daily with some antiseptic solution, care being exercised to prevent the external wound from healing before the formation of the pus has ceased. In every case provision must be made for free drainage at the lowest point.

I serous abscess (one in which we find the rellowish, watery, and often bloody scrum) is treated as follows: ('lip the hair away and wash the skin with an antiseptic; with an instrument that has been thoroughly disinfeeted make a small opening; after all fluid has cscaped apply a blister of biniodide of mereury, 1 to 6 , over the ontside of the area ocenpied by the original swelling. If it fills again, repeat the treatment.

Soft, puffy swellings on the abdominal wall must be carefully examinocl. They may be the results of rupture, in which case openine would bo fatal. 


\title{
C'TIAP'TER VI.
}

\section{DISEASES OF TIE RESPIRATORY SYSTEM AND INFLUENZA.}

\author{
ACUTE NASAI, CATARRII.
}

Acute nasal catarrh (simple cold in the head) is usually caused by standing in a draft, and may be detected by the discharge from the nostrils. It is usually accompanied by a cough, loss of appetite, and clevation of temperature (fever). The discharge is at first of the consistency of water, but may in severe cases become much thicker, and form clry crusts on the edges of the nostrils.

Treatment.-The mild form does not require treatment; it ends rapidly in a cure. In severe cases, the animal should have complete rest; fumigation (steaining) from a hot solution of creolin or carbolic acid (1 ounce to $\frac{1}{2}$ pail of hot water) constitutes an excellent local treatment. Give bran mashes, and administer twice daily $\frac{1}{2}$ ounce of saltpeter, or 2 drams of chloricle of ammonia, until the animal has recovered; the chloride of ammonia is best administered on the tongue. If the cough is frequent and the horse has difficulty in swallowing, the following liniment should be applied to the throat: Solution of ammonia 1 part, oil of turpentine 1 part, olive oil 2 parts. Apply twice caily.

\section{CHRONIC NASAL, CATARRII.}

Chronic nasal catarrh is usually an unfavorable termination of simple catarrlı; or it may result from injury and chronic inflammation of the nasal carities; from tumors, parasites, abscesses, etc., in the nasal cavities; from diseases of the teeth; from chronic discases of the respiratory (breathing) apparatus in general; and from chronic constitutional diseases.

Symptoms.-The discharge is quite thick and becomes glued to the sides of the nostrils; its color varies from a dirty white to a yellowish gray; it frequently has a fetid (foul) odor; the quantity varies; the discharge is usually from one nostril, but both may be affected; in cases of long standing small ulcers (sores) may occasionally be seen in the nostrils; they are superficial (on the surface), are defined by sharp edges that are not thickened, and heal without leaving 
a sear. (The ulcer of glanders, which will be studied later, has edges shaped like saw teeth, and when healed leaves a jagred scar.)

Treatment. - Is usually local and as follows: Fumigation with hot water, to which antiseptics have been arlded (2 ounces of creolin or 2 ounces of (arbolic acid to a half bucketful of water); the steaming to continue at least one-half hour twice daily. If no definite cause of the discharge can be found, good results may be obtained by administering 2 drams of powdered copper sulphate or the same amount of iron sulphate, in the food or in a ball, once daily. In most cases, when the discharge is from one nostril only, an operation is necessary to effect a cure.

As the symptoms of this discase are so similar to glanders, the animal should be isolated, and the utensils, such as buckets, forks, brooms, curryeombs, blankets, ete., should not be used about other horses, until by the use of mallein (see Glanders) the disease has been definitely determined.

\section{PIIAIYNGITIS AND LARYNGITIS-SORE TIIROA'T.}

Sore throat is an inflammation of the lining membrane immediately in the rear of the mouth and is caused by irritating medicines, by bodies bruising the tissues, by sudden changes in the temperature, and by infection.

Symptoms.-Diminution of the appetite, cough, stiffness of the head, soreness when pressure is applied to the throat, a considerable amount of mucus and saliva in the mouth, escaping in long, transparent threads, and usually a profuse thick discharge from the nose. Swallowing of liquids is painful; they are ejected through the nose, and are often of a greenish color and contain quantities of food. Temperature may range from normal to $106^{\circ} \mathrm{F}$., with difliculty in breathing.

Treatment.-The sick animal should be separated from the healthy ones and placed in a comfortable box stall, free from drafts, but well ventilated, and should be given green food or very fine hay, steaned oats, bran, or gruel; fresh water should be left within reach. Four drams of either ammonium chloride or potassium nitrate should be added to the drinking wates.

The lips and nostrils should be kept perfectly elean and the mouth washed frequently with fresh water. Cold compresses should be used if the parts are hot, tender, and painful. In a mild case, use the ammonia liniment as in acute nasal catarh. If an abscess is likely to form, poultices of linseed meal may be applied, and the ahseess, when ready, should be opened, but never with a knife. Cut through the skin only and then insert a blunt instrument, or the finger, and allow the pus to escape. 
If the animal breathes with great difficulty, manifested by making a loud, wheezing sound, an opening should be made in his windpipe and the edges of the opening held apart by inserting a suture in each side, tying the silk ends up over the neek; or a tube may be inserted in the opening. This operation is called tracheotomy.

The sore-throat patient should never be drenched. If the horse should cough while taking medicine in this manner, the liquid might enter the lungs and cause pnemonia.

Fever may be combatted by cold-water injections into the rectum, 1 to 2 gallons at a time.

\section{STIR.NGLES, (OMWONLY C.LLED "DISTEMPER."}

Strangles is an acute, infectious disease, and usually attacks young horses.

Symptoms. - The disease begrins with a high fever, ranging from $104^{\circ}$ to $106^{\circ}$; a discharge from the nose, at first watery, rapilly becoming thicker, and later assuming a whitish-gray or greenishycllow color. The glands below the lower jaw become swollen, hot, and painful, and occasionally there is soreness of the throat; loss of appetite, depression, great muscular weakness, and, occasionally, swelling of the hind legs follow. Sometimes a swelling may be found on some portion of the windpipe or other part of the body.

Treatment.-Separate the sick animal from the healthy ones and place him in a well-ventilated stall, free from drafts; clean the nostrils frequently; clothe the body according to the season of the year; apply hot poultices to the abscess several times daily, and, as soon as pus is formed, open and wash twice daily.

Give casily digested food, green fodder, roots, or slops made of bran or steamed oats, and to his drinking water add $\frac{1}{2}$ ounce of saltpeter; do not drench, as the throat in many cases is sore.

\section{PNELMONIA.}

Pneumonia is an inflammation of the lung structure, and usually rums a course of from seven to ten days.

Among the extemal causes of the disease are to be particularly mentioned excessive exertion and cold; also carelessness in giving a drench, particularly if the anmal has a sore throat. This disease frequently follows acute nasal catarrh, sore throat or strangles, and may accompany influenza.

Symptoms.-The first symptom is an intense fever accompanied by a chill; the patient shows great fatigue and muscular weakness; temperature ranges from $103^{\circ}$ to $107^{\circ}$, the appetite is diminished, at times almost wanting; the patient is constipated; breathing is rapid and difficult; the nostrils are much dilated, and expired air is 
warmer than usual; the ears and legs are cold. 'There is frequently a rusty red or rusty yellow discharge from the nose. The animal remains standing constantly, rith the fore legs spread, or it may lice down for a short time only; a cough may or may not be present.

Treatment.- Great care should be given to the diet; in order to kecp up his strength, give any food that the animal will cat - steamed oats, carrots, or green grass if possible, gruel, etc. Place him in a well-ventilated box stali free from drafts, and clothe the body and legs according to the season of the year; warm blankets wrapped around the chest if the weather is not too hot will be of adrantage. In warm weather, if flies are troublesome, a thin sheet made of runny sacks should be placed-upon the animal. Quinine sulphate 1 dram, gentian root 2 drams, makes a good tonic. It should be repeated three times daily.

Cold injections into the rectum will reduce the fever.

Alcohol, 4 to 5 ounces, well diluted, should be given as a drench, twice daily, and potassium nitrate, $\frac{1}{2}$ ounce, should be added to the drinking water.

In the first stage of pmeumonia (called congestion of the lungs), caused by overexertion of the animal when he is in a wealiened condition, the disease may be often broken up by the use of stimulants.

\section{IIEAYES.}

Heaves is a chronic disease of the lungs, manifested in a quick inspiration and a double expiration.

Symptoms.-Cough of a chronic nature; discharge from the nostrils after exertion; characteristic breathing, as described above, which is agcravated by damp, muggy weather, and by dusty, coarse, and bulky fodder, such as clover hay or dirty oats. Climate has a marked influence; in high, dry altitudes this trouble is unknown.

Treatment.-Always water before feeding, and feed more grain and less hay. The food must be clean, should be moistened before feeding, and the bowels should be kept loosened by frequent bran mashes. Never exercise a horse with heaves just after feeding; if he must accompany the organization, feed him earlier than the others.

\section{INFLCENZA (PINK EYE).}

Influenza is a contagious disease. It affects first the respiratory tract, but also involves the nerve centers, circulatory system, the lining membranes of the intestines, and the eyes.

Symptoms.-The first symptoms are loss of appetite, depression and weakness; the temperature rises rapidly to $105^{\circ}$ or $107^{\circ}$ in severe eases; the animal holds his head low and has a stupid look; he stagrers when walking, and the visible mucous membranes are of a ycllowish tingre. 
When the digestive organs are affected, colics (gripes) oceur frequently. In the beginning, constipation is the rule and the dung is coated with a whitish-yellow, mucus layer; later diarrhea oceurs and the dung is doughy, soft, or liquid. The eyelids are sonetimes swollen shut and are hot and sensitive to the touch. The legs and sheath are sometimes swollen and the lower portion of the belly may be similarly affected.

Treatment.-Isolate sick animals for their own comfort and the safety of healthy subjects, as influenza is usually a serious disease. Give quinine sulphate 1 dram, gentian 2 drams, in a ball, three times daily; add $\frac{1}{2}$ ounce saltpeter to the drinking water twice daily. The fever may be reduced by rectal injections of cold water.

Intestinal troubles may be relieved by the administration of biearbonate of soda in dram doses three times daily; if pain is very severe, 2 drams of fluid extract of camnabis indiea may be given. Bathe the eyes, if swollen, with warm water. Good nursing and laxative food are essential, cold water being kept where the animal can help himself. $5417-09-5$ 


\section{CILPTER VII.}

\section{DISEASES OF THE DIGESTIVE, URINARY, NER VOCS, AND LYMPIATIC SYSTEMS.}

DISE.LSE OF THE DIGESTIE SYSTE!̣.

SPASIODIC COLIC-CIRIPES.

(Plate XII.)

Spasmodic colic is a painful contraction of the intestines. The usual seat of the trouble is the small intestines, and it is usually calused by indigestible or chilled food or drink, and frequently by sudden chilling of the body.

Symptoms. - The suffering is very violent but of short duration; the spasms appear suddenly and disappear with the same rapidity. The horse paws, stamps, looks around at his flanks, lies down and rolls, and if the pain is rery severe, sweats profusely. During the attack a few pellets of dung may be passed, and attempts to pass urine are frecuently made. This latter symptom has misled many persons to the impression that the disease was located in the "urinary organs."

Treatment.-Place the animal in a large, well-bedded stall and give the following: (annabis indica 20 to 4 drams, aromatic spirits ammonia 1 ounce, water to make 1 pint. (Or, fluid extract belladomma 2 drams, nitrous other 2 ounces, water to make 1 pint. Either one of these prescriptions can be given at one dose and repeated in three-fuarters of an hour. If the animal is not relieved in one hour, give a purgative of aloes (phirsie ball).

Warm-water injections. per rectum, are often of adrantage.

\section{FL.ATTLENT COLIC.}

Flatulent colic is gencrally due to the anmal having eaten improper fouds, such as musty oats, sour bran, green corn, ete, which interfore with the process of digestion and give ofl much gas. It is sometimus calued morely by a sudden change of diet from oats to corn. This trouble is also frequently observed in horses that have the hil hit of wind sucking. 
PLATE XII

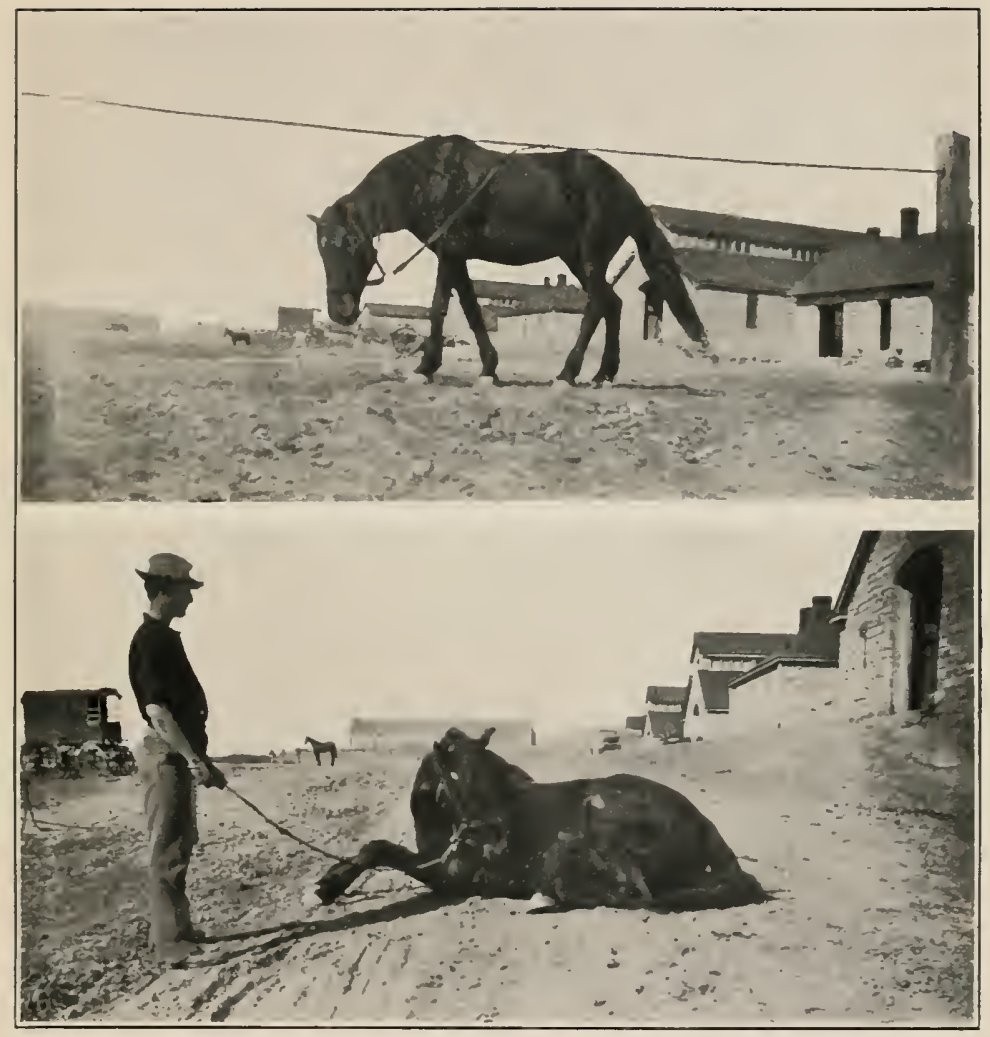

Characteristic symptoms of spasmodic colic. 

Symptoms. - The rapid swelling of the belly constitutes the characteristic symptom. The abdomen is clistended, the pain is not so severe as in spasmodic colic, but more constant. With tho increase of swelling the breathing becomes more diflicult, anxiety and restlessness are shown, walking is painful, and the animal staggers, lies down and rolls, but only for a short time.

Treatment.-Place the horse in a large, roomy stall, and give the following drench: Sulphuric ether 22 ounces, aromatic spirits of ammonia 1 ounce, fluid extract belladonna '2 drams, water to make 1 pint. Repeat in one hour if necessary. Should the animal not be relieved after the second dose, administer a purgative. Coldwater injections into the rectum are sometimes of advantage. If the abdomen continues to distend with gats, the trocar and canula must be used. This is an instrument for puncturing the intestine, but should be used only by one who understands the operation. The instrument, as well as the seat of the operation, should be thoroughly disinfected.

\section{ENTERITIS-INFLAMMATION OF THE BOWELS,}

Cause. - This disease is sometimes due to the action of cold: suctcten chilling when the body is in a perspiring condition, the swallowing of rery cold water,. of frozen or frost-covered fodder, etc. It is sometimes a complication of the colics and is frequently seen ats a result of impaction or twisting of the bowels.

Symptoms. - The nucous membrane of the nose, mouth, and eyes is congested and reddened, the mouth is hot and dry. Respiration is increased, pulse is hard and rapid, temperature is elevated, $10: 3^{\circ}$ to $105^{\circ} \mathrm{F}$. Colicky pains are continuous: the horse walks abont the stall, paws, lies down carefully, rolls, and tries to balance himself on his back. As a rule the bowels are constipated, but when this disease is due to irritating foods or medicines purgation and flatulency may be present.

The small, hard pulse; high temperature; aged and anxious appearance of the face: continuous pain, which is increased by pressure upon the abdomen: position of the horse when down, and coklness of the ears and legs, will enable anyone to diagnose al case of enteritis. When mortification (death) of the bowels sets in, all pain ceases and the animal will stand quietly, sometimes for several hours. Toward the last he sighs, breathes hard, staggers and pitches about, and dies in a state of delirium.

It is a very serious discase and in the majority of cases proves fatal. Death may take place in six hours, or not until after several days. 
Tratment. - To control the pain give largere doses of powdered opium, laulamum, or cannalis indicil.

The following prescription is recommended: ()pium, powdered, 22 drams; calomel, $\frac{1}{2}$ dram. Make into a ball; give at once, and repeat in one or two hours if necessary. Blankets wrung out in hot water and applied to the ablomen are sometimes of benefit, but to obtain grood results they must be kept hot for several hours.

\section{CIIRONIC INDIGESTION.}

Chronic indigestion is a chronic catarth of the stomacla and bowels, the caluses of which are: Irregularity in feeding and watering; feeding when the animal is in an cxhausted condition; imperfect mastication and incomplete salivation of food due to irregularities of the grinding surfaces of the molar teeth; and food of a poor quality, defieient in nutriment.

The presence of worms is a frequent cause of this discise.

Symptoms.-Appetite diminished or capricious and depraved, frequent gaping, constipation; periodic colies are frequently observed, the coat is rough and staring, and the skin is tightly adherent to the body, the condition known as "hidebound." The animal has an unthrifty appearance generally.

Treatment.- Give small quantities of grood, nutritious, and wollsalted food three times daily.

The water shoukl be pure and given regularly.

Regular exereise and good grooming will hasten recovery, by stimulating the skin as well as other parts of the body.

If the appetite is diminished, give as a tonic: Gentian '2 ounces, iron sulphate 1 ounce, nux vomica $1 \frac{1}{2}$ ounces, nitrate potash $1 \frac{1}{2}$ ounces. Mix. Make twelve powders. Give one powder twice a day.

Bicarbonate of soda is a very useful medicine to comberatet the acility (sourness) of the stomach. Dose, 1 dram, twice a diy; the doses may be continued for several days.

If intestinal worms are the exciting eause, they must be removed, and until this has been accomplished the animal will retain its unthrifty condition although it may brighten up temporarily.

The following prescription is recommended: Spirits turpentine : ounces, oil linseed $t$ ounces. Give before feeding and repeat once a day for four days; then follow up with 1 pint of linseed oil.

DIARIRIIEA.

This term is applied to all cases of simple purging in which the feces (dumg) are loose, liquirl, and frepuently discharged.

Diarhera may be a spontaneous eflort to discharge from the intestimes something which is obnoxious to them or to the system gen- 
erally. It is caused by various agencies, such as incligestible food, sudden change of diet-particularly from a dry to a moist onemedicinal substances, worms, derangement of the liver, or large drafts of water when the animal is heated. Some animals are particularly predisposed to diarhea from trivial causes. Narrow-loined, flat-sided, and loosely coupled horses--that is to say, horses in which the distance between the point of the hip and last rib is long-and those of a nervous tomperament are apt to purge without apparent cause. These are called washy horses. They are hard to keep in condition and require the hest of food.

Symptoms.-Purging, the fecal matter being semifluid, of a dirtybrown color, without ollensive odor, or clay-colored and fetid. If the condition continues long the animal loses flesh and the appetite is wanting.

Treatment.- When the purging arises from the presence of some offending matter in the intestinal canal (sand, worms, undigested food, etc.) its expulsion must be aicled by a moderate dose of linseed oil ( $1 \frac{1}{2}$ pints).

If the purging arises from no apparent cause, or if the bowels do not regain their normal condition after the action of the oil has subsiderl, it will be necessary to give astringents (binding medicines), such as timnic acid, 1 to 2 drams. The following preseription may also be used: Gum camphor 1 ounce, opium, powdered, 1 ounce. Mix. Make eight powders and give one powder every three or four hours, according to the severity of the case. Great care must be exercised, as evil results may follow if the bowels are checked too soon.

\section{Diseases OF TIIE TriNARY Sistey.}

\section{ACUTE NEPIIRITIS-INFIAMMATION OF THE KIINEYS.}

Causes.-It is at times produced by the action of cold; it also happens frequently in the course of infectious (catching) diseases. The kidneys become irritated by the presence of waste materials of the food, such as mold, rust, ete, or by the passage of certain medicines, such as turpentine, cantharides, etc. Inflammation and partial or total clogging of the organ results. Cantharides will reach the kidneys after absorption from a large blistered surface.

Symptoms. - The most important and often the only manifestations of nephritis (in the course of infectious diseases, for instance) are furnished by the urine. Its quantity is diminished; it is thickened; of abnormal color; occasionally it is the color of blood. Micturition (pissing) is painful; the urine often runs off drop by drop only, notwithstanding the riolent eflorts made by the patient. In serious cases the urinary secretion may be completely suppressed. 
The lumbar region is very sensitive to the pressure of the hand. It the begimning of the disease we often have renal or kidney colies. The back is arched, the gait stifl and stagrering, rising is painful; the animal remains ahmost constantly standing. The appetite may he lost. The temperature is elevated; in some cases it may range very high.

Treatment.-Remove the cause if possible; aroid all irritating food or medicines, and give alsolute rest. 'Try to induce sweating by energetic rubbings upon the surface of the whole body; also by warm blankets, and wet, tepid compresses applied upon the loins. Give the following physic: Nloes 6 drams, calomel 1 dram, ginger 1 dram. Make into a ball and give at one dose. It has a most favorable action, because the purging draws a large quantity of water from the system.

If there is a total suppression of urine, $\frac{1}{2}$ ounce of fluid extract digitalis, well rubbed in on each side of the loins over the kidneys, will have a beneficial effect by stimulating the kidneys without causing irritation. This application should not be used more than onec.

\section{DIABETES INSIPIDUS-SIMPLE DIABETES (PISSING).}

A disease characterized by great thirst, excessive urination, and great languor and emaciation.

In the majority of eases it is caused by poor and tainted food. In some cases it seems to be due to a constitutional cause.

Symptoms.-Excessive urination, from 6 to 12 gallons every twentyfour hours; great thirst, the animal sometimes drinking from 20 to 2.5 gallons of water in twenty-four hours; depraved appetite; urine of a very pale color, sometimes as clear as water: the skin is harsh and the coat is unhealthy looking.

Treatment.-Give good, clean, and nutritious food. Administer iodine in 1-dram doses three times a day and diminish quantity as the thirst is lessened and the urine is diminished.

RETENTION OF THE TIRIN.

An inability, total or partial, to expel by natural eflort the mine contained in the bladeler. It is caused by spasm of the neck of the blatder, and is often a complication of colic.

symptoms.-Frequent and incllectual attempts to urinate; if standing the animal will streteh himself out, strain violently, and groan with pain, discharging but a few drops of urine, or none at all: by examination per rectum the bladker is felt to be greatly distended, and this is the diagnostic or distinguishing symptom.

Trectment.- Pass the catheter and draw off the urine. If retention of the urine is due to an aceumulation of dirt in the penis, washing will remove the cause. 


\section{Diseasfes of thr. Nemiols Srsteu.}

('OXGESTION WF THE BRAN-— MIIXI) STAGGHAS.'

This disease is raused by an alecumulation of bhoul in the vessels of the brain, due to some obstacle to its return to the veins.

Canses.-Disease of the heart; excessive cxertion; the influence of extreme heat; sudden and great excitement ; artificial stimulants; any mechanieal obstuction which prevents the leturn of blook through the veins to the heart, such as a small ill-fitting collar: tumors or abscesses pressing on the vein in its course; extreme fat; compression of the vascular structures (arterial capillaries) by an abnormal tension of gas in the stomach and intestines; orer-feeding after a piolonged abstinence or when the excreise is insufficient; and foods difficult of digestion. Fat horses or those with short, thick necks are especially liable to attacks of this malady.

Symptoms.--Congestion of the hrain usually appears sudlenly and is of short duration.

The animal may stop very suddenly and shake his head, or stand quietly braced on his legs, then stagger, make a plunge and fall; the eyes are staring, breathing hurried and snoring, nostrils widely dilated; this may be folloved by coma (insensibility), riolent conrulsive movement, and death.

Generally, however, the animal gains relief in a short time, but he may remain weak and giddy for several days. If it is due to organic change in the heart of disease of the blood ressels in the brain the symptoms may be of slow development, manifested by drowsiness, diminished or impaired vision, difficulty in roluntary morements, diminished sensibility of the skin, loss of eonsciousness, deliriun, and deatl.

Treatment.-Prompt removal of all mechanical obstruetion to the circulation. If it is due to venous obstruetion by too tight al collar, the loosening of the collar will give immerliate relief. If due to tumors or abscesses, a surgical operation becomes neeressaly. To relieve the animal, if he becomes partially or totally unconscious, cold water should be dashed on the head, and if this dioes not afford relief, recourse must be hiul to bleeding to lessen arterial tension. If symptoms of paralysis remain after two or three days, an aletive physic should be given, followed, after twenty-four hours, by iodide of potassium given in 2-dram doses three times daily. Place the animal in a cool, dark, well-rentilated stable, keep him perfectly quiet, and give cooling diet. 
SUXSTROKE AND IIEATSTROKE.

These are cerebral troubles: Sunstroke is produced by the rays of the sun falling directly upon the cranium. Heatstroke is caused by the orerheating of the whole body or by excessive exertion.

Symptoms.- Sunstroke is manifested sudflenly: the animal stops, drops his head, begins to stagger, the breathing is marked by great snoring, the pulse is very slow and irregular, cold sweats break out in patches on the surface of the body, and the animal of ten dies without recovering conscionsmess.

Tn heatstroke the animal usually requires urging for some time previous to the appearance of any other symptom. Crenerally perspiration is ehecked; he becomes weak in his gait; the breathing grows hurried or panting; the eyes watery and hloodshot; nostrils dilated and highly reddened to a dark purple color; the pulse is rapid and weak; the heart bounding, frequently followed by unconscionsness and death. Temperature reaches $107^{\circ}$ to $112^{\circ} \mathrm{F}$. If recovery takes place convalesence extends over a long periogl of time, during which locomotion shows lack of full control.

Treatment.-The treatment consists in the application of cold in the form of ice or cold water on the heal, cold injections per rectum, and the arlministration of stimulants, such as 2 ounces aromatic spirits of ammonia or 4 ounces of alcohol in 8 ounces of water; repeat in one hour if necessary. Place the animal in a cool and shady place, and bat he the whole body with cold water until the temperature is lowered.

\section{Disfases of tile Lympintic System.}

Acute inflammation of the lymph gland usually occurs m connection with some inflammatory process in the region from which the lymph is gathered.

The lymph glands between the branches of the lower jaw almost invariably become affected in strangles, nasal catarrh (acute or (hronic), diseased or ulcerated teeth. Infected wounds of any part of the borly may cause inflammation of the noighboring lymphatics.

Symptoms.-The glandis swell and berome painful to the touch, the connective tissue suroun.ung them becomes involved, suppuration (formation of pus) usually takes place, and one or more aloseesses form. If the inflammation is of a milder type the swelling may disappear and the gland will assume its normal condition without suppuration. The temperature will be elevated. Sometimes the glands will remain hard and considerably swollen for some length of time. In man these swollen glands are known as kernels.

Treatment.-Fomentations with hot water will relieve the soreness, unless an absecess is forming. If such is known to be the case a poultice of bran or flaxseed meal should be applied, and ats soon as fluctuit- 
<smiles>CC#CC1CC2CC12</smiles>

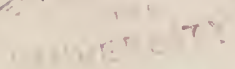


PLATE XIII.

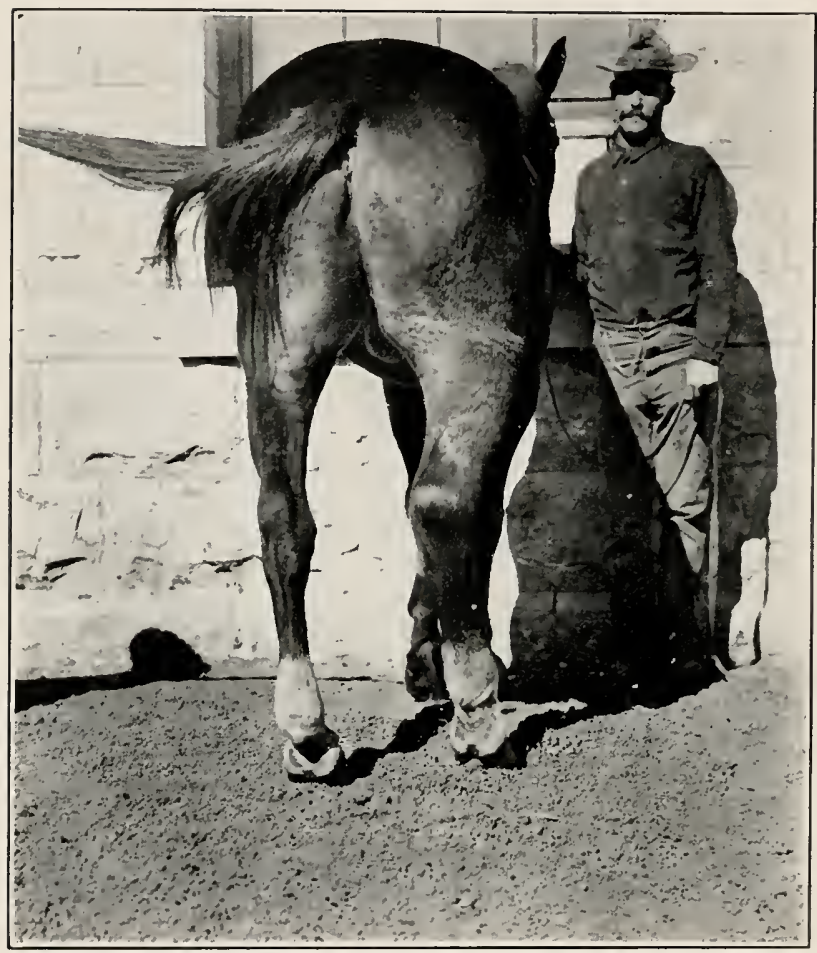

Lymphangitis. 
tion can be felt a free opening must be made and the abscess washed with a solution of bichloride mercury 1-1000, or creolin 1-50. If the gland does not suppurate, the enlargement may be reduced by tincture of iodine applied twice daily.

\section{LYMPIIANGITIS.}

(Plate XIII.)

Inflammation of the lymphatic structures, usually affecting the hind leg, very scldom the fore leg. This disease is very sudden in its attack, exceedingly painful, accompanied by a high temperature and great general disturbance.

Causes.-It usually attacks well-ferl animals, especially after one or two days' rest, and in such cases may be due to an excess of nutritious elements in the blood. It may also result from an infected woumr.

Symptoms.-The first symptom noticed will be lameness in one leg and swelling on the inside of the thigh. The swelling gradually surromels the whole limb, contimuing downward until it reaches the foot. The limb is excessively tender to the touch and is held up. The breathing is increased, pulse hard and quick ( $\$ 0$ to 100), and the temperature may reach $106^{\circ}$. The bowels early become constipated and the urine scanty and high colored. Occasionally the lympluatic glands in the groin undergo suppuration, blood poisoning may supervene and prove fatal.

Treatment.-Fomentations with warm water, to be continued for one hour and repeated several times daily. Give a physic composed of 6 to $\mathrm{S}$ drams of aloes, 1 dram eninger, and water to make a ball. Give at once. After the physic has operated give $\frac{1}{2}$-ounce doses of nitrate of potash twice daily. After the pain diminishes, moderate exercise and hand rubbing will be of benefit. If the glands suppurate, open, and wash them ont with an antiseptic. The irrigations must be continued until the gland is well.

If caused by a wound, similar treatment should be pursued, together with thorough disinfection of the wound. If, after one weok, the swelling still remains, give potassium iodide, 2 drams, twice daily until it is reduced. 


\section{CHAPTER VIII}

\section{MISCELLANEOCS IISHASES.}

PURPURA IIEMORRIIAGICA-PURI'LRA-PETECIIIAL FEVEI.

(Plate XIV.)

This is an acute, infectious disease, the cause of which is as yet little known. Sometimes it is primary; in other instances it follows other infectious diseases, strangles, pharyngitis, contagious pneumonia, influenza, etc.

Symptoms.-Petechial fever is generally manifested by the appearance upon the mucous membranes of numerous dark-red petechix (recklish spots); sometimes they are insignificant as a flea bite, then again they may attain the size of a pea or an acorn; they often become joined and form spots or bands of rariable length. In serious cases the nasal mucous membrane becomes affected by gangrene (death of the affected spot) or covered over with ulecrations. The discharge is bloody and of bad aspect, breathing is very laborious, and the expired air has a fetid odor. The general condition sometines becomes rery rapilly aggravated; then, in the majority of cases, the disease ends in death.

Corresponding with the appearance of the reddish spots, or a few days later, swellings appear beneath the skin; this symptom, which is the most prominent, is often the first symptom noticed. The swellings will range in size from a ten-cent piece to a silver dollar; they are usually upon dependent regions, such as the heal, extremities, abdomen, sheath, and chest. These swellings are not hot, and only slightly sensitive: they gradually extend until they grow together, and we have in a few hours the swelling up of the legs and belly, or the head, to an enormous size; they have always al characteristic constricted border, which looks as if it hat been tied with a cord. The swolling stands out abruptly at this border, often as much as an inch.

The swelling in the legs will cause stiflness. The head may be swollen to such a size that it resembles the hearl of a hippopotamus lather than that of a horse; the caliber of the nostril may be so lessened as to cause the horse to breathe with difliculty. The pulse, if 
PLATE XIV.

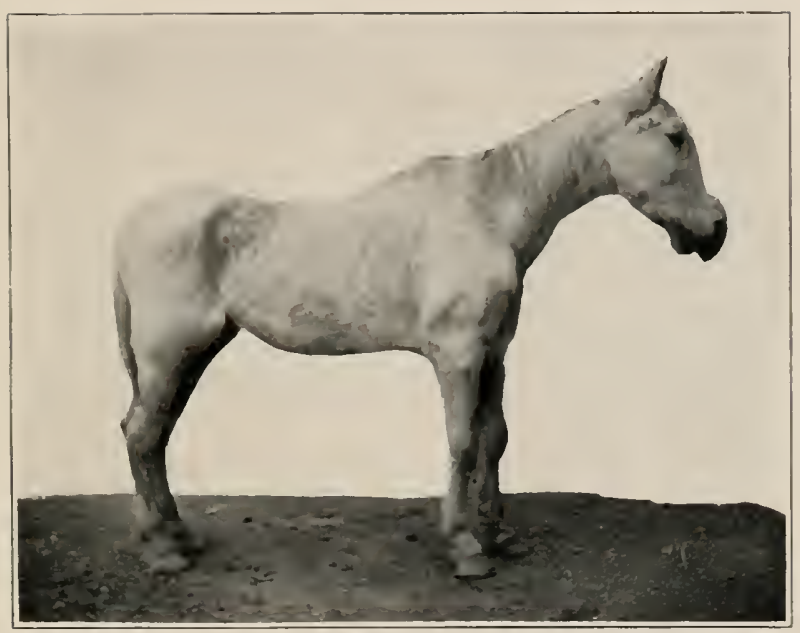

Purpura hemorrhagica. 

altered at all, is a little weaker than usual, the appetite remains normal as a rule, although at times the animal will have difliculty in mastication. The temperature at first is normal, but in a few days it may have reached $102^{\circ}, 103^{\circ}$, or $104^{\circ}$.

Over the surface of the skin covering the swollen parts wo find a slight serous sweating, which, when it dries, grives the appearance of an eruption of some cutaneous (skin) disease. If this is oxcessive we may see irritated spots, followed by suppuration. This suppuration may become excessive from the great distention and loss of ritality of the skin.

During the course of this disease colics may sometimes oceur; later the pulse may beat 60 to 80 times por minute; the dung is ordinarily coated.

Iligh temperatures indicate complications.

The mortality is about j0 per cent.

Treatment.-Place the patient in a clean, well-ventilated, roomy box stall, and tie the head up high; in case the head is already swollen, remove the halter at once and use a head sling. If necessary to blanket never use the surcingle. Give soft food, clean hay, and green fodcler, if possible, and plenty of fresh pure water to drink.

When the legs and parts of the body are covered hy the rried serum the surface must be softened by the application of cosmoline or olive oil, to which may be adrled a small amount of creolin (1 to 50) or of carbolic acid (1 to 25$)$.

If sloughing has taken place, the sores must receive surcrical at tontion; dead tissue must be removed and antisepties applied.

If the animal has great difficulty in breathing. we must resort to the use of the tracheotomy tube.

Try to sustain the strength of the animal and give tonics to increase the appetite: Tincture of chloride of iron 1 to 2 ounces in a pint of water, or iron sulphate 2- drams, quinine 1 dram: either dose three times daily.

Spirits of turpentine, 3 ounces, in 6 ounces of linseed oil, given twice daily, will have a beneficial eflect by stimulating the heart and kidneys. Sponge the head, where swollen, with either ice-cold or very warm water; repoat this several times daily.

\section{IZOTYTIRI.}

Azoturia is the result of the confinement of a strong, rigorous horse for several days in a badly ventilated, damp stable, where he receives full rations and no exercise, followed by sudden exposure to a lower temperature. It is not a disease of the kidneys, as is commonly supposed. 
Symptoms. - These consist of troubles of locomotion (movement), which appear during exercise and generally within a quarter to half an lour after starting.

The disease begins very suddenly, in an unusual degree of restlessness, with profuse perspiration; these symptoms are speedily succeeded by a desire to lie down, by great sluggishness, by loss of moving power in the hind limbs, and by violent spasms of the large muscles of the loins, thighs, and hind quarters. The aflected muscles are swollen and rery hard, and later may atrophy, especially those loeaterl above the stifle. If the animal is down, he makes an effort to stand, but, from the total loss of power in the hind limbs, is nnable to rise.

The fore limbs and shoulder muscles may be similarly affected, but in this ease the lisease is less serere.

The pulse usually becomes rapid: the temperature rarely increases. even in the grave form; the appetite is seldom diminished, and. as a rule, the animal will drink large quantities of water.

The urine is cotfec-colored and is generally retained in the bladder.

Treatment.-As soon as the first symptoms are noticed, halt at once. Keep the animal on his feet: unsaddle or unharness and blanket promptly: then move him as gently as possible to the nearest shelter, where he must hare complete rest. If possible, heat some common salt or some oats; place in a sack and spread orer the loins (under the blanket), to reliere the pain. Feed only good hay or laxative fond and aroid oats and corn. Encourage the horse to drink as much water as possible, as this will assist the kidneys in carrying the poisonous material out of the blood. Then the urine clears, the animal may be gradually returned to work.

If it has been possible to reach the stables, place the horse in a roony stall: if there is then danger of his lying down, use the suspending slings, provided he is able to partially support his weight on his hind legs: then give 2 ounces of sweet spirits of niter and 2 to 4 drams of fluil extract of cannabis indica in a pint of water. In a half hour administer a physic ball.

If the animal has dropped on the roal and is unable to rise he must be taken to the stable by the use of a stone boat or other extemporized means: plenty of bedding must then be supplied and the patient frequently turned from side to side: apply $\frac{1}{2}$ ounce of fluid extract of digitalis to the loins and rub in well. to stimulate the action of the kidneys. If the patient has retention of urine, the bladder must be emptied several times daily: this can be accomplished by passing the hand into the rectum and applying moderate pressure upon the bladder, or by the introduction of the catheter.

This disease securs in the army only through carelessness. When the horse is left resting for twenty-four to forty-eight hours or longer 


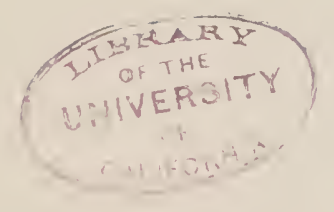




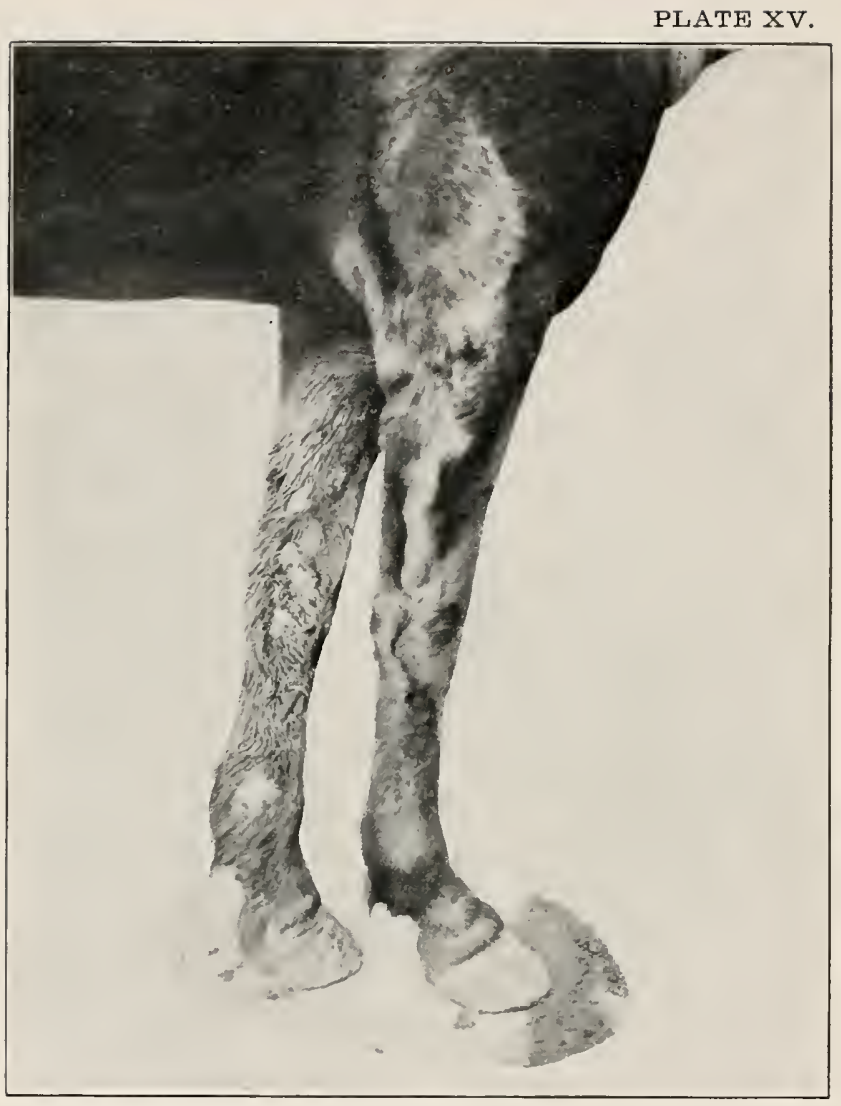

Farcy. 
the food ration shoukd be diminished, and the animal must be given a little exereise in the open air every day to keep him accustomed to the outsicle temperature.

GLANDERS AND FARCY.

Glanders is a contagrious constitutional disease of the horse and mule, and may be communicated to man. The disease is due to a germ called "bacillus mallei," and affects the Schneiderian membrane and internal organs.

When the disease is located in the lymphatic glands situated on the external parts of the body it is called farcy. (Plate XV.)

Glanders and farcy are one and the same disease.

It may be acute or chronic. In acute glanders the bacilli enter the blood and the disease spreads throughout the system.

\section{Chronic glanders.}

The begimning of chronic crlanders is often hidden from view and passes unobserved.

The first visible symptom is generally a discharge from one or both nostrils of a yellowish green matter of bad aspect; quite frequently it is tinged with blood.

Then pimples and ulcers are observed upon the Schneiderian membrane. The pimples are of short duration; they are soon transformed into ulcers mole or less deep, with sawtooth-shaped, thickened edges; these may heal, but will always leare a scar.

The enlargement of the lymphatic glands situated in the space between the lower jaw is another important symptom. In the beginning the gland is a little sensitive, slightly doughy, and adheres to the base of the tongue or to the lower maxillae: in some subjects it allheres to the skin. In exceptional cases the enlarerement of the glant is absent.

The general health of the animal suffers as the affection progresses; emaciation appears: the hair becomes dull and bristly.

There is frequently difficulty in breathing, and the patient becomes rapilly fatigued.

\section{Frorr?!.}

(1'late $\mathrm{xr}$.

Farey is more rare in the chronic than in the acute form of the disease; its favorite regions are the inner side of the extremities, shoulders, neck, chest, and abdomen.

The pimples and tumors rary from the size of a pea to that of a wahut, or larger; they suppurate and discharge a rellow, sticky liquid of bad aspect. They rarely heal, and if they do a jagged scar remains. 


\section{Arute glanders.}

Symptoms. - Acute granders is rale in the horse (10 per cent), except in transit and in tropical climates. It is, on the contrary, the ordinary form in the mule. Sometimes it is primary; in other instances it follows the chronic form, where the vitality of the animal has been lessened by other acute aflections.

The discase produces an ulcerous destruction of the respiratory mucous nembrane, and also involves the skin, lungs, and other organs.

It begins with a chill, followed by intense ferer, which reaches $107^{\circ}$ F. A sticky, yellowisls, irritating, bloody nasal discharge appears. The nasal mucous membrane is overrun with pimples and ulcers, which rapidly join one another; they may perforate the septum nasi. The respiration is rattling, wheezing, and moaning, due to contraction of the larynx; to these symptons are of ten added those of farey. We may find diarrhea. The patient is extremely weak and emaciation progresses rapidly.

In general, acute glanders runs a rapid course; its usual termination is leath. This ordinarily takes place within from three to fourteen days.

In the horse there is no disease of which an exact diagnosis is so important as that of glanders.

In order to correctly diagnose obseure cases (those with no outward symptoms) we must resort to the use of mallein. This is a liquid, the injection of which will cause a reaction (rise in temperature) in glandered horses apparently enjoying the best of health.

Tratment. - This disease is not only contagious to horses, mules, and men, but is incurable in all alike; therefore, the first step, when a suspicious case presents itself, is to isolate the animal, and as soon as it is proved that glanders exists, the animal should he killed at once and the careass burned. Fverything in the way of partitions, mangers, feed boxes, buckets, and all stable utensils must be burned, and the stalls and surroundings thoroughly disinfected. Chloride of lime, s ounces in 1 gallon of water, makes a good and efficient disinfectant. With this solution all parts of the stalle in which the affectod animal stood must be thorouglily washed.

\section{TETANLS LCR.J.AW.}

(1'late XVI.)

Tetanus is an infectious clisease, the specific cause of which is a bacillus or germ which, in most localities, is found in abunclance in the superficial layer of the carth in gardens, around buildings. stables, etr.

'The disease, when present, always follows a wound, more especially one produced by a nail puncture. 
PLATE XVI.

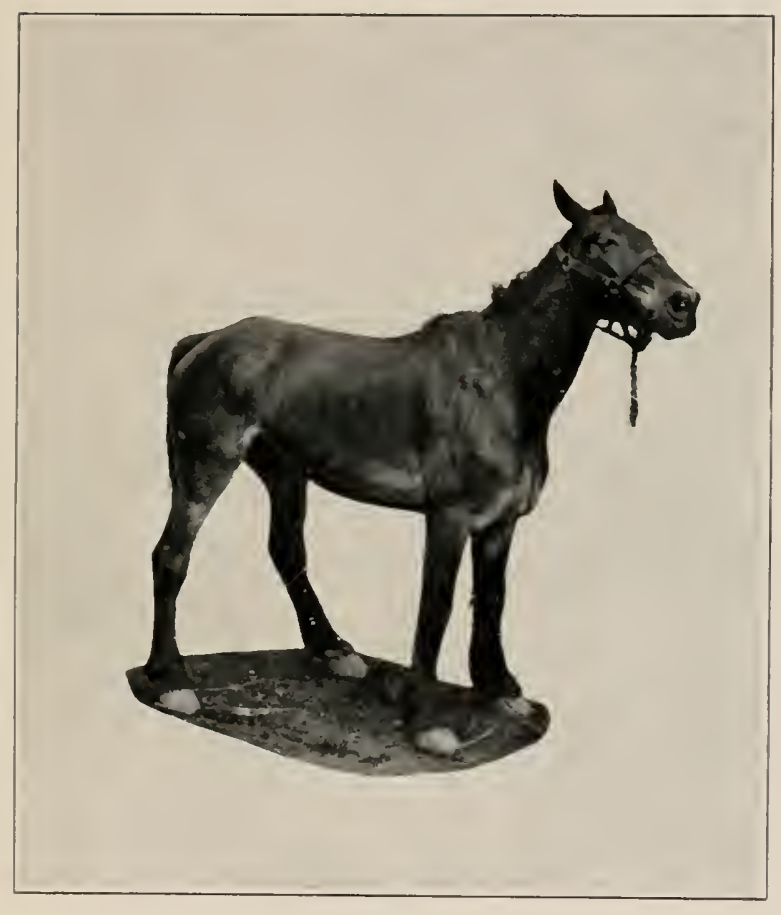

Tetanus. 

The germ will not develop in the presence of oxygen: consequently, all punctured wounds of the foot shoukl be frecly opened to almit of the introluction of air, as well as to allow of thorough cleansing with an antiseptic. This preventive treatment is generally suceessful.

In warm countries, especially in tropical climates, cases of tetanus are much more frequent than in cold regions.

Symptoms.-Tetanic spasms (spasmodic or continuous contractions of the muscles) appear, as a rule, in the muscles of the neck and head; thence they extend to the shoulders, trunk, and extremities; or the stiffness may start in the region of the injured organ or member.

('ontraction of the rheek muscles; the inferior maxillary is then no longer able to execute the slightest morement, and the prehension and mastication of fool becomes difficult or quite impossible. This inability to open the jaws has given to the disease the name of lockjaw.

Contraction of the great posterior muscles of the eve causes a retraction of this organ within the orbit, and a protrusion of the liaw upon the cyeball.

The animal is rery stifl, holds his head in an extencled position as if suffering from a sore throat; the tail is elevated and the ears drawn closer together; the nostrils are much dilated; the legs stand apart; the eyes indicate excitement and anxiety, the mucous membranes are rediened; some muscular groups, principally the muscles of the cheeks and of the back of the neck, are hard and distinctly outlined, as if carved: the muscles of the jaws, neck and shoulders, back, lumbar region, eroup and tail are as hard as wood.

The tail and ears may be moved by the hand, but they inmediately retum to their former position.

There is profuse sweating when the animal is clisturbed or when he is in a spasm; respiration is accelerated and laborious. When the paticnt is approached for an examination, his excitement increases instantly; the lower jaw is pressed hard against the upper, and can not he separated from it, eren by the most violent efforts of the examiner; on parting the lips a fetidl liguid rums out of the mouth, which is more or less filled with particles of food ; if the head is lifted the whole haw obscares the greater part of the eyeball.

Backing is extremely diflicult or even impossible; turning is also very laborious; the trunk, neck, and shoulders can not be flexed, the extremities are as stiff as stilts.

The course of tetamis is variable, according to the individual. It commonly develops rapilly, and death talies place in two or three days. In some (ases death oceurs more slowly, within four to eight days on an average. In others, again, where the spasm is 
moderate and of little rextent, the disease may continue for several weeks.

liecovery before the thirel week is rare; about this time the spasm begins to decline, the appetite returns, respiration becones calmer, and the morements more iree; very often recovery takes place only at the end of five or six weeks; there may he a continuance of the stiflness of morement and tension of the muscles of the hack for a fong perion of time.

Tratment.- I systematic course of food and the freedom of the patient from all kinds of excitement are the two essentials in the treatment.

It is advisable to place the patient in a dark stall, so situated as to be isolated and free from all noises, and with only one man in attendance; strangers entering the stall of a patient aflected with only a mild attack may cause such excitement that the animal is thrown into a violent spasm and dies in a short time.

Give the patient gruel, mealy drinks, liquid food, and, if he can eat it, green fodder.

Medicinal agents are of secondary importance in the treatment of lockjaw. Large doses (2 to 8 ounces) of bromide of potassium should be given in the liquid food, twice daily. The administration of medicines by the mouth is not practicable; not only because of the loeked jaws, but because it causes excitement.

The infected wound requires special care. It should be wrell opened up, disinfected, foreign bodies extracted, etc.

Some authorities recommend the use of the suspending sling.

In the horse the mortality from this discase is from so to s.5 per (ent.

In localities where tetanus is common, a preventive serum, called "antitetenic," is injected into the blood, whenever the horse receives a punctured or suspicious wound.

IMEASES (IF 'THE TEETI.

On account of the character of its food the horse has been supplied with molar teeth, with roughened grinding surfanes. The lower jaw is narrower than the upper jaw, and the table (errinding) surfices are sloping. The distance from the gum to the grinding surface is greater on the outside surface of the upper molars and the reverse in the lower molars.

On account of this conformation a sharp ridge of points is liable to develop on the outside of the upper molars and may oceur on the inside of the lower ones. These points are sometimes so sharp that they lacerate the checks and tomerne during mastication. A horse this aflected will frequently bolt his food before thoroughly 
masticating it, thereby causing chronic indigestion. He will also flinch when reined, causing great amoyance to his rider or driver.

Such irregularities can be easily detected by an examination of the animal's mouth with the hand; when found, the sharp edges must be removed by the use of a float.

\section{Decayed teeth.}

All teeth are apt to decay, such decay being generally due to an injury.

$A$ decayed tooth will be found in one of the following conditions: Split, broken, or shorter than the surrounding ones, and having a fetid odor. The opposing tooth in the opposite jaw is often found to be elongated.

Symptoms of irregularitics in teeth.-Quidding of the food, holding the head to one side while masticating food or drinking water, slobbering, chronic catarrh, fetid breath, swelling of the maxilha in the neighborhood of the teeth, general unthrifty appearance, ete.

Treatment.-A diseased tooth must be extracted, and an clongated one must be shortened to correspond with its fellows.

SPASM OF THE DIAPHRAGM-TIUMPS.

Caused by severe exertion.

Symptoms.-In the region of the lower part of the left flank, near the border of the false ribs, will be observed shocks which, at times, shake the whole body; they are ustally accompanied by a short, jerking expiration, and by a dull, thumping sound which is heard at a distance of several paces. The trouble may be followed by inflammation of the lungs or by founder.

Treatment.-Absolute quiet and fresh air free from draughts.

Give the following: Aromatic spirits ammonia 2 ounces, water 1 pint. Or, sweet spirits of niter 2 ounces, fld. ext. belladonna 2 drams, water to make 1 pint. Either mixture may be repeated in one hour if necessary.

If inflammation of the lungs or founder follows, treat accordingly. $5417-09-6$ 


\title{
CHAPTER IX.
}

\section{DISEASES OF THE SKIN AND FYE.}

\author{
ERYTHEMA.
}

Erythema is a slightly inflamed condition of the skin, unattended by any eruption. The parts are slightly swollen, hot, tender, or itchy, and dry, and if the skin is white there is redness.

Erythema may arise from a variety of causes, as chilling or partial freezing, heat and burning, chapping, urine, and medicine.

Treatment.-Apply the following several times daily: Sulphate of zinc 1 ounce, acetate of lead 1 ounce, water 1 quart. Or, use the following ointment twice daily: Oxide of zinc 1 ounce, cosmoline 6 ounces.

\section{(iREASE.}

(Ilate XYII.)

Grease is a chronic inflammation of the skin of the back part of the fetlock and pastern. It is usually caused by lack of cleanliness, but may result from orerfeeling without exercise.

The skin is at first red, swollen, painful, and hot. It is soon covered by vesicles (blisters) which burst and discharge a thin, yellowish liquid, which is at first without odor. The hairs are matted together ereet, or fall out in large quantities.

Grease produces, in the course of time, serious alterations in the pastern or fetlock. The excreted liquid becomes decomposed and softens the epidermis. I kind of sticky, doughy exudate is formed, which is of bad aspect, of fetid odor, and very irritating.

The back part of the pastern and fotlock becomes the seat of granulating wounds, the granulations ranging in size from that of a pea to a large grape (the so-called grapy stage).

Treatment.-In the first stage cleamliness and the application of the ordinary drying powder or antiseptic ointments are sufficient. In cases where jouml flesh exists, the gramulations must be removed with the knife and burned with red-hot iron or lunar calustir and then 
PLATE XVII.

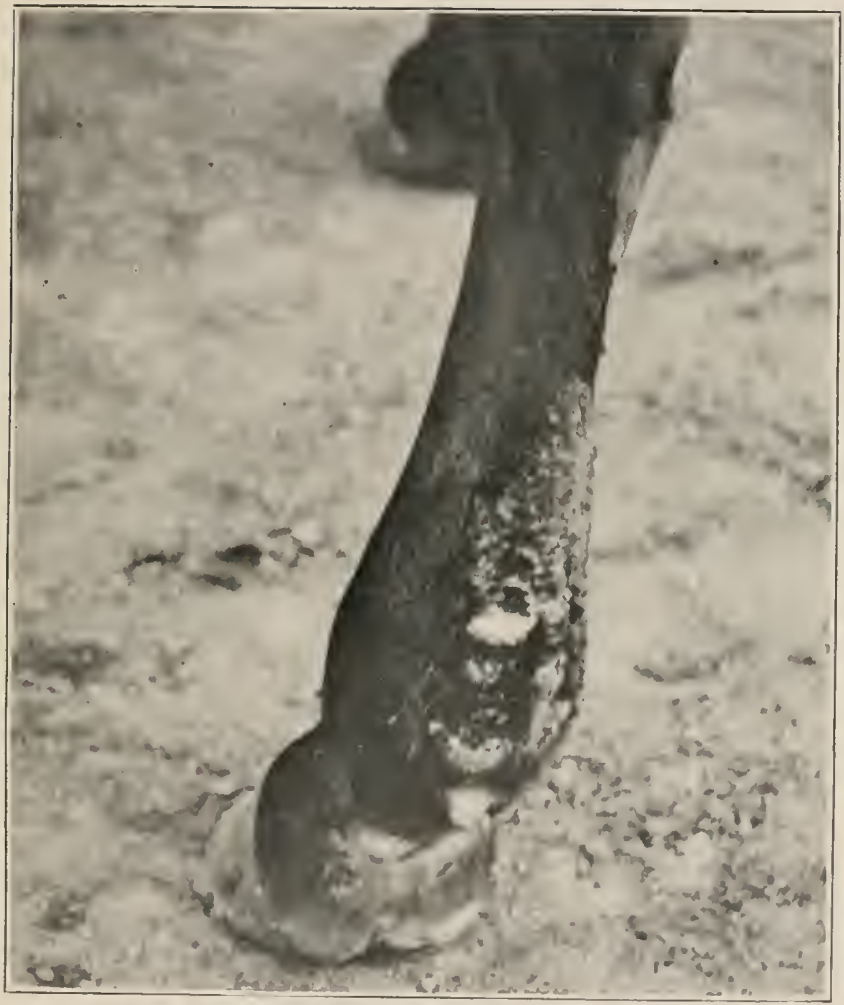

Grease. 

treated as a fresh wound. Applications of iodine and glycerin in equal parts, or of the three sulphintes, mily be beneficial.

\section{SCRITCHES.}

Scratches is allied to grease and results from similar causes; it is not so severe, but if neglecterl may teminate in that disease. It is usually of a dry nature, with shallow cracks in the skin, and often discharying a thin licpuid, which does not irritate the skin. The disease is locaterl in the back part of the pastern joint.

Trentment.-Cleanse thoroughly with castile soap and water, dry, and apply: Sulphate of zinc 1 ounce, acetate of lead 1 ounce, water 1 quart. Or, oxide of zine 1 part, lanolin 10 parts. Or, tincture of iodine may be resorted to. Good results are obtained by a dressing of equal parts of zinc oxide and acetanilid, kept in place by a piece of gauze or cotton and a bandage.

\section{SCABIES-MANGE.}

This is a contagious skin discase produced by parasites and can be transmitted to man.

There are three parasites that cause mange; two varieties burrow into the deeper layers of the skin, the first being found about the head and neek (though it may spread over the surface of the body'), the second at the roots of the mane and tail; the third species does not burrow into the skin and is found on the extremities.

Symptoms. - This disease is characterized by great itching associaterl with the formation of pustules (pimples). Is the disease developes, large surfaces become destitute of hair and are covered by powdery crusts of variable thickness. It a later period the skin becones thickened, wrinkled, and fissured, assuming the appearance of the skin of the rhinoceros.

Treatment.-The first essential is the separation and isolation of the unhealthy from the well animals. Wash the affected parts thorouglly witl warm water, soap, and a scrubbing brush, and apply the following: Acetanilid 10 parts, creolin 5 parts, cosmoline 20 parts. Melt the cosmoline and mix with the other ingredients while coolingr. This ointment should be applied twice a day and the parts thoroughly washed every other day. Continue the treatment until the skin becomes healthy.

\section{SIMPLE IXJUIES TO THE EYELIDS.}

Inflammation of the mucous membrane lining the eyelids may be caused by hruises or the presence of a foreign body, surh as sand, chafl, etc. If the eyeliels should become torn, they must be sutured; 
the utmost care is necessary as the needle may puncture the eycball and blinduess will follow.

Trutment.-lieep the parts clean with a saturated solution of boracic acid, and dust with iodoform.

SIMPIE OPHTIIALAIA-CONJTNC'IVITIS.

Inflammation of the outer parts of the eyeball, and of the exposed vascular, sensitive mucous membrane (conjunctiva) which (overs the ball, the erelids, and the haw.

The causes of external ophthalmia are mainly those which act locally-blows with whips, chubs, and twigs; the presence of foreign bodles, such as chaff, dust, sand, ammonia arising from the excrement, etc.

Symptoms.-Watering of the eye, swollen lids, rechness of the mucous membrane exposed by the separation of the lids, and a bluish opacity of the cornea, which normally is clear and transparent. The eyelids may be kept closed, the eyeball retracted, and the liaw protruded over one-third or one-half of the ball. If the affection has resulted from a wound of the cornea, a white speck or fleecy cloud is formed, and often blood ressels begin to extend from the adjacent vascular covering of the eye to the white spot, and that portion of the cornea is rendered permanenty opaque.

Treatment.-Place the horse in a dark stall and bathe the outside of the eye with tepid water; a few drops of the following lotion should be dropped insile the eyelids: Zine sulphate 20 grains, boracic acid 1 dram, fluid extract of belladonna 1 dram, water 4 ounces. Cover the eye with a clean, dark cloth on the inside of which a piece of absorbent cotton has been sewerl; keep the cotton saturated with the same lotion. This treatment should be applied and continued twice daily until the parts assume their normal condition. In cise of wound or ulcer on the cormea, make use of a quill, through which blow iodoform into the eve daily.

\section{IRECTRRENT OPHTIIALMIA-MOONBLINDNESS.}

This affection, sometimes called periodic ophthalmia, is an inflammation of the interior of the eye: it is intimately related to certain soils and climates, and to certain animal systems, in which it shows a strong tendency to recur again and again, usually ending in blindness from cataract or other serious injury. Continuous exposure to bright sunlight is frequently an exciting cause.

Symptoms vary according to the severity of the attack. In some cases there is marked ferer. The local symptoms are in the main those of simple ophthalmia: opacity advances from the marcrin over a part or the whole of the cornea. An attack lasts from ten 
to fifteen days. The attacks may follow each other at intervals of a month, more or less, but they show no particular relation to any particular phase of the moon. From five to seven attacks usually result in blindness, and then the other eve is liable to be attacked until it also is ruined.

Treatmont.-Is largely the same as that for simple ophthalmia. During recovery a course of tonics is often very beneficial and acts in assisting to ward off another attack. Such a tonic is the following: Sulphate iron 1 ounce, gentian $1 \frac{1}{2}$ ounces, nux vomica $1 \frac{1}{2}$ ounces. Make into twelve powders and give one powder, in feed, twice a day.

If opacity of the cornea remains, benefit may be obtained from the use of silver nitrate, 4 grains to 1 ounce of water, a few drops dropped into the eye twice daily. A saturated solution of iodide of potassium may be used in the same manner.

CATARACT.

Cataract is usually the result of repeated attacks of recurrent ophthalmia. It is an opacity, not of the cornea, but of the crystalline lens. No treatment will restore it to its normal condition. 


\section{C'HAPTER X'.}

\section{DISEASES OF TIE FEET.}

liemoving pressure means trimming the bearing surfaces of the foot in such a way that the shoe can not cause pressure upon diseased structures.

CORNS.

A corn is the result of bruising the sensitive sole or sensitive laminx of the quarters or bars and appears as a reddish spot in the angle formed by the wall and bar, usually on the inside of the front feet, seldom, if ever, in the hind feet.

Causes.-A rapicl gait on hard roads; lowering one quarter more than the other; shoes so fitted that they press on the sole at the heel, and shoes left on so long that the wall orergrows the hecls of the shoe and causes the shoe to press on the sole; long fect, which remore the frog too far from the ground, thus preventing the proper expansion of the foot.

Treatment.-First remore the cause by taking off the shoc; shorten the toe, lower the quarter that is too high, or correct any faults that may hare existed in the preparation of the foot. Remove all pressure from the affected spot and reshoc.

In case of severe inflammation and probable suppuration, poultice or soak the foot until the horn softens and pus appears; open freely, disinfect, remove all horn that is underrun by pus and then pack with the "three sulphates" until suppuration ceases. Plug the corn with oakum or tar and shoe with a bar shoe, removing all pressure from the affected quarter. (The special function of the bar shoe is to produce frog pressure.) The three-quarter shoe may also be used. This shoe will prevent pressure on the discased spot, but it las a tendency to give a rocking motion to the foot in action.

\section{THRL'SII.}

Thrush is a discased condition of the frog, characterized by a darkcolored discharge of oflensive odor.

C'anses.- Uncleanliness; horses standing in stalls saturated with urine, or in wet earth filled with decomposing vegetable matter. 
Symptoms. - At first there is simply an increased moisture in the cleft of the frog, accompanied by an oftensive smell. Ifter a time the discharge is more profuse, then watery and highly offensive, changing gradually to a thick, putrid matter, which rapidly destroys the horn of the frog.

Treatment.-Remove the cause: keep stalls clean and dry. Pare away all lose portions of the horn, so as to expose the discased parts; clean thoroughly by washing with warm water; dry with oakum and pack with powdered alum, calomol, or copper sulphate; if the dressing will not remain in place use a leather boot.

\section{C.NKKR.}

Canker is a disease of the frog and sole, marked by an offensivesmolling, cheesy discharge, by a softening and breaking down of the horny frog and sole, and a spongy enlargement of the sensitive frog and sole. When this disease follows an injury which has exposed the soft structures of the foot, it soon causes a separation of the soft and horny portions, presenting a very unhealthy appearance and discharging a thin, watery fluid.

Causes.-Canker is generally believed to be caused by a regetable parasite, the development of which is assisted by filthy stables or low, wet ground.

Treatment.-That part of the frog or sole that has been underrun must be remored with the knife and the canker exposed; the unhealthy growth is then touched with a red-hot iron, burning it off level with the surrounding healthy structures, are being exercised not to injure the sensitive portions of the foot. Next, wash clean, then dry and apply the following powder: Equal parts of sulphate of zinc, sulphate of iron, and sulphate of copper. Place over this a pad of oakum, and orer all a leather boot. This dressing must be changed once a day (twice a day in bad cases); treatment is continued until a healthy growth ol horn covers the whole foot. The horse can now be shod. Pack the foot with oakum and tar and cover with a leather sole, which is held in place by the shor.

If it is desirable to change dressings on the shod foot, a more convenient appliance to keep them in place is made in the following manner: Cut a piece of sheet zine to cover about two-thirds of the sole and frog, the outer edge of the piece fitting under the shoe; cut another piece to corer the remaining third and wide enough to lap orer the first piece, the lap to run parallel to the cleft of the frog; then cut a strip about $1 \mathrm{inch}$ wide to act as a keeper: the ends of this strip are pressed under the shoe, the strip passing across the foot from quarter to quarter. 


\section{QUITTOR.}

A quittor is a running sore, situated on the coronet of the foot, with one or more tubes (sinuses) leading in a downward direction and discharging pus.

Causes.-Pricks in shoeingr; punetures of the coronet, sole or fing; bruises or suppurating coms.

Symptoms. - I swelling on the coronet, presenting a peculiarly unhealthy appearance, and in the center of which are one or more sinuses communicating with the diseased structures inside of the foot. In nearly all cases the horse is very lame.

Treatment. - Find out, if possible, what has caused the quittor. If it is the result of a nail prick or a festered corn, open it up on the underside of the foot, allow the pus to run out, and then treat as lescribed under "Puncture." If no nail prick or eorn can be found, treat the quittor from above, by injecting into the sinuses one of the following solutions: Carbolic acid, 1 to 20: creolin, 1 to 25 ; bichloride of mercury, 1 to 500 . This treatment should be continued for several lays, at the end of which period, if the parts do not appear in a healthier condition, injeet into the tubes 1 dram of bichloriele of mereury well shaken up in 1 ounce of water. This will cause a separation of the diseased walls of the tube from the healthy parts of the foot. Poultices of flaxseed meal assist this separation. Keep the parts clean and wash out with carbolic acid or creolin as at first. If the sore does not heal under this treatment a surgical operation will be necessary.

QLARTER CRACKS AND TOE CRACKS.

A toe or quarter crack (often called a sand crack) is a split in the horn of the wall: the position of the erack determines the name applied to it. Horses with thin, weak quarters are predisposed to quarter crack.

Causes.-Excessive drrness of the hoof; alternate changing from damp to dry: heary shoes: large nails, and nails set too far back toward the heels.

Symptoms.- The crack generally starts at the coronary band and gradually extends downward to the lower border of the wall. The most common form of quarter crack is a deep fissure extenting through the wall and eausing a pinching of the sensitive structures. When, however, the crack is not deep there is seldom any lameness.

Trentmont. - The first step is to remove the shoe and soften the hom loy poultices or by standing in warm or cold water for a few days, then cut away the hard orerlapping edges of the fissure and thin the wall on each side so that there will be no friction between the exlges of the crack. As the wall grows down from the coronet 
the upper end of the crack must be carefully observed to see that the new horn grows down strong and smooth. In time the crack will disappear at the lower edge of the wall. If the sensitive laminse have heen exposed by this operation, the parts should be washed with a solution of ereolin, 1 to 50 , and the wound should be dusted with acetanilid and covered with a parl of oakum held in place hy a boot or bandage. In a few days a thin layer of horn will be thrown out, covering the sensitive lamina. The lorse ean then generally be put to work.

After a quarter erack has been trimmed out, the liorse should be shod with a bar shoe, the wall undermeath the quarter crack being ent away so that it will not eome in eontact with the shoe.

In a case of toe crack the operation is the same. In shoeing, the wall is ent away at the toe to prevent pressure.

PUNCTIRE OF THE SOLF AND FROG-PRICKS IN SIIOEIN(i.

A puncture of the sole or frog is usually caused by a lorse stepping on a nail, a piece of broken glass, or other sharp object. If the wound enters the soft structures of the foot, it results in lameness and the formation of pus.

Pricks in shoeing are of two kinds: First, when the nail is driren into the soft struetures, and, seeond, when it is driven too close, causing a bulging of the inner layer of horn, which is foreed in upon the sensitive lamina. In the first ease the horse goes lame immediately; in the second case lameness may not appear for sereral days or weeks.

To detect a punctured wound of the foot remove the shoe, examining each nail as it is withdrawn for traces of moisture. Then test with the pinchers. When the sore spot is pressed, the horse will flinel.

Treatment.-Open the wound and let out any pus that may have formed; wash out with a solution of creolin, 1 to 25 , or of earbolic aeid, 1 to 20. Tnless the pus has a good outlet, it will burrow into the surrounding tissues and quittor or canker may follow. Moreover, there is always danger of tetanus in all eases of punctured woumds, especially in the feet. The germ of this clisease is present in nearly all soils and is rery liable to be carried into the wound upon the nail or other object. Ifter the wound has been opened up and washed out, the foot should be placed in a hot flaxseed poultice, a fresh one being applied three or four times a clay, and the parts washed out after each poultice, as in the first instance. The treatment should be continued until inflammation is reduced and the formation of pus has caised. The hole can then be plugged with oakum and tar, the shoe reset, and the horse put to work. 
Laminitis is an inflammation of the sensitive lamina (generally of the front feet) and may involve the adjoining structures. There aro three forms of the discise-areute, subareute, and chonenic.

The exudation of blood is greatest at the toe, the foot being more vaseular at that point. The pain of acute laminitis is very persistent and agenizing, becallse the swollen and sensitive portions of the foot are surrounded hy the hasd and unyielding hoof and the engorged blood vessels are not permitted free exudation and swolling, the normal means by which congested blood ressels are relieved.

f'auses. The most common are concussion, overexertion, exhaustion, rapid changes of temperature, the eating of various improper foods, such as musty grain, hay, etc., and the drinking of cold water when the animal is overheated.

Symptoms.--In acute laminitis of both front feet the animal is excessively lame, moves with great difficulty, especially when starting, and appears as if the entire body were in a state of (ramp; he stands with the hind legs drawn under the belly and the fore feet advaneed, in order to relieve them of as much weight as possible. Occasionally he may be seen to sway backward, elevating the toes and throwing the weight for a moment upon the heels of the front feet, and then resuming the original position. If compelled to move, he raises the feet laboriously, not because the muscles of locomotion are inflamed, as is sometimes supposed, but because, if all four feet are not on the ground at the same time to bear the weight of the body, his suffering is inereased. He will often groan with pain and sweat will break out orer the body. To diagnose a ease quickly, the best method is to push the horse backward, when, if affected, he will elerate the toes and throw his weight upon the heels.

The pulse in acute laminitis is full, strones, and rapid and will mantain these characteristics even after general debility has become manifest. In some instances the animal will lie down upon his side, with the leces stretched out, for hours at at time, evidently feeling great relief in this position: in other eases, particularly during the carly period of the disease, he will stand persistently. The tenperature ranges from $102^{\circ}$ to $104^{\circ}$.

Treatment.- Remove the shoes from the aflected feet: stand the borse in hot water for sereral hours each day, or, what is equally grood and perhaps safer, apply hot flaxseed poultices, changing them every hour as they become cold. After two or three days of this treatment change to cold water, which can be applied either in the form of a footbath or by standing the animal in a running stream for five or six hours at a time. As soon als the pain has diminished, moderate exereise is beneficial; this may be gradually 
increased until the animal shows no further sign of trouble. If, after five or six dars, pronounced symptoms of recorery are not apparent, apply a stifl blister of cantharides around the coronet, repeating the blister if necessary. In addition to the local treatment, nitrate of potash (saltpeter), in doses of 2 to 4 ounces, may be given three times a dar. If the horse is constipated, give 1 quart of raw linseed oil. The subacute and chronic forms maty be reliered by softening the foot as in "Dry feet," hy aceasional blistering and by intelligent shoeing.

\section{SEEDY TOE.}

Seedy toe is a mealy condition of the imner wall of the hoof, the white line, and sometimes the sole. It is most frequently seen in the front feet.

Causes.-- Undue pressure, clips on shoes, or the result of laminitis.

Treatment.-Pare the wall of the cavity until healthy horn is reached and pack with tar and oakum. Stimulate healthy growth of horn by the application of a cantharides blister at the coronet. Omit the clip in reshoeing.

\section{CONTRACTED FEET.}

Contracted feet is an unnatural shrinking or narrowing of the feet at the heels. Most often seen in the front feet.

Causes.-Lack of exercise; lack of moisture; thrush: shoes with bearing web inclining inward at the heels. The practice of using the knife to "open the heels" usually produces this trouble.

Treatment.-Ascertain the cause and remove it if possible. The remedy is to secure normal pressure on the frog, bars, and heels. If the feet are extremely dry and hard they may he softened by standing the animal in moist clay or in water. If the character of the gromel will permit let the horse go barefoot; if not, shoe with the tip, preferably; otherwise, with the bar shoe.

\section{1)RY FEET.}

Soften the hoofs by thorough soaking in water and then apply cosmoline or linseed oil to prevent the water from evaporating. This should he done daily for a week or two. A thick paste of ground flaxseed and water, pareked into the cavity of the font between the branches of the shoe, or a packing of moist clay, will keep the foot soft.

\section{COFFIN-JUINT 1.DMENESS.}

Sprain of the coflin joint results from slipping, stepping upon a rolling stone, stepping into at hole, ete.

Symptoms.-Shortened gait: lameness and pointing of discased foot; heat over the region of the collin joint; tenderness on pressure. 
Treatment.-Remove the shoe and give the animal complete rest; poultice the foot with flaxseed meal or stand the forst in a tulo of cold water: if relief is not obtained in a week, apply a hlister of biniodirle of mercury, 1 to 5 , around the coronet and leeels, rubbing it in well over the rewion of the heols.

Sprain of the coflu joint, unless carefully nursed. may terminate in chronic navicular lisease, in which the coffin-joint st ruct ures and the coflin bone itself becone ulerrated. This diseatse is incurable.

If, after navirular disease has developed, it be necessary to keep the horse in the service, the heel of the diseased foot should be elevated by the use of a shoe with calks or with thick heels. The foot should bo kept soft with footbaths and poultices and a blister applierl when limeness is especially marked. Whenever possible keep the shoe off during treatment. 


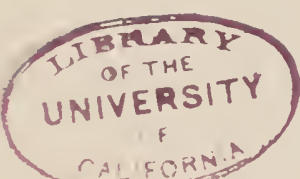


PLATE XVIII.

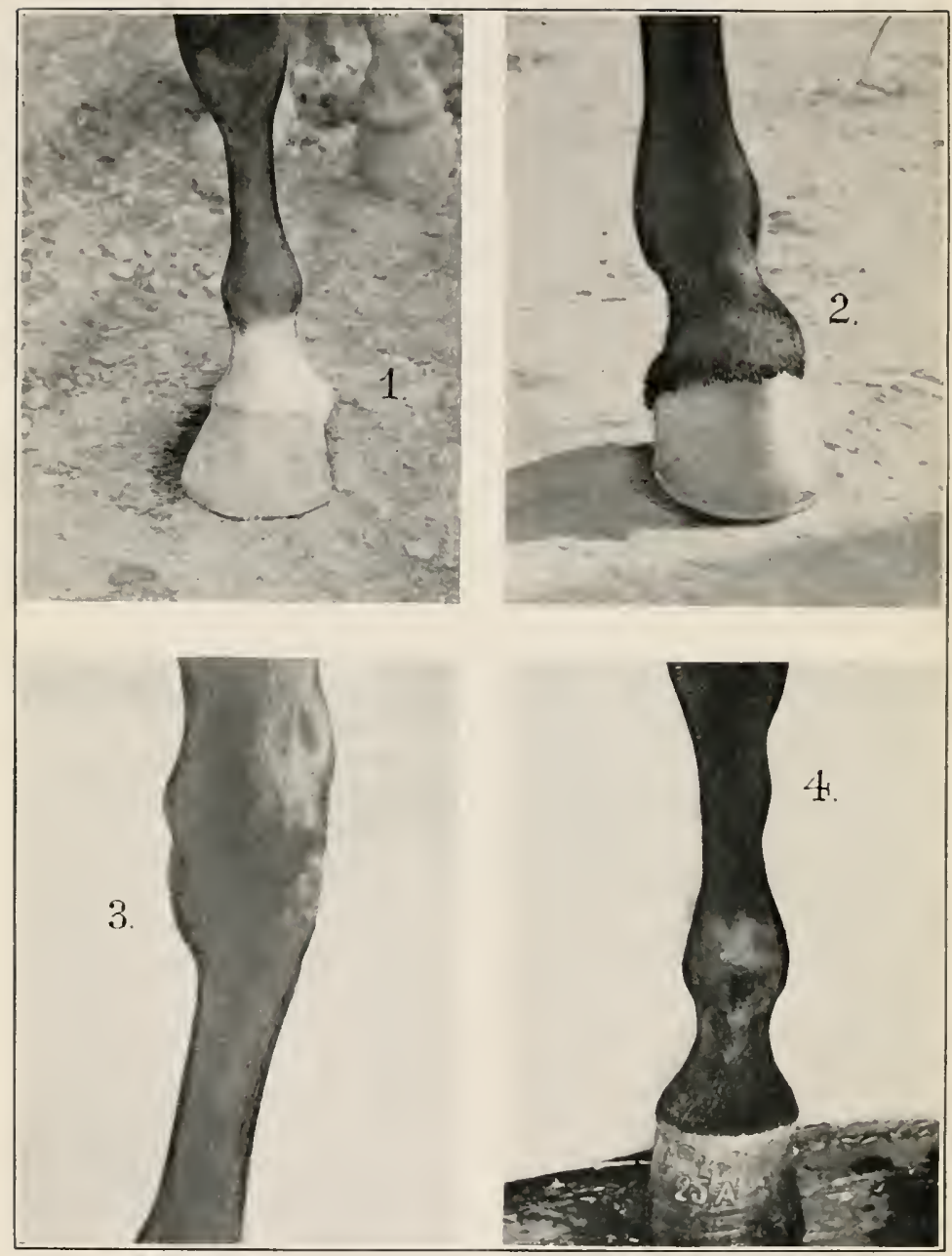

Fig. 1, Sidebone. Fig. 2, Ringbone. Fig. 3, Bone spavin. Fig. 4, Splint. 


\title{
CHAPTER XI.
}

\section{DISEASES OF BONE AND DETECTION OF LAMENESS.}

\author{
SIDEBONES.
}

(Plate X̃VIII, fig. 1.)

Sidebone is an ossification (turning into bone) of the lateral cartilage. IIorses with flat feet and weak quarters are predisposed to this disease.

Symptoms. - I hard, unyiclding condition of the lateral curtilage, with or without lameness.

Treatment.-If the horse is lame the first step is to remove the shoe and level the foot: then let the horse stand in a tub of cold water for several hours a day, or apply, around the coronet, swabs kept wet with cold water. As soon as the fever has disappeared clip off the hair over the sidebones and blister with this ointment: Biniodide of mercury 1 part, cosmoline 5 parts; mix thoroughly and rub in for ten minutes. Tie up the horse's head so that he can not reach the blistered part with his lips, and keep him in this position for twenty-four to forty-eight hours. Then wash of the blister, using warm water and castile soap. The washing must be repeated ercry day until all the scabs formed by the blister have been removed. During this time keep the horse standing quietly in a clean and level stall. If after ten days he has not improved, firing, followed by a long period of rest, may prove beneficial.

\section{RINGBONE.}

(Plate XYIII, fig. 2.)

Ringbone is a bony enlargement, more or less prominent, situated upon either the os suffraginis or as coronæ, and it may also involve the articular cartilages.

Causes.-Blows, sprains, jumping, fast work on hard roads, and faulty conformation.

Symptoms.-Lameness is usually the first symptom, and cliagnosis is assisted by palpation (feeting) and comparison of the two legs. The enlargement is hard, painless on pressure, and the skin covering is movable.

Treatment.-The foot must be pared perfectly level and a blister applied to the enlargement and repeated in two weeks if noressary. 
P'rfect rest and quietude for four to six weeks are esintial, or no beneficial results can be expected.

If the rest and blisters fail to remore the lameness firing may sometimes be resorted to. Puncture firing in two or three rows is often very effective. After firing the seat of the injury should be blistered with biniondide of mercury, 1 to 5 , and the animal liept quiet in a single stall for at least one month.

\section{HONE SPATIX.}

(Plate XVIII. fig. 3.)

Bone sparin is a disease involving the bones in the hock joint and is usually manifested in a bony enlargement, situated at the inner and lower part of the tarsus.

Causes.- Teakness, faulty conformation, severe strains, hard and rapid work, ete.

Symptoms.-The appearance of this disease is usually accompanied by lameness, which in the early stages of the disease is noticed only when the animal is first moved after a rest, and then the toe is generally placed upon the ground first. Then standing, the animal often rests the diseased leg on the toe.

The "sparin test" is sometimes useful in diagnosing sparin lameness. It consists in keeping the hock joint flexed for one or two minutes and then trotting the horse. If a sparin exists lameness is very marked.

Tratment.-The treatment of bone sparin is the same as that prescribed for ringbone.

SPLIXTTS.

(Plate XVIII. fig. 4.)

Splints are bony enlargements, usually situated between the inner splint bone and the cannon bone, at their upper third. They vecasionally occur on the outside of the hind leg.

Causes.-Faulty action or faulty conformation causing unequal distribution of pressure in the knee may throw an excessire load on the inner small metacarpal and cause rupture of the tissue aflixing the small to the large metacarpal. The irritation produces growth of bone.

Symptoms.-Soreness may or may not be present: when the splint is painful the horse is lame.

Treatment.-If there is lameness give the animal absolute rest and apply at blister composed as follows: Biniodide of mereury 1 dram. cosmoline 5 drams. Repeat in ten clays if necessary.

\section{DETECTION OF LAMENESS.}

Serere lamenens is readily recounized, eren when the animal is at rest. Distinct symptoms, such ats pointing or frequent raising of the 
affected limb, are noticed, the animal's instinct leading him to place the affected part in a position to relieve the pain.

In making an examination for lameness, the animal, having free use of his head, should be led at a slow trot toward and from the observer. Too short a hold on the halter shank will prevent free play of all the muscles concerned in locomotion.

If lame in one fore leg, the right one for instance, the hearl will nod (drop) more or less when he steps on the left fore leg, while the head jerks up at the moment the right leg (the lame one) is placed upon the ground. Hence, the head of the lame animal always nods when the sound lear is planted.

Should there be lameness in both fore legs the action is stilty (stifl); the natural, elastic stride is wanting; the steps are shortened, and the feet kept close to the ground. Almost invariably the hind legs are picked up higher than normally; the shoulders appear stifl and the head is carried rather high, while the lumbar region is arched.

Lameness behind is detected by trotting the horse from the observer, the croup being the essential part to be watched, since it drops with the sound leg and rises with the lame one.

If lame in both hind legs, the striele is shortened and awkward; the fore lears are kept back of the rertical line, and are apt to be raised higher than usual, while the head is lowered. Backing is difficult; it is almost impossible to keep the animal at a trot when he is lame in more than one leg.

Horses lame in both fore or both hind legs show a waddling gait behind, often mistaken for lameness originating in the lumbar region. This peculiar motion is simply due to the fact that the hind legs are unduly advanced under the body for their own relief or that of the front legs. Close attention is to be paid to the animal's action as he turns while being trotted to and from the observer, as at this moment - that is, while he turns-any hitch becones visible; as, for instance, spavin or stringhalt lameness.

Always place the lame leg in its natural position and inspect the various parts of the leg both with the hand and eye, comparing them always with the sound legr to find anatomical changes.

In all cases examine the foot thoroughly and carefully, removing the shoe if necessary. Heat, pain, and swelling are always guides in the diagnosis of lameness.

All lameness is divided into two classes: Suinging-leg lameness. which is shown by a shortened stride and more or less dragging of the leg; and supporting-leg lameness, which shows itself when the leg supports the weight of the body. The former is shown in diseased condition of the muscles. The latter is shown in disease of bone, tendons, ligaments, and the hoof. 


\section{CHAPTER XII.}

\section{AGE BY THE TEETH.}

By their growth, changes, form, and wear, the teeth of the horse furnish a very reliable guide to determine the animal's agre. In the adult animal they number from 36 in the formale to 40 in the male, and are classerl aceording to their location, form, and function, as incisors, cunines, and molars.

The incisols, or cutters, oceupy the front part of the mouth. They are 12 in number, 6 in the upper jaw and 6 in the lower. In each jaw there are 2 central, 2 lateral, and 2 comer incisors.

The eanines, or tushes, occupy the front part of the interdental space. 'The tushes are usually absent in the mare, or, if present, are very small. They are 4 in number, 2 in each jaw.

The molars, or grinders, occupy the back part of the mouth. They are 24 in number, 6 on each side of each jaw. Naming from front to rear they are designated first, second, third, ete. Quite frequently supplementary molars, called "wolf teeth," are present. If so, threy appear directly in front of the first molar, in the upper jaw, and very rarely in the lower jaw.

Like other animals, the horse is provided with two sets of teeth, temporary and permanent. The temporary, or milk teeth, are those of the first growth or dentition. They are 24 in number, 12 incisors and the first, second, and third molars. They are all up and in wear when the colt is about 11 months old. Each of them is ultimately shed and replaeed by a permanent tooth. The first shedding takes place at $2 \frac{1}{2}$ and the last is completed at $4 \frac{1}{2}$ years of age. The first permanent tooth to show itself, however, is the fourth molar, which appears at about the age of 1 year.

The permanent incisor differs in appearance from the temporary one by being larger, longer, darker, or more yellowish in color. and by having a well-marked groove down the anterior or front face of the crown. It does not have the constrieted neck which is characteristic of the milk tooth.

The three principal tooth substances are called dentine, enamol, and cement. The dentine composes the main body of the tooth. It is protected hy a covering of chamel, which is very white in color and is the lardest of all animal substances. The cement is a yellowish 
colored bony material. It also forms a protective covering for the tooth, being spread in a thin layer over the surface of the enamel. This cement gives the permanent tooth the color which distinguishes it from the milk tooth. By the time the animal is 7 or 8 years of age, this substance, through constant rubbing by the lips and washing with saliva, has been worn from the enamel, and the teeth consequently appenr much whiter than they did when the animal was but 5 or 6 .

The grinding surface of the tonth is called the table. In the new unworn tooth this is irregular and is eovered with cnamel. The infundibutum is the infoliing of the enamel on the table of the tooth. This forms in the incisors a cavity, the bottom of which is filled with eement to a depth which varies in different animals. The unfilled portion of this cavity forms what is ealled the cup. The cups are deeper in the upper incisors than they are in the lower ones. 'They soon become stained by the food juices so that they appear very black in color. Ordinarily after a lower incisor has been in wear for three years its table surface has been worn down to the cement filling and the blackened cup eavity has disappeared. It is often diffieult for the inexperienced observer to determine when the cup has actually disappeared. He expects to see the table surface perfectly level and of uniform color, whereas the enamel being so much harder than either the dentine or the cement, stands in relief on the table surface, and envelops a very shallow and sometimes slightly stained depression (of cement) for several years after the black cup cavity is considered to have disappeared. The enamel of the infundibulum persists in the lowers usually until the animal is about 15 and in the uppers until he is about 18 years of age. Standing in relief on the table surface as it does, this enamel is frequently termed "the enamel istand."

In the center of the tooth, and extending almost its entire length, is the pulp cavity, a channel, which in life is filled with a fleshy tissue or pulp through the medium of which the tooth derives its nourishment. As the tooth is worn off with age the outer extremity of the sensitive pulp, which would otherwise become exposed, is changed into a yellowish colored ivory-like substance that completely fills and closes the cavity. Hence, when the tooth has worn down to the pulp cavity, the latter appears on the table surface (just in front of the remains of the eup) as a yellowish colored mark called the dental star. This usually makes its appearance when the animal is $S$ years old, although in very hard teeth it is often not apparent until about 11 .

Depending upon the hardness of the dentine and the character of the food, the teeth wear away at the rate of about one-twelfth of an inch per year. As an ineisor is not of uniform shape or size from its $5417-09-7$ 
crown to its root, it is at once apparent that wear will continually change the form of its talsle surface.

In the roung mouth the tables of the incisors are clongated from side to side, while in the old mouth they are elongated from front to rear. 'The intermediate forms through which they successively pass are oval, round, and triangular. Roughly speaking, the incisors are oval from 7 till 9 (centrals at 7 , laterals at 8 , and corner's at 9 ), round from 10 till 13, triangular from 14 till 17 , and elongated from front to rear at 18 or 19.

In the young animal, while the teeth are still unworn to any extent, the upper and lower incisors meet in such a way that they appear as an evenly rounded arch. This arch, however, gradually clianges as the teeth wear away, until in age it las become very angular or pointed.

In examining the mouth of the horse to determine his age, three features of the incisor teeth are studied: First, the angle at which the uppers and lowers meet; second, the character and color of their crown faces, and, third, the shape and appearance of the tables.

To obtain the best view of the mouth, grasp the upper lip firmly with the right hand, and place the left in the interdental space from the right side, using the thumb to depress the lower lip, and the back of the hand to press the tongue upward and backward. In this way the right hand serves as a twitch to hold the horse, while the left one uncovers the lower incisors.

As has already been stated, the temporary teeth are all up and in wear at about the age of 11 months. Between the ages of 1 and 2 the incisors remain the same in their arrangement, but begin to show the effects of wear.

At 2 the mouth presents very much the same appearance as it does at 5 , the difference being that the incisors are temporary in the former and permanent in the latter, and that the 2-year-old has but five molars on the sicle of each jaw, while the 5-year-old has all six. This is the only case in which the molars might render assistance in the determination of the age. At about the age of $2 \frac{1}{2}$ years the tempolury centrals are pushed out by permanent ones. The uppers are usually shed a few weeks before the lowers. After these tecth make their appearance, and until they are up and in wear, the horse is lising, that is approaching, 3 .

At 3 the colt has two permanent incisors (the centrals) and four temporary ones (the laterals and cormers) in each jaw. The centrals are up and in wear; that is, they are on a level with the temporary teeth. The permanent centrals are seen to be darker or more yellowish in color than their neighbors, and to have a well-marked groove down their front face. Another important observation to make is the appearance of the cups. In either the temporary or the 
permanent full mouth the centrals, having been in wear for the longest period of time, show the shallowest cups, while in the 3-ycar-old mouth the new centrals, having been in wear for the shortest period of time, show the largest, deepest, and blackest ones. The colt is said to be 3 years past when the permanent centrals show wear on both their front and rear borders. At about the age of $3 \frac{1}{2}$ years the temporary laterals are shed, and until their permanent successors are up and in wear the colt is rising 4.

At 4 the colt has four permanent incisors (the centrals and laterals) and two temporary ones (the corners) in each jaw. The laterals are worn on both their front and rear borders, and the cups of the lower centrals, having been in wear for one year and being about onethird gone, show smaller than the cups of the laterals. At this age the contrast between the large permanent incisors and the small temporary corners is very striking. The colt is about $4 \frac{1}{2}$ years old when the comers begin to shed. At about this time the mouth of the male begins to show the tushes. After the temporary corners have all been shed, and until the four permanent corners are in contact, the colt is rising 5 .

At 5 the mouth is full. All the incisors are now permanent, and in each jaw they have all reached the same level. The front borders of the corners are in wear but the rear borders are not yet up. The cups of the centrals, having been in wear for two years, are about two-thirds gone, while those of the laterals, having been in wear for one year, are about one-third gone. Usually the rear borders of the corners come up and in the wear while the animal is between 5 and 6 years old, but sometimes they do not come up as they should, and such a conclition constitutes what is known as a shell mouth. This condition may cause an S-yenr-old animal to be mistaken for a 6 yearr-old.

At 6 the cup cavities are worn entirely out of the centrals, twothirds out of the laterals, and one-third out of the corners. At 6 past, a notch begins to form on the outer border of the upper corners.

At 7 the cups are gone from the centrals and the laterals, and the noteh which began forming at 6 past on the upper corners is now well marked. The enamel is now beginning to lose its cement eovering, with the result that the teeth are showing whiter than they did when the arimal was 6 . The tables of the centrals are becoming oval in form.

At $\mathrm{S}$ the blackened cups have usually disappeared from all of the lower incisors, although in some cases those of the corners persist for a year or two longer. The noteh in the upper corners is hardly as prominent at this age as it was at 7 because, on account of wear, the angle of meeting is now beginning to change, and the upper corners in 
consequence are fiucling a greater grinding surface on the lower ones. In some cases the dental star may now be detected between the enamel island and the front border of the tooth in the central incisors. It appears in the form of a ycllowish transverse line.

After the age of 6 wear alune, by ehanging the form and appearance of the table surfaces and the ancrle at which the uppers and lowers meet, furnishes the indications of acre; and as the wear varics with the hardness of the teeth and the character of the food, it is at once apparent that no two cases will be exactly the same. Ilener, after the animal is 8 years old the age indications have become unreliable. From now on with the passing of each year they become less and less reliable. After the twelfth year there is but little probability of judging the age accurately.

On an average it is found that the cups of the upper incisors are worn out in the centrals at the age of 10 .

At 15 in most cases the enamel island has disappeared from the lowers, and the dental star has become distinct and round in the center of the tables. The enamel island persists in the uppers usually until the animal is about 18 .

After 20 the horse is considered to have reached the limit of his life. The characters then presented by the teeth are those of extreme age. The table surfaces are elongated from front to rear. Sometimes the crowns are very long and extend almost in prolongation of the jaws. Sometimes they are very short and are worn clown to a level with the gums. The crowns now appear to converge toward the median line, whereas in youth they appeared straight or slightly divergent.

Many deceptions may be practiced or many conditions may exist which render the determination of the age very difficult. Some dishonest dealers and breeders resort to pulling the milk teeth a few months before they would fall, thereby hastening the appearance of the permanent ones and giving the mouth an older appearance. Sometimes the notches in the upper corners are rasped away to malie the 7-year-old mouth look younger. "Bishoping" is another form of deception that is sometimes practiced. This is done to make an old mouth appear young. New cups are drilled in the old teeth, and these cups are then stained black by some artificial means. This practice, however, should never deceive the close observer because the ring of enamel, which is always present around the natural cup, can not be reproduced in the bishoped mouth. Moreover the teeth will show by the angle at which they meet and by the form of their table surfaces that the mouth is too old for cups to be present.

Horses with parrot or overshot mouths, and horses in the habit of cribbing, subject their teeth to unnatural wear, which renders the determination of their age very difficult. 


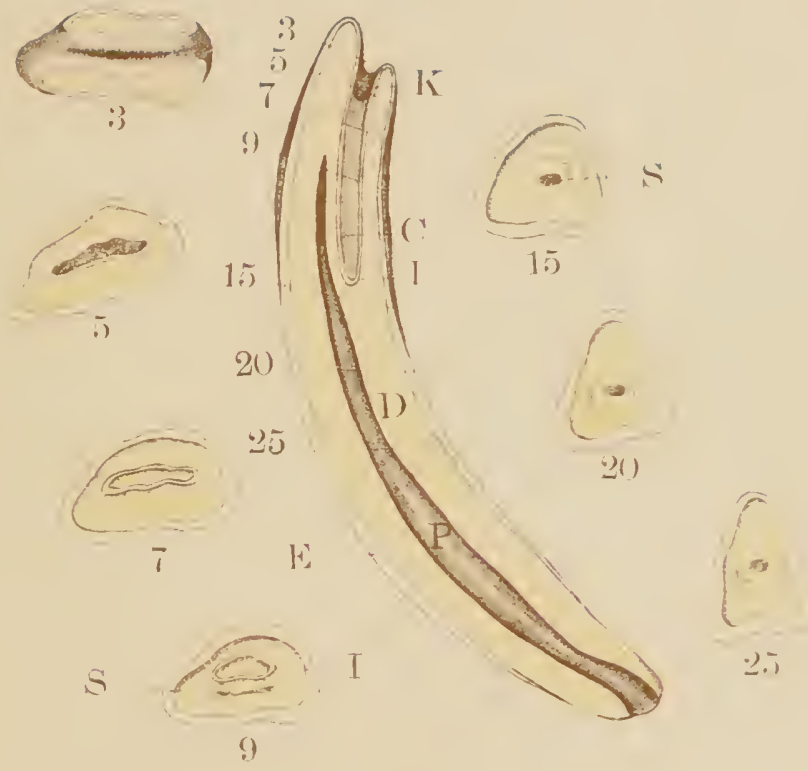

DLATE XIX

Longitudinal Section of left central lower incisor and cross secions of same tooth showing table surfaces as they appear at the ages of 3 , $5,7,9,15,20$ and 25 years.

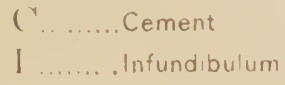

\begin{tabular}{|c|c|c|}
\hline I) .........Dentıne & $\mathrm{H}$ & Enamel \\
\hline ......... Cup & $\mathrm{P}^{P}$ & Pulp Cavitv \\
\hline Star & & \\
\hline
\end{tabular}


$\Rightarrow$ 


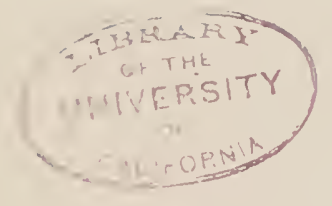


PLATE XIX $a$.

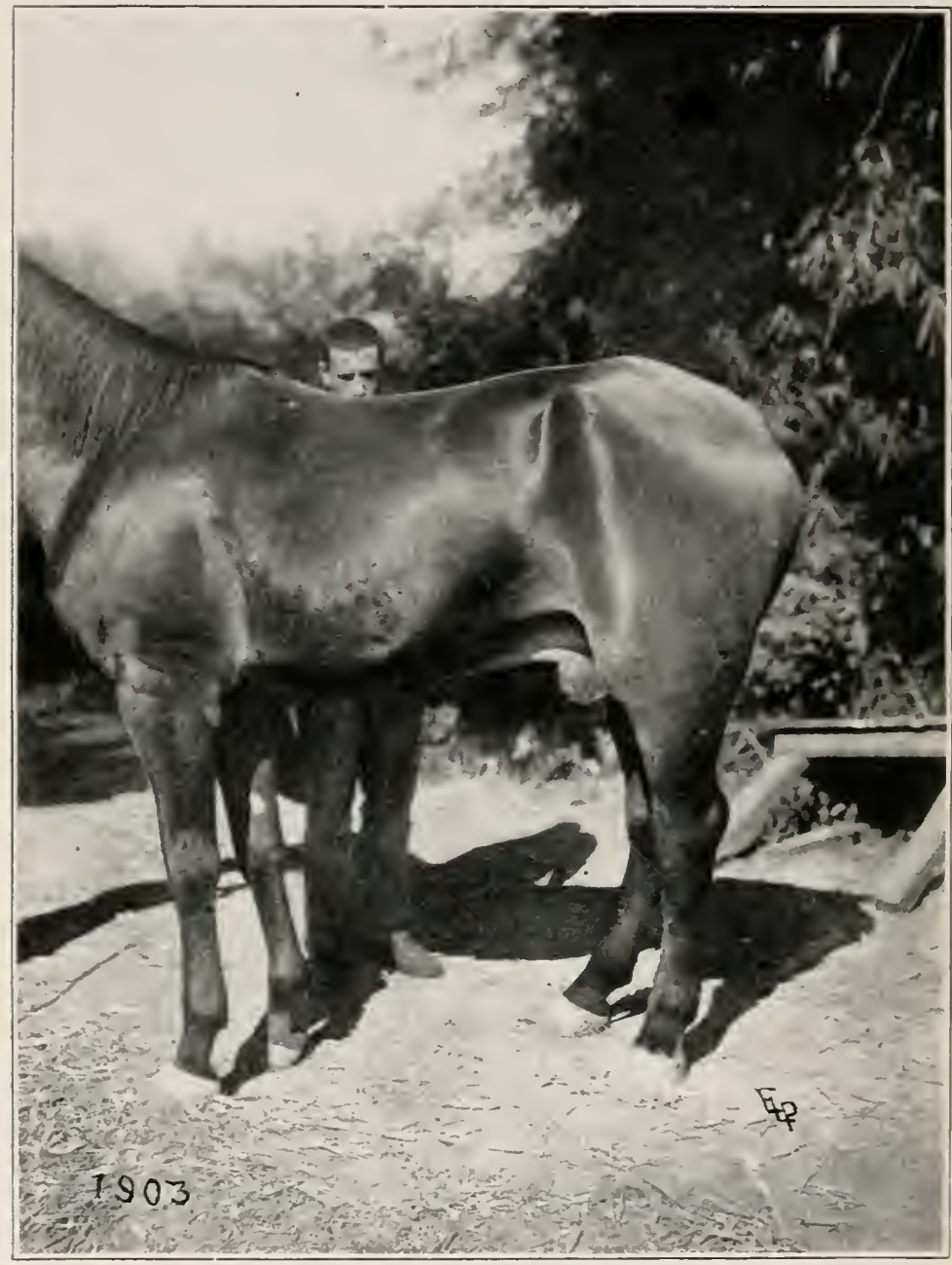

Surra: Characteristic swellings. 


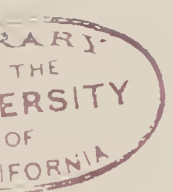




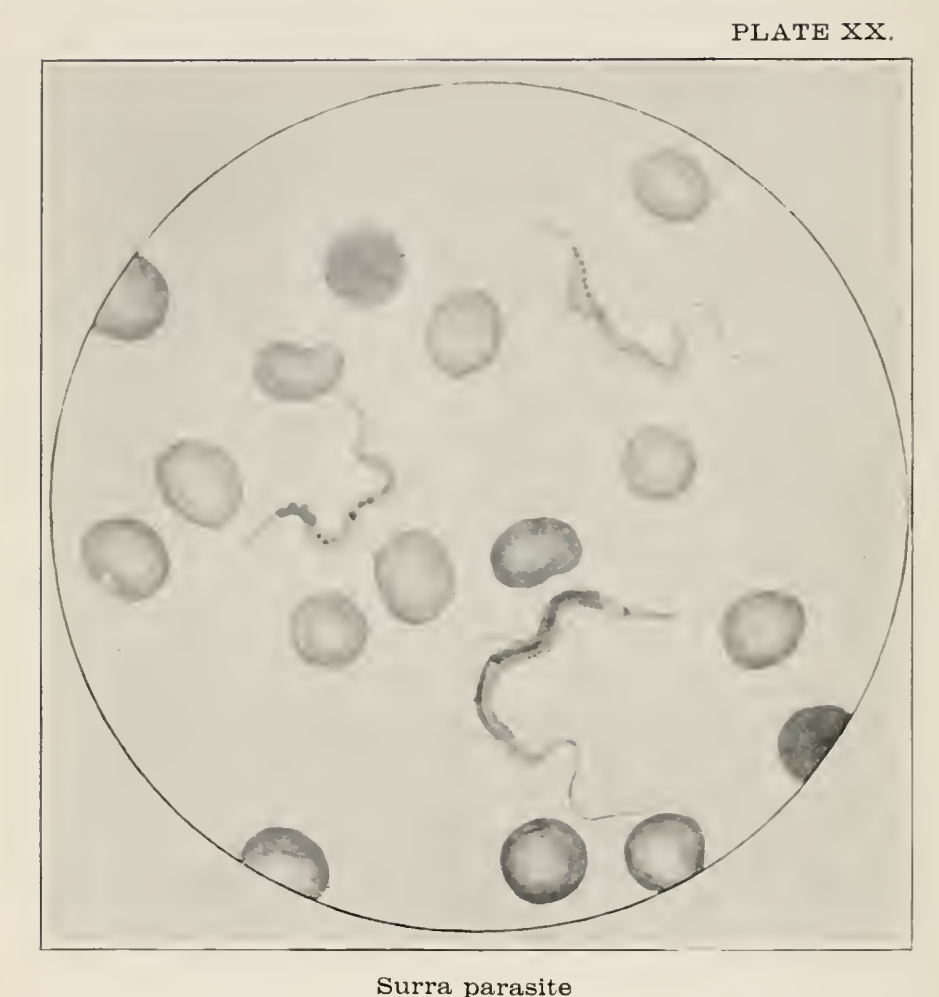




\section{CHAPTER XIII.}

\section{TROPICAI、DISEASES.}

SURRA.

This disease is caused by the Trypanasoma Evansi, an organism which is a low form of animal life and is found in the blood of affected animals. It attacks and destroys the red blood cells, causing rapid loss of flesh and, sooner or later, death. It is claimed by some authorities that the disease originates from the use of water and grass from low lands.

Symptoms.- Variable temperature, ranging from normal to $102^{\circ}$ and even to $106^{\circ} \mathrm{F}$; d dullness; lack of rigor; sometimes swelling of the submaxillary lymph glands; thin, watery discharge from the nostrils; swelling of the sheath and legs, more frequently the hind ones (Plate XIX), and swelling along the belly; these swellings pit on pressure. The mucous membrane of the eye, especially of the haw, shows dark-red spots (petechial spots); the urine is highly colored and is usually passed in large quantities; the bowels are constipated in the early stage and profuse diarrhea oceurs later. In chronic cases paralysis of the hind extremities takes place, the animal staggering when moved. The paralysis may later become complete and the horse will be unable to rise. In the acute type of the discase the animal dies in twelve or fifteen days, while in the chronic case he may linger for one or two months. The diagnosis is complete only when a microscopic examination of the blood discloses the parasite (Plate XX). Is a rule, the parasite is seen only when the temperature is considerably elevated.

Surra is always fatal, and as the danger to other animals is great on account of its highly contagions nature, all animals that have been proved to have the parasite in the blood should be removed at once from contact with healthy stock and destroyed. The carcasses should be saturated with oil and bumed. Measures to prevent the spread of the disease should always be enforced. When in a district infested with surra the temperature of horses should be taken regularly every two or three days. Any animal showing, without a 
known cause, a temperature of $102^{\circ} \mathrm{F}$. should be isolated, and thereafter blood examinations should be made and temperatures taken daily. As flies are known to be carriers of the surra parasite, great care should be exercised to remove and avoid any breeding places for these pests. If stables could be sereened in would be a great advantage in surra outbreaks.

\section{EPIZOOTIC OR LLCERATIVE IXMPIIAXGITIS.}

This peculiar tropical disease closely resembles glanders of the farey form, so much so that the two might be easily confused by a person uninformed on tropical diseases. In observing epizootic ly'mphangitis the high ferer and sudden loss of flesh and vigor are not seen as in tropical glanders.

The disease in the early stage responds to treatment, but often requires months to effect a cure. It is caused by a fungus, called cryptococcus, and is contagious.

Symptoms.-Small bunches or nodules, the size of a half dollar, may appear upon the skin of any part of the body: there may be one or many. They often appear in chains along the course of the lymphatics (1, Plate XXI); they may spread around an infected area into an irregular patch (2, Plate XXI), apparently not following the lymphatics; again, the disease may start with a hard, painful swelling in the region of the chest or shoulder, or between the forelegs, the swelling later softening in spots and forming the small abscesses.

Ordinarily, the nodules soon soften and break upon the surface: if not, they should be opened; in either ease they end in the typical ulcers of the disease. The small bunches or abscesses, when opened, contain a white, creamy pus; they do not respond readily to ordinary healing methods and persist after the most heroic measures have been adopted. In cases of long standing the ulcerations may extend over the greater part of the body, the limbs especially being covered with sores; there is usually great enlargement and thickening of the legs and the patient becomes badly emaciated (poor in flesh). In the ordinary case, however, the animal does not lose flesh and does not carry any marked ferer.

Treatment.-The treatment consists in opening the ulcers freely with a knife or cautery point heated to white heat, or, better still, if they are not too numerous, in dissecting them out entirely with-. out opening the abscess wall.

The dressings must be of a caustic nature, so as to destroy the cause of the disense; for instance, alcohol 4 ounces, salicylie acicl 1 ounce, bichloride of mercury 2 drans; alternate this with a dressing made of equal parts of olive oil and creolin, or one made of tincture of iodine 2 ounces and tincture of iron 2 ounces. Apply 


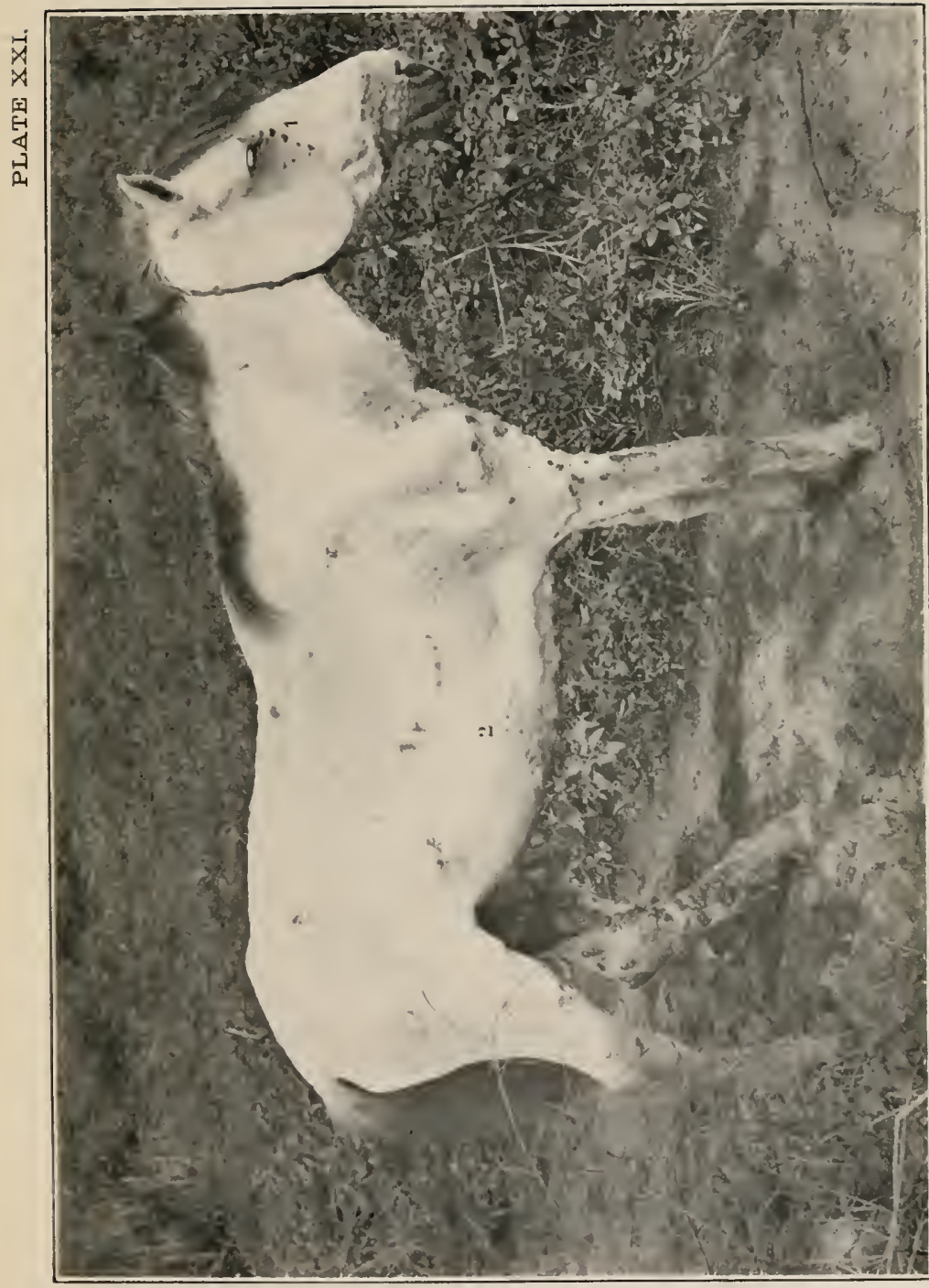

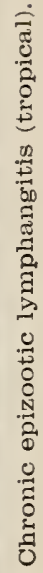


ITRAR

OF THE

UNIVERSITY

IF

CAL'FORNIA 
any of these dressings once daily and then use a dusting powder made of equal parts of iodoform and tannic acid.

Care should be exercised to isolate the diseased animals and to thoroughly disinfect combs, brushes, blankets, halters, and such articles as may have come in contact with the diseased parts; for this purpose use a 1 to 20 solution of creolin or of carbolic acicl.

DIIOBIF ITCH.

This is a very troublesome skin disease peculiar to the Tropies. It is contagious and caused by a fungus.

Symptoms.-Itching, the animal rubbing against the posts and sides of the stall; small eruptions of the skin, which spread rapidly and discharge a thin, watery secretion, crusts forming over the sores; the hair falls out and the skin becomes thickened on account of the irritation. Often the skin of a large part of the surface of the body becomes infected with these sores, and ordinary healing washes have no beneficial action. The treatment, like that of epizootic lymphangitis, should be prompt and energetic, and, since both diseases are caused by a fungus, should be similar in nature. One of the most valuable remedies is made of equal parts of olive oil and creolin, which should be applied once daily after thoroughly washing the sores and removing the scabs. A mixture of alcohol 6 ounces and salicylic acid 1 ounce is of value and is applied daily. In the absence of alcohol, sulphuric ether may be substituted. 'Tincture of iodine often effects a cure. If the case is persistent, cauterize the parts with pure carbolic acid and then apply alcohol after the acid has been on one minute. After cauterizing use the olive oil and creolin dressing daily.

On account of its contagious nature, all animals suffering from this disease should be isolated, and brushes, combs, blankets, etc., should be thoroughly disinfected with creolin or carbolic acid solution.

The common diseases of temperate countries assume a more aggravated form in the Tropies. Infectious diseases are more fatal and infected wounds heal more slowly. This is due to the lower vitality of the animal and to the hot and moist climate, which favors germ growth. Pneumonia is almost always fatal in the Philippines. Canker and thrush are found in the most aucrarated type. Periodic ophthalmia is very prevalent, resulting in many animals becoming blind. Heatstroke is a frequent occurrence, on account of the excessive heat and moisture, and is fatal in the majority of cases. The temperature in heatstroke frequently rises to $110^{\circ}$ to $113^{\circ} \mathrm{F}$. 
Glanders, which is very common, runs a rapid and fatal course. American horses rarely suffer from the chronic form of the disease often manilested in cooler climates.

In the 'Tropics a careful daily inspection of the liorses should be male and the temperature of every animal should be taken at least once a week. Any animal with a suspicious discharge from the nose or with sores upon the body indicating farey buds and any animal showing a rise of 2 degrees above normal temperature should be isolated and kept under observation by a veterinarian. In case of an outlorak, temperatures should be taken daily. Normal temperature in the Tropics is usually about 1 degree highter than in a cool climate, and it may rise as much as 4 degrees with excrcise of a moderate nature. These facts should be taken into consideration in recording temperatures. 


\section{CIIAPTER XIT.}

\section{MEDICINES; THEIR ACTION ANI USES.}

Antiseptics.-Remedies which arrest putrefaction. They kill or prevent the development of those bacteria which produce decomposition.

Examples: Corros. sub., carbolic acid, creolin.

Disinfectants.-Destroy the specific poisons of communicable diseases by killing those germs which produce disease.

Examples: Lime, sulphur gas, etc.

Deodorants.-Disguise or lestroy odors.

Examples: Iron sulphate, carbolic aciil, ete.

Rubefacients.-Cause redness of the skin.

Examples: Alcohol, turpentine; ete.

Vesicants.-Cause a discharge of serum from the skin.

Example: Cantharides.

Stomachics.-Promote digestion.

Examples: Gentian, ginger, etc.

Vermicides.-Kill worms.

Examples: Turpentine, iron sulphate, etc.

Termifuges.-Remove intestinal worms by purgation.

Parasiticides.-Destroy parasites.

Examples: Carbolic acid, creolin, etc.

Purgatives.-Evacuate the bowels.

Examples: Aloes.

Laxatives.-Mild purgatives.

Examples: Bran mash, small close of linseed oil.

Cholagogues.-Promote secretion of bile.

Examples: Aloes, calomel.

Diaploretics.-Increase perspiration.

Examples: Ethers. Same action produced mechanically by warm clothing.

Diurctics.-Increase secretion of urine.

Examples: Potass. nit., turpentine.

Tonics.-Gradually but permanently improve appetite and increase vigor.

Examples: Quinine, iron, gentiun, ete. 
Ancsthetics.-Produce loss of conseiousness.

Example: Chloroform.

Styptics.-Check hemorrhage.

Example: Tincture of iron.

Cuustics.-Destroy tissue by burning.

Examples: I.unar caustic, copper sulphate, etc.

Expectorants. - Act upon the mucous membrane of the respiratory organs and cause an expulsion of their' secretions.

Example: Chloride of ammonia.

Stimulants.-Promptly but temporarily increase nervous vigor, thus increasing action of the heart and other functions.

Examples: Alcohol, ammonia, ether.

Alteratives.-Correct morbid conditions without causing marked physiological effects.

Examples: Iodide of potassium, potassium nitrate.

Astringents.-Contract living tissues.

Examples: Alum, zine sulphate, tannic aciel.

Sedatives.-Depress (slow) the nervous system.

Example: Potas. bromide.

Anodynes.-Relieve pain by diminishing the excitability of nerres and nerve centers.

Examples: Opium, belladonna.

Antispasmodics.-Prevent or remove spasmodic contractions of voluntary or involuntary muscles.

Examples: Belladonna, sulphuric ether.

Carminatives.- Ail in the expulsion of gas from the intestines by increasing natural movement, stinulating circulation, ete.

Examples: Capsicum, ginger, aromatic spts. ammonia, sulphuric ether, etc.

Febrifuges or antipuretics.-Agents which reduce high temperature of the blood; reduce fever.

Examples: Acetanilid, cold water.

\section{YETERINARY MEDICINES.}

Acetanilid.-Is a febrifuge and antiseptic. Used internally to lower fever in doses of from 1 to 4 drams. Used externally as an antiseptic in the form of a dry dressing.

Acirl, arsenious (arsenic).- - Is an irritant, corrosive poison, given internally in doses of from 1 to 6 grains as a digestive tonic, and for skin diseases, usually in combination with iron sulphate and gentian. Externally it is used to remove warts, in the form of an ointment, 1 part of arsenic to $S$ or 10 of lard.

Acid, boracic-Action, antiseptic; a saturated solution is very useful in conjunctivitis. With oxide of zinc it makes a very nice dressing for abrasions, scratches, etc. 
Acid, carbolic.-A valuable antiseptic and disinfectant. A 1 to 20 solution makes a very good wash for all wounds. A rery good prescription for local use is the following:

Carbolic acid, 6 drams.

Glycerin, $1 \frac{1}{2}$ ounces.

Water to make 1 pint.

Acid, salicylic.-A useful antiseptic; a saturated solution of salicylic acid in alcohol is a good dressing for indolent sores and ulcers.

Salicylic acid dusted upon a wound will remove the granulations of proud flesh.

Acid, tannic.-An astringent and antiseptic. It is given internally in diarrhea and dysentery. Dose, 30 grains to 1 dram.

The following preseription may be used:

Acid, tannic, $\frac{1}{2}$ to 1 dram.

Opium, powdered, $\frac{1}{2}$ to 1 dran.

Make into one ball and repeat every two hours until the diarthea is checked.

Tannic acid is an excellent remedy, used in the form of a saturated solution (with witch-hazel water), for hardening tender shoulders.

Aconite.-Is a dangerous poison and should not be used internally, but locally. Mixed with other drugs it makes a good anodyne liniment.

Aconite, 2 ounces.

Alcohol, 5 ounces.

Opium, tincture, 4 ounces.

Witch-hazel, distilled, 5 ounces.

Mix, and apply several times daily.

Alcohol.-Stimulant. Given for weak heart in debilitating diseases, such as lung troubles, ete. Dose, 2 to 4 ounces in 1 pint of water, and repeated every four to six hours, as required.

It is useful in the formation of liniments.

Aloes, Barbados.--Is the general purgative for the horse. Dose, 6 to 8 clrams.

Aloes, Barbados, 6 to 8 clrams.

Ginger, 1 dram.

Make into a ball and give upon an empty stomach.

The "cathartic capsule," to be supplied, will take the place of aloes. It will contain aloin, strychnine, ginger, and calomel.

A purgative should never be given in cliseases of the respiratory system.

It generally takes about twenty-four hours to operate.

Alum.-Astringent. It is useful as a wash for sore mouths; used in the strength of $\frac{1}{2}$ ounce to 1 quart of water. Externally it is a valuable remedy in the treatment of thrush. Bumt alum is useful for the removal of proud flesh. 
Ammonia, aromatic spirits of.-Stimulant and ralminative. A very useful remedy in the treatment of colies, and exhaustion. Dose, 1 lo 3 ounces, well diluted.

Ammonia, solution of - - Used externally only, in combination with other drugs, as a stimulating luniment.

Ammonia, solution of, 1 part.

Turpentine, oil of, 1 part.

Olive oil, 2 parts.

To be well shaken before using. It is an excellent external applieation for sore throat.

Ammonia, chloride of.- - Tsed in all cases where an expectorant is indicated, such as diseases of the respiratory system. Dose, 1 to 4 drans. For catarrhal diseases it is usually combined with quinine and nitrate of potash, prepared in the following manner:

Ammonia, chloride of, 3 ounces.

Quinine sulphate, 6 drams.

Nitrate of potash, 3 ounces.

Make into twelve powlers and give one every three of four hours. Bclladonna, fluid extract.-Antispasmodic and anodyne. Used in eases of colic in conjunetion with other medicines. Dose, 1 to 2 drams.

Then applied to the eyes it ditates the pupil and soothes the irritated membrane. Generally used in combination with sulphate of zine or boracic-aeid solutions.

A rery useful wash for the treatment of conjunctivitis is made as follows :

Sulphate of zine, 20 grains.

Belladonna, fld. ext., 1 dram.

Water, $3 \frac{1}{2}$ ounces.

Apply twice a day.

Camplor, gum.-Antispasmodic and antiseptic. Dose, 1 to 2 drams. A very good remedy for diarrhea is made as follows:

Camphor, gum, 1 dram.

Opium, powdered, 1 dram.

Make into a ball; give, and repeat every two hours until relief is aftorded.

Externally it is useful for sprains, combined with other medicines, forming what is known as the soap liniment.

Castile soap, 10 parts.

Camphor, 5 parts.

Aleohol, 70 parts.

Water, 15 parts.

- To be used only externally as a mild, stimulating, anodyne liniment.

A useful dressing for wounds is made of grum eamplior, $S$ ounces, carbolic acid, 3 ounces. This is especially valuable in fly time. 
Cannabis indica (Indian hemp).-Antispasmodic and anodyne. Its main use is in colic, as it relieves pain without causing constipation. Dose, 2 to 4 drams.

Cannabis indica, 2 to 4 drams.

Ammonia, aromatic spirits, 1 ounce.

Water, 1 pint.

Give at one dose and repeat in three-quarters of an hour if necessary. This is an excellent remedy for colic.

Cantharides, powdered (Spanish fly ).- Used only for its blistering effect. Prepare by rubbing the cantharides and cosmoline together ( 1 to 5 or 6 ) with a spatula on a piece of glass.

Capsicum (cayenne pepper).-Stomachic and carminative. Given internally in combination with gentian and ginger in mild cases of indigestion attended with flatuleney. Dose, $\frac{1}{2}$ to 1 dram.

Charcoal.-A mild antiseptic and deodorant. It is very good mixed with poultices, especially for wounds and sores that have a foul odor. It may be dusted on the surface of foul sores and will soon destroy the odor. Internally it is giren in doses of 2 to 4 drams, and is useful in chronic indigestion and diarrhea.

Copper sulphate (blue vitriol, bluestone).-A caustic, tonic, vermicide, and astringent. Used principally as a caustic for thrush and canker. A good remedy for thrush or canker is equal parts of sulplate of copper (powdered), sulphate of zinc, and sulphate of iron: "The three sulphates." This powder can be applied two or three times daily. Used also internally as a tonic in chronic nasal catarrh. Dose, 1 to 2 drams.

Collodion.-When painted over wounds it forms an air-tight coating and in small wounds keeps the edges in a fixed position and promotes healing. Especially valuable when applied to punctured wounds of joints.

Chloroform.-Antispasmodic, stimulant, and anodyne. Useful in colics. Dose, 1 to 2 drams, well diluted. It may be added to anodyne liniments. When inhaled, it acts as an anesthetic.

Cosmoline.-A by-product of petroleum. Used as a base for ointments. It is also valuable to apply upon the skin, when wound secretions are abundant to prevent dropping out of the hair.

Creolin.-A nonpoisonous, nonirritating antiseptic and parasiticide. It is one of the best medicines that we hare, not only as a valuable application for all wounds, but to destroy all parasites with which the animal may become infested.

Used in solution or ointment in a strength of 1 to 50 or 1 to 20 . For mange it is used in a 1 to 10 solution.

Digitalis, fluid extract of.-A very dangerous poison, and should not be administered internally. A valuable diuretic when applied over the kidneys and well rubbed in. 
Ether, nitrous, spirits of (sweet spirits of niter).-Stimulant, antispasmodic, diuretic, and diaphoretic. Dose, 1 to 2 ounces.

A rely useful stimulant in all cases of weakness of the heart action. For its stimulating and antispasmodic actions it is given in colies combined with belladonna or cannabis indica.

Ether, sulphuric.-Stimulant, antispasmodic, and carminative. Dose, 1 to 2 ounces, well diluted.

Combined with belladonna or cannabis indica its antispasmodic action is increased.

Fenugreek:-Aromatic and stomachic. Sometimes combined with tonics to disguise their ollors. Dose, 1 ounce.

Flaxseed meal.- Used for poultices.

Gentian.-Stomachic and bitter tonic. It improres the appetite and general tone. Dose, $\frac{1}{2}$ to 1 ounce.

Ginger.-Stomachic and carminative. Combined with purgatives it diminishes their tendency to gripe, and also somewhat hastens their action. Dose, $\frac{1}{2}$ to 1 ounce.

Glycerin.-Used as a base in the same manner as cosmoline. Useful, combined with equal parts of iodine, in the treatment of grease.

Iodine.-Given internally in diabetes insipidus. Dose, 20 grains to 1 dram, to be repeated three times daily until the quantity of urine is lessened. Best given made into a ball with fiaxseed meal.

Externally it is used for the removal of swellings, curbs, enlarged tendons, etc. It is also a useful stimulant for indolent sores and ulcers. A good solution for external use is made as follows:

Iodine, 1 ounce.

Iodide of potassium, 3 ounces.

Water, 1 pint.

'To be applied several times daily.

Tincture of iodine is made of iodine, 1 ounce: alcohol, 1 pint.

Iodoform.-Antiseptic. Used externally as a dry dressing, either alone or combined with other drugs, such as boracic acid, acetanilirl etc.

Iron, tincture of the chloride of. - I valuable tonic, building up the system and enriching the blood. Useful in purpura and in convalescence after all debilitating diseases. Dose, 1 to 2 ounces, well diluted.

Used externally as an astringent and styptic in scrious hemorrhages. A small piece of cotton saturated with it and applied to the bleeding part is the proper mode of application.

Iron, sulphate of (Ferrisulphate).-Tonic and rermicide. It increases the appetite and builds up the system. Dose, $\frac{1}{2}$ to 1 dram. Frequently combined with nux romica, etc. 
Lanolin.-Used as a base for ointments in the same manner as cosmoline.

Lead, acetute of.-Astringent and a valuable remedy for relieving local pain. Used externally to cool and relieve sprains, inflamed tendons and joints, and to relieve itching skin diseases.

The white lotion is made as follows:

Acetate of learl, 1 ounce.

Sulphate of zine, 1 ounce.

Water, 1 quart.

Shake well and apply sereral times daily.

The lotion is a very valuable remedy for the relief of all external diseases accompanied by heat and swelling; also an excellent dressing for wounds.

Lime, chloride of.-This is the best disinfectant that we have. Four ounces to 1 gallon of water is the proper strength. This solution should be used as a wash for the disinfection of stables. A small portion of chloride of lime placed around in stables will destroy the odor arising from decomposed urine.

Lunar caustic.--Used for the removal of warts and proud flesh. Four grains to 1 ounce of water make a good application for the removal of the cloudiness remaining after an attack of ophthalmia.

Mercury, bichloride of (corrosive sublimate; antiseptic tablets).Dissolved in water this is the most energetic antiseptic; 1 to 1,000 solution is the proper strength to use in the treatment of all wounds. Two tablets to a quart of water give this strength; if the bichloride is in bulk, use 15 grains to a quart of water, and add 15 grains of chloride of ammonia to insure complete dissolution.

Mcrcury, mild chloride (calomel).-Internally, a cholagogue. Dose, $\frac{1}{2}$ to 2 drams. It is not used alone, but is combined with aloes.

Calomel, 1 dram.

Barbados aloes, 4 drams.

Ginger, 1 dram.

Water to make a ball.

Externally, antiseptic and drying. Used in the treatment of ulcers and thrush.

Mercury, biniodide.-Used as a blister; its effects are very penetrating. Used principally in the treatment of sparins, splints, sidebones, ringbones, and all bony enlargements.

Binioide of mercury, 1 part.

Cosmoline, 5 to 6 parts.

Mix and rub together thoroughly.

Apply with friction for at least ten minutes.

Nux vomica, powdered.-A nerve stimulant and tonic. Dose, $\frac{1}{2}$ to 1 dram. It is a very useful tomic in building up the tone of the 
system in convalescence from deloilitating diseases and greneral lack ol' vitality. Crencrally griven in combination with gentian, iron, and other tonies.

Oil, linsed.-Laxative (mild purgative). Dose, $\frac{1}{2}$ to 1 guart. Do not use boiled oil.

()il, olive-Generally used as a vehicle in making liniments and oily solutions.

()il of tur (pine tar).-Eseful for plugging holes and cavities in the hoof after all sippuration has (eased.

Oil of turpentine.-Diuretic, stimulant, antispasmodic, rermicicle, and expectorant. Dose, 1 to 3 ounces diluted with oil.

Externally it is used in the formation of liniments (see Solution of Ammonia).

Opium, tincture of (laudanum).-Anodyne, antispasmodic. Checks secretion of mucus membrane. On account of these properties it is a valuable remedy in diarrhea and dysentery.

Very useful in the treatment of all abdominal pain where there are no symptoms of constipation, but as a rule belladonna and cannabis indica are preferable. Dose, 1 to 2 ounces.

Externally, opium tincture is used to relieve pain of sprains and bruises.

A very good anodyne lotion is made as follows:

Opium tincture, 4 ounces.

Acetate of lead, 2 ounces.

Water to make 1 quart.

Apply every few hours.

Opium, powdered.-Not used externally. It is used internally for the same purpose as the tincture. Dose, $\frac{1}{2}$ to 2 drams.

Potassium bromide.-Nerve sedative. Dose, $\frac{1}{2}$ to 2 ounces. In tetanus this medicine can be given in large doses.

Potassium nitrate (saltpeter).- Alterative, febrifuge, and diuretic. Dose, 1 to 4 drams. In the treatment of laminitis the dose is 2 to 4 ounces, repeated three times a day. Externally it makes a good cooling lotion:

Nitrate potassium (saltpeter), 5 ounces

Chloride of ammonia, 5 ounces.

Water, 16 ounces.

Mix and keep the affected parts saturated with this lotion.

Internally, saltpeter is a most excellent medicine in the treatment of catarrhal and febrile diseases. It is also useful in the treatment of swollen legs.

Potassium iodide.-Alterative, diuretic, and expectorant. Dose, 2 to 4 drams. It is given to promote absorption of enlargements, such as enlarged glands in lymphangitis, and in partial paralysis resulting from injury to the brain or spinal cord. 
For such purposes full doses are given twice a day for two weeks. Potassium permanganat. - Intiseptic, disinfectant, and cleodorant. Useful for the removal of foul odors arising from mhealthy wounds: also for cleaning hands and instruments. From 1 te t drams, water 1 pint, is the proper strength of the solution for use.

Quinine, sulphate of.-Tonic, stomachic, antiscetic, and mild febrifuge. Dose, $\frac{1}{2}$ to 1 dram, repeated three tinces a day. It is griven in all febrile and debilitating diseases. Combincd with sulphate of iron it is very useful in purpura. In influenza and pnenmonia it is generally combined with gentian and nitrate of potash, male into powders in the following proportions:

Quinine sulphate, 1 ounce.

Gentian, 3 onnces.

Make twelve powders and give three times a day.

Salol.-Antiseptic. Used internally and externally for its antiseptic properties. Dose, 2 to +1 drams.

Sodium bicarbonate.-Carminative, stomachic, relieves acidity of the stomach. Dose, 1 to 2 drams. This is an excellent medieine in clironic indigestion and flatulency.

Sulphur.-Parasiticide. This medicine may be used for the treatment of mange, but it is inferior to creolin or carbolic acid.

Witch-hazel.-A cooling astringent wash, very useful when combined with other medicines in the form of limiments or lotions.

Zine sulphate.- Externally it is much used as a caustic and astringent for wounds, foul ulcers, etc. It is an excellent remedy for the treatment of thrush and canker.

Sulphate of zine

Sulphate of copper - Equal parts.

Sulphate of iron

Zine oxide.-Antiseptic and astringent. lised either as a dry powder dusted on the wounds or can be made into an ointment with lanolin:

Zine oxide, 1 part.

Lanolin, 6 parts.

Zinc chloride.-An irritant and corrosive poison, never given internally. Externally it is applied as a stimulant, astringent, caustic. and parasiticide. It is also used as an antiseptic, disinfectant, and deodorant. From 2 to 4 drams to the pint of water are used for ordinary antiseptic purposes.

DOSES.

Grouped according to amounts; for reference and for convenience in memorizing:

GRAINS.

Arsenic 1 to 6 .

Iodine 20 to 60 . 
1.2 (1) 1 .

DRAMS. arisl.

Capricum; Iton sulphate; Nux vomica, prowlered; Quinines sulphate; Tannic $1,10: 2$.

('alomel; "1pium, powdered.

I 111 2

Belladona, fluid extract; (amphor, gum; chloroform; Copper sulphate; Sodium licurbonate.

I i1) 4

Aretanilid; Ammonia, chloride; Potassimm, nitrate. $210+$

Cannabis indisa, fluil extract; ('harcoal; Potassinm iodide; Salol. (i) 1 i) 8

Aloes.

\section{OUNC'ES.}

1.2 to 1

Gentian; Ginger.

1

Fenugreek.

1 i, to 2

Bromide of potasinm.

1 to 2

Sulphuric ether; Sweet spirits of niter; Tinct. Chloride of iron; Tinct. Opium. 1 to 3

Aromatic spirits of ammonia; Oil of turpentine.

2104

Alcohol; Potassium nitrate (in laminitis).

$\mathrm{O}$

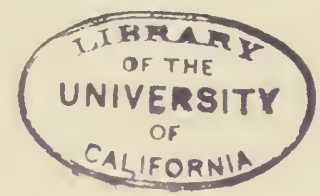







\section{DAY USE}

RETURN TO DESK FROM WHICH BORROWED

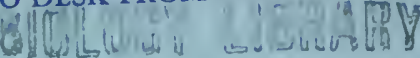

This book is due on the last date stamped below, or

on the date to which renewed.

Renewed books are subject to immediate recall.

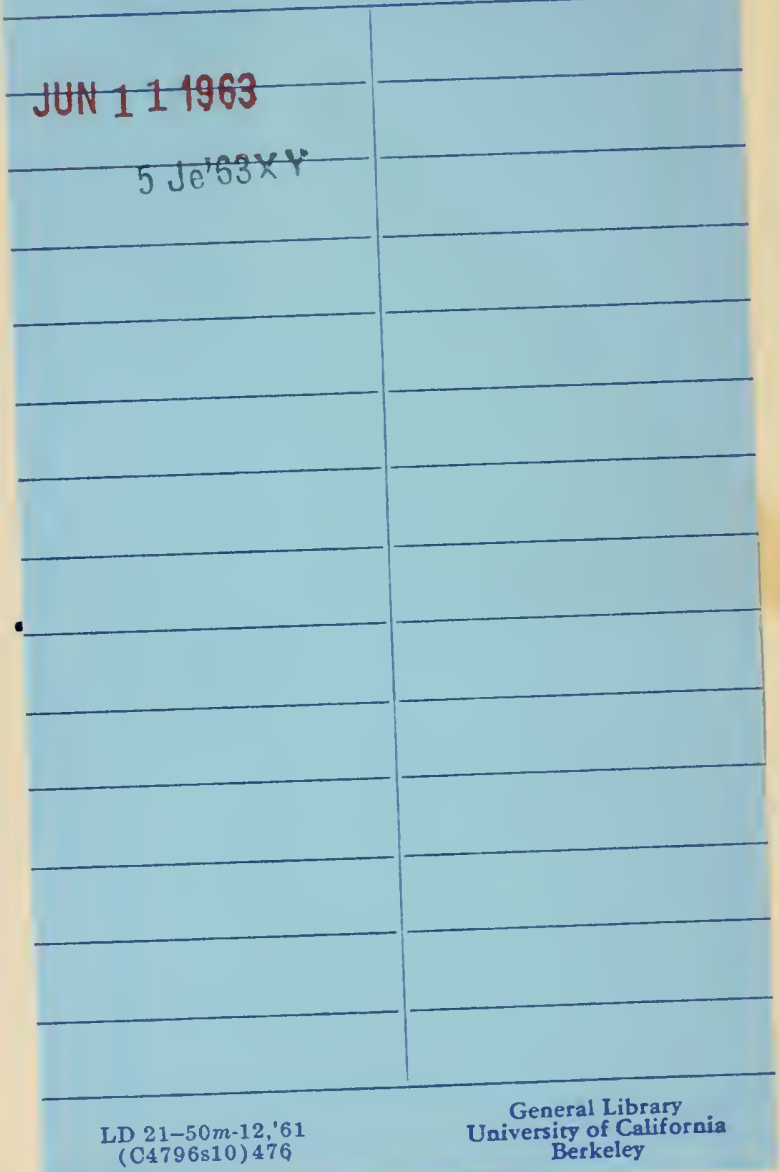




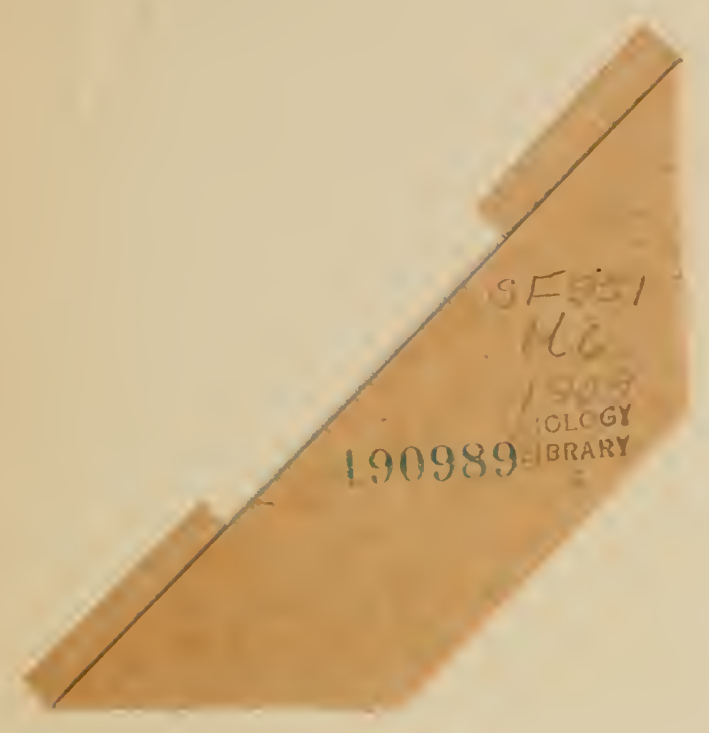


